"BLACK MEN HAVE TO WORK MUCH HARDER": AN EXPLORATORY STUDY ON THE GENDERED-RACIALIZED EXPERIENCES AND HIV VULNERABILITIES OF HETEROSEXUAL YOUNG BLACK MEN

\author{
by \\ Kimberly M. Bryce \\ BScN Ryerson University, 2011, BA, Carleton University, 2005
}

\author{
A thesis \\ presented to Ryerson University \\ in partial fulfillment of the \\ requirements for the degree of \\ Master of Nursing \\ in the program of \\ Nursing
}

Toronto, Ontario, Canada, 2018

(C) Kimberly M. Bryce, 2018 


\section{AUTHOR'S DECLARATION FOR ELECTRONIC SUBMISSION OF A THESIS}

I hereby declare that I am the sole author of this thesis. This is a true copy of the thesis, including any required final revisions, as accepted by my examiners.

I authorize Ryerson University to lend this thesis to other institutions or individuals for the purpose of scholarly research.

I further authorize Ryerson University to reproduce this thesis by photocopying or by other means, in total or in part, at the request of other institutions or individuals for the purpose of scholarly research.

I understand that my thesis may be made electronically available to the public. 


\title{
"BLACK MEN HAVE TO WORK MUCH HARDER": AN EXPLORATORY STUDY ON THE GENDERED-RACIALIZED EXPERIENCES AND HIV VULNERABILITIES OF HETEROSEXUAL YOUNG BLACK MEN
}

\author{
ABSTRACT \\ Kimberly M. Bryce \\ Master of Nursing, Ryerson University, 2018
}

Research literature on the HIV vulnerabilities of heterosexual young Black men tend to focus on individual risky behaviours, without acknowledging the structural conditions that put them at risk. The aim of this study was to explore the gendered and racialized experiences of heterosexual young Black men, their HIV vulnerabilities, and conditions that promote their collective resilience. Using a narrative approach, I conducted two focus groups and five individual interviews $(\mathrm{N}=15)$. I also applied the lenses of Critical Race Theory $(\mathrm{CRT})$ and intersectionality to critically analyze the participants' narratives. The study results showed that social vulnerabilities, produced through anti-Black racism and White hegemonic masculine expectations, shaped the racialized and gendered identities of the participants and increased their HIV vulnerabilities. Participants identified social support, mentorship, access to equitable opportunities and safe space for critical dialogue as conditions that promote their resilience. Thus, effective HIV prevention responses must be underpinned by social justice. 


\section{ACKNOWLEDGEMENTS}

I would first and foremost like to thank my thesis supervisor Dr. Josephine P. Wong for her patient guidance and committed mentorship, throughout the completion of this thesis. You have truly made this more than a learning opportunity; you have challenged me to think critically about the world around me and to think about how research can be used to bring about social change.

I would also like to thank my thesis committee members, Dr. Mandana Vahabi and Dr. Annette Bailey of the Daphne Cockewell School of Nursing for their critical feedback and willingness to support me throughout this process. I appreciate your enthusiasm and for pushing me to produce quality work.

To the research team at weSpeak, thank you for your mentorship and for giving me an opportunity to participate as a graduate fellow in the great work that you are doing. I would especially like to thank Dr. Winston Husbands, Desmond Miller, Wesley Oakes, Henry Luyombya and Andre Harriott. I am forever grateful to you all.

To my wonderful support group, aunties, uncles and cousins, thank you for your prayers and positive words of encouragement. To my sisters Sherine and Camille, you are the best! Thanks for your willingness to walk with me throughout this journey. To Narome, thank you for always being my friend and for pushing me to keep going when I wanted to give up.

I also acknowledge the generous financial support in the form of graduate fellowship and scholarships from the weSpeak project, Daphne Cockwell School of Nursing, and the Registered Nurses' Association of Ontario. 


\section{DEDICATION}

I dedicate this thesis to the loving memory of my grandmother, Vera Agatha Davis. Her life has taught me so much about being strong, seizing opportunities, and ending well. I know that you did not have the opportunity to go to school and fulfill your dreams, but I have been able to accomplish some of my dreams because of you; I stand on the shoulders of your hard work and sacrifice. I am eternally grateful for the lessons your life has taught me. You are missed.

I would also like to dedicate this work to my parents, Barrington and Iris Bryce. To my dad, thank you for your strength, for keeping me grounded and for raising me to embrace and be proud of the brilliance and beauty of our people. To my mom, thank you for your passion for the things that matter to me, for being my number one encourager and for always reminding me that giving up was never an option.

Finally, I dedicate this thesis to all of the young Black men who shared their stories with me. I appreciate your candidness about your fears, struggles and dreams. Your resilience, despite your many challenges, continues to inspire me daily. I hope I have done your stories justice and that this thesis will inspire the types of changes needed for greater equality for young Black men everywhere. 


\section{TABLE OF CONTENTS}

AUTHOR'S DECLARATION FOR ELECTRONIC SUBMISSION OF A THESIS .............. ii

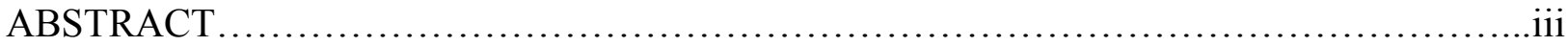

ACKNOWLEDGEMENTS ............................................................ iv

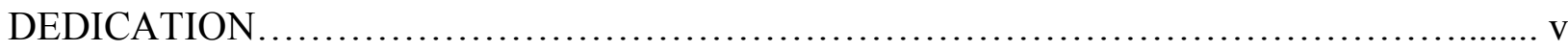

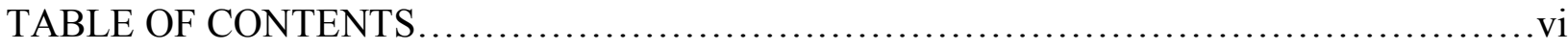

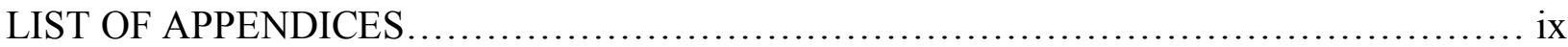

CHAPTER 1: INTRODUCTION TO THE STUDY ................................................... 1

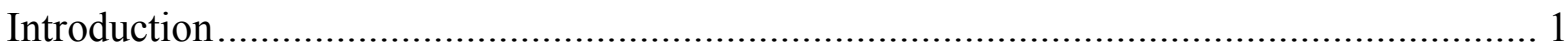

Social Context of the Study ................................................................................ 1

Personal and Professional Interests ................................................................... 6

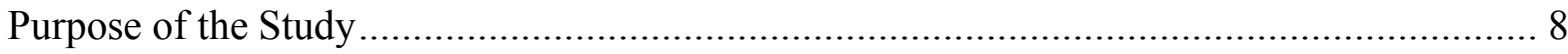

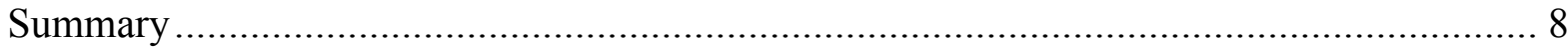

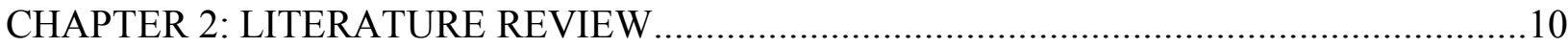

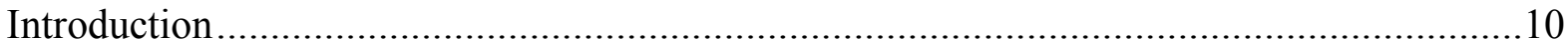

Critical Review of Current Knowledge ................................................................. 10

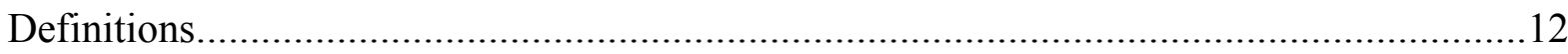

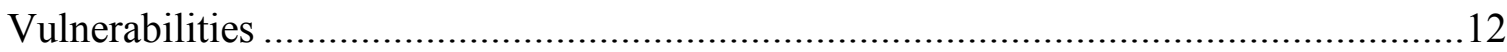

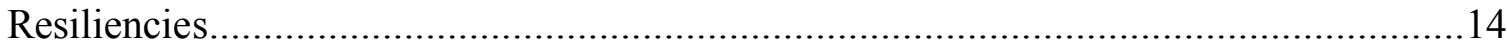

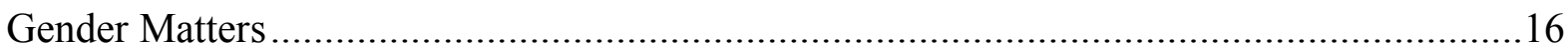

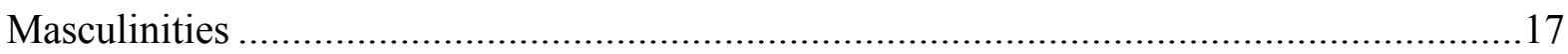

Effects of Hegemonic Masculinity on Subordinated Men...........................................19

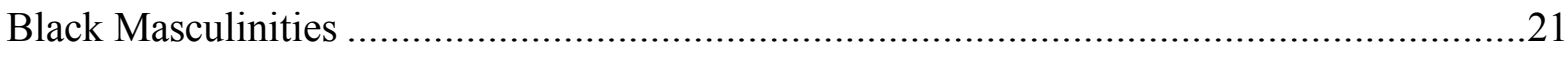

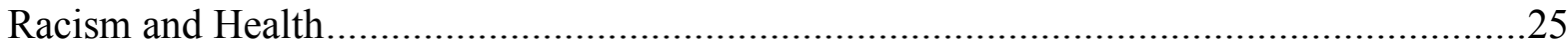

Racism and HIV Vulnerabilities of Heterosexual Black Men .........................................27

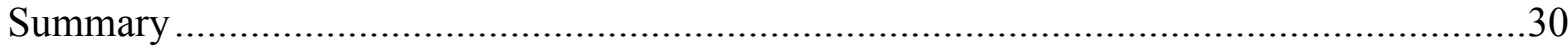

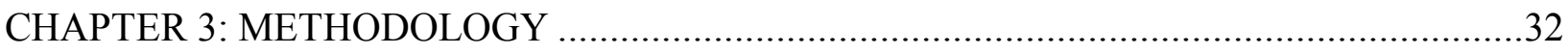

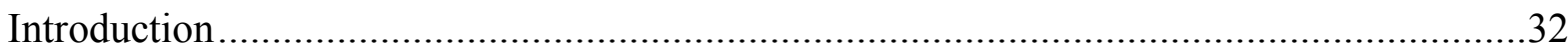

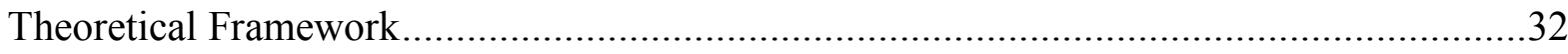

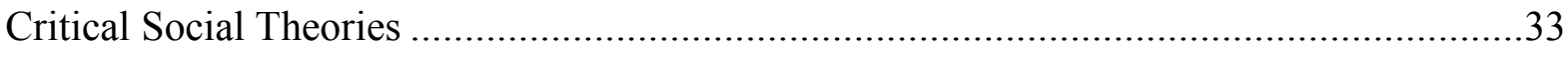

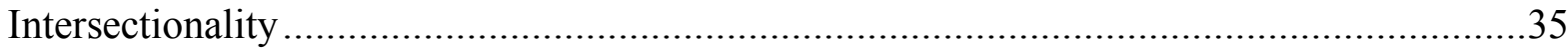




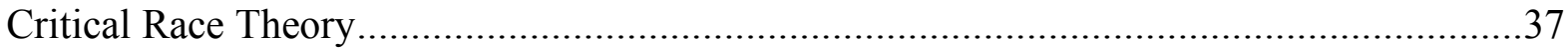

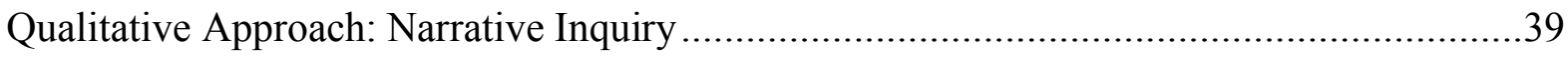

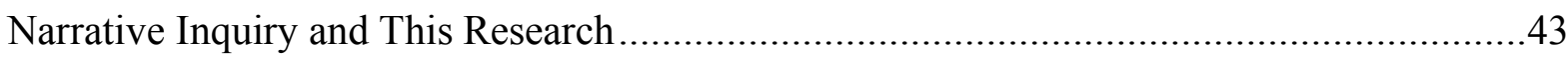

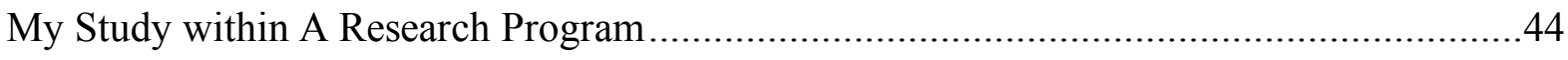

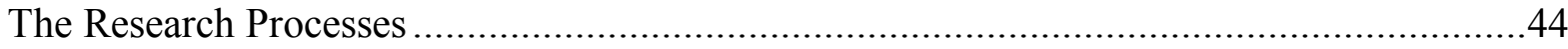

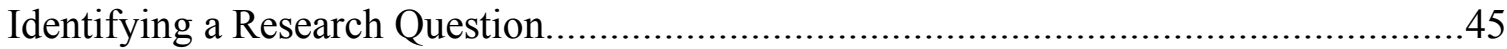

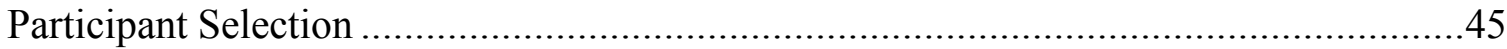

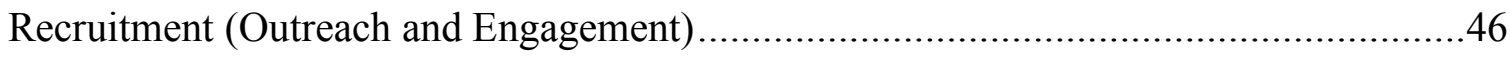

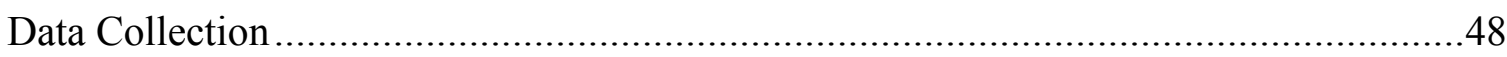

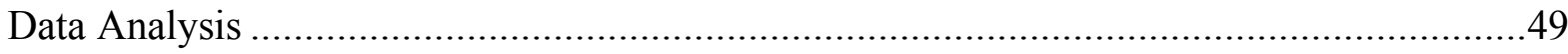

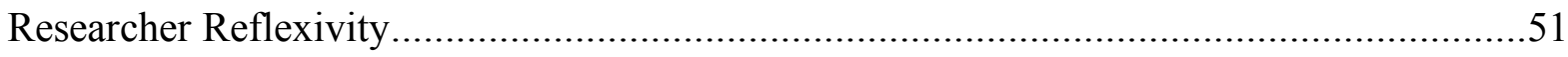

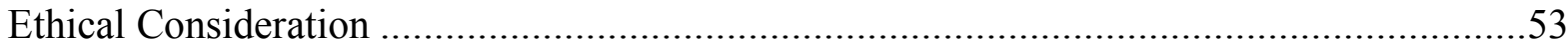

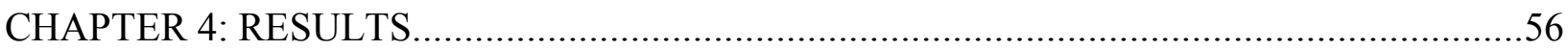

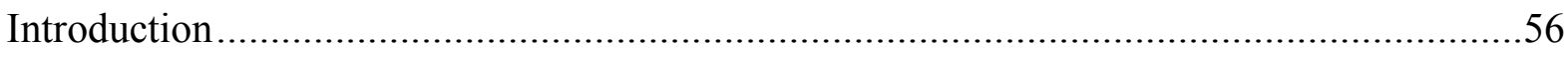

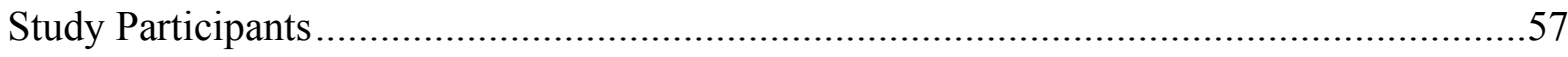

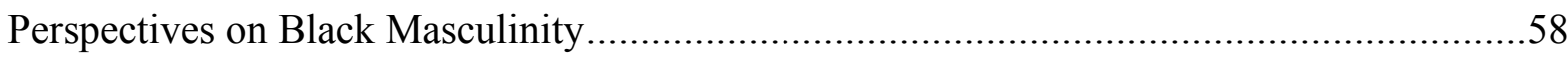

Being Black Men: Masculine Expectations of Black Men ...........................................58

Being 'Straight': Heteronormative Expectations of Young Black Men ............................62

Racist Stereotypes of Black Men: Internalization and Resistance ........................................66

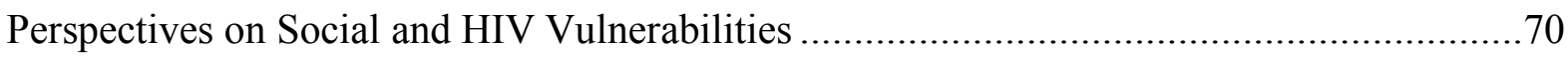

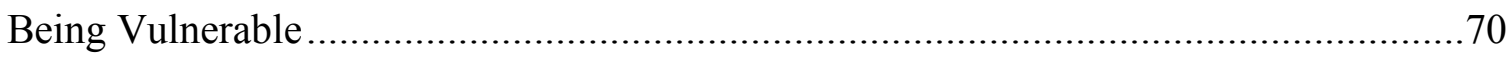

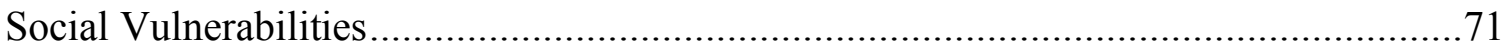

Social vulnerabilities: Race and class matters.........................................................

HIV vulnerabilities: "It ain't going to happen to me."................................................74

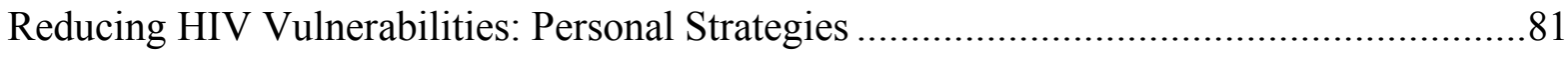

Reducing HIV Vulnerabilities: Access to Effective Sex Education ....................................... 82

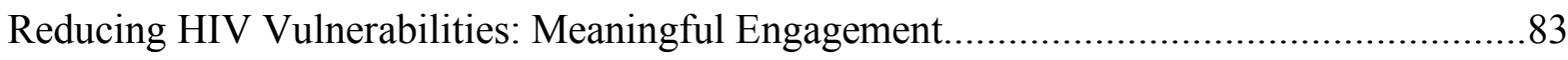

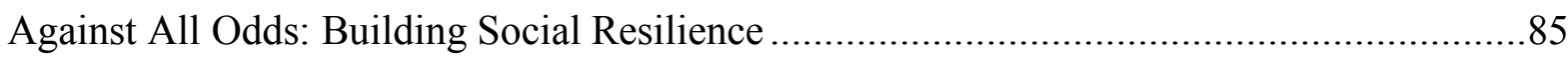

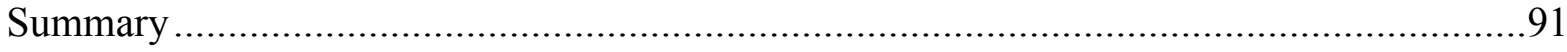

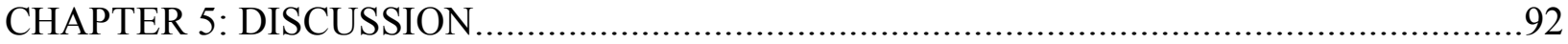

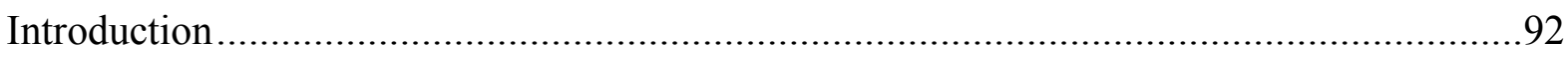

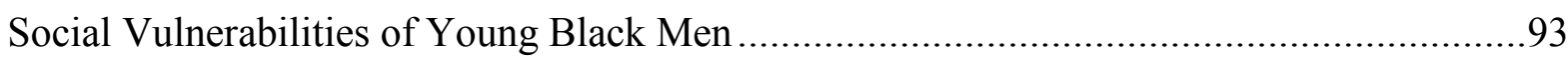


Black Heterosexual Masculine Identities in the Context of Anti-Black Racism .....................98

Social Contexts of HIV Vulnerabilities Among Young Heterosexual Black Men ................105

Building Collective Resilience: Social Support and Education .........................................111

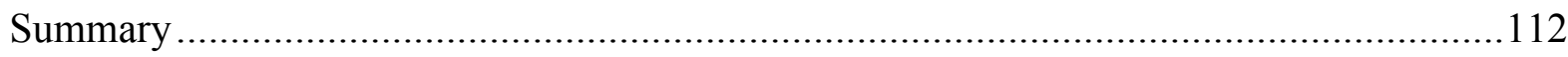

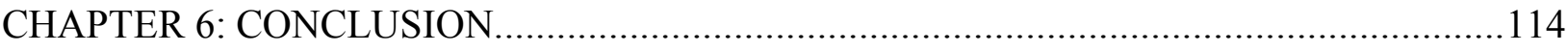

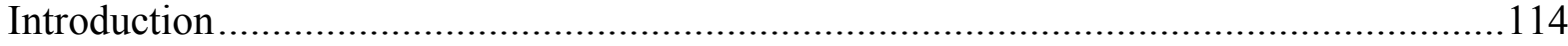

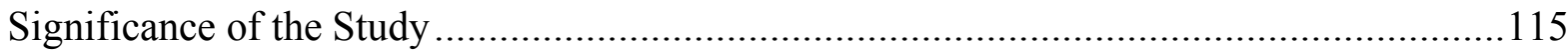

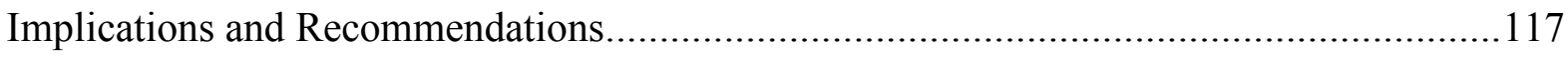

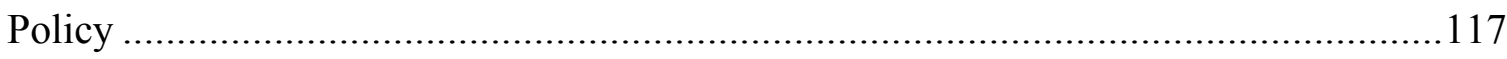

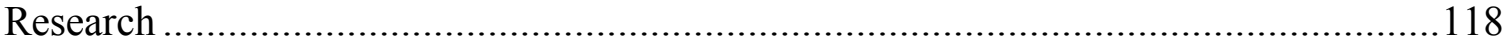

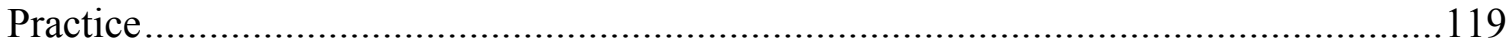

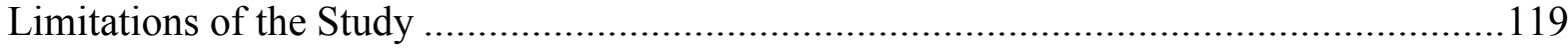

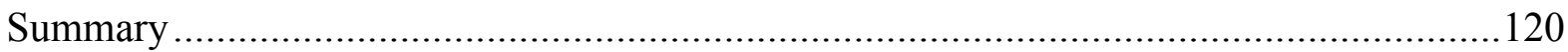

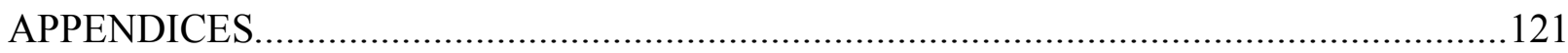

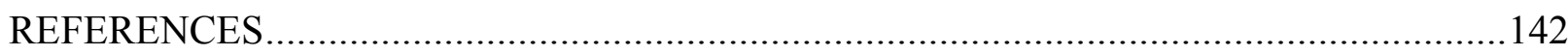




\section{LIST OF APPENDICES}

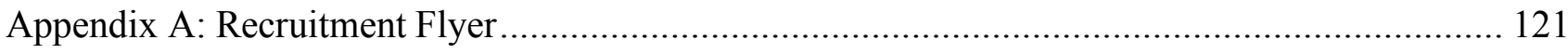

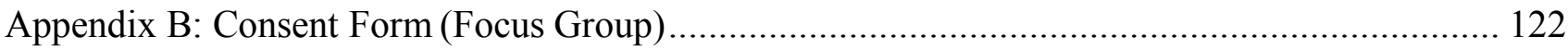

Appendix C: Consent Form (Individual Interview) ............................................................... 127

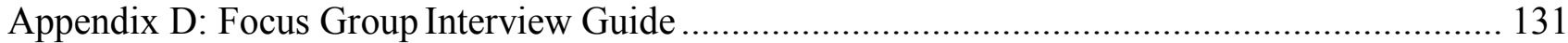

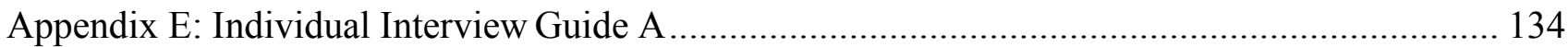

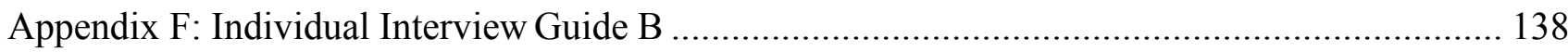

Appendix G: Tri-Council Policy Statement: Ethical Conduct for Research Involving Humans

Course on Research Ethics (TCPS 2: CORE)...................................................... 141 


\section{CHAPTER 1: INTRODUCTION TO THE STUDY}

\section{Introduction}

In this chapter I will provide an overview of the effects of the human immunodeficiency virus (HIV) globally and in Black communities, in Canada. My aim in this chapter is to contextualize the issue of HIV as it relates to heterosexual young Black men, and to share my own personal and professional reasons for engaging in this work. I hope to spark your interest as a reader, in better understanding the spread of HIV, not as a simplistic and linear process, but as a complex, multifaceted issue, coloured with various layers of social inequality. In addition to challenging pre-existing misconceptions about HIV in the Black community, I will demonstrate that, in the context of HIV research, this study is both relevant for building on and improving existing HIV prevention strategies and necessary to enhance the health of heterosexual young Black men in Ontario.

\section{Social Context of the Study}

In Canada, men have an average life expectancy of 79 years of age (Statistics Canada, 2012). However, amongst men there are vast disparities in health based on factors such as income and race. In Canada, racialized communities experience poorer health and wellbeing than non-racialized groups, which can be attributed to their experiences of oppression, based on interrelated social determinants including racism, low income, high unemployment and underemployment (Mikkonen \& Raphael, 2010; Toronto Public Health, 2013). For example, it is known that men from lower income communities have a shorter life span (i.e., four years less) than men from higher income communities. Moreover, people from low-income communities 
tend to have higher rates of suicide, diabetes and heart attacks (Mikkonen \& Raphael, 2010). Likewise, research shows that immigrants (e.g., Blacks and South Asians) in Canada are more likely to have diabetes and higher rates of hypertension, than Canadian Whites. Black immigrant men in Canada are also more likely to be diabetic and have hypertension than immigrant White men (Patterson \& Veenstra, 2016). As it relates to sexual health, Black people continue to be disproportionately affected by HIV, compared to other Canadians, as people from Black communities in Canada are 6 times more likely to contract HIV, than other Canadians (Canadian HIV/AIDS Black, African and Caribbean Network, 2016).

Young people and more specifically racialized young men, living in Canada are also affected by HIV. Canadian youth, between the ages of 15 to 29 are said to be vulnerable to contracting HIV and AIDS, for reasons including a lack of understanding about what makes them vulnerable to HIV (i.e., not knowing how HIV is transmitted) and not routinely accessing health care professionals and health related information (Public Health Agency of Canada [PHAC], 2011). Amongst the youth population, young men and Black youth are also disproportionately affected. Data collected by the PHAC (2011) between 1985 and 2008, shows that young men between the ages 15-29 had a higher proportion of AIDS diagnoses compared to young females in the same age category. The same report documents that between 1988 and 2004, HIV was on the rise in the Black youth population in Canada (PHAC, 2011). Although many young men infected with HIV are young men who have sex with men (MSM), heterosexual young men also remain vulnerable to the illness (PHAC, 2011). Unfortunately, even with this knowledge about the HIV vulnerabilities for heterosexual young men and Black youth, there is a paucity of research about HIV among heterosexual young Black men in Canada. 
Although HIV was identified approximately three decades ago and there have been advances in anti-retroviral treatment (ART), HIV remains a significant public health issue in need of a thoughtful response from community, health care organizations and government. HIV transmission continues to be a global public health concern, as there is an estimated 36.9 million people living with HIV worldwide (World Health Organization [WHO], 2015). HIV has reached every continent and is endemic to countries in Africa (in particular sub-Saharan Africa) and the Caribbean, amongst other countries (PHAC, 2015). ${ }^{1} \mathrm{HIV}$ endemic countries are characterized as having a population whereby the prevalence of HIV in adults (i.e., people between the ages 1549 years old) is at $1.0 \%$ or greater. In addition to this, for a country to be identified as HIV endemic it must have the following: 50\% or more HIV cases from heterosexual transmission; an HIV prevalence of 2:1, male to female ratio or; $2 \%$ or more HIV prevalence among women receiving prenatal care (PHAC, 2015). Statistics on HIV's global reach, particularly in HIV endemic countries are important, as they reflect the HIV burden across certain populations and regions of the world.

In Canada, the estimated number of people living with HIV was 71,300 in 2011, or an estimated prevalence of $280 / 100,000$ persons. It is estimated that $35 \%$ of the Canadian population have contracted HIV through heterosexual sex and are unaware of their HIV status (PHAC, 2014). Epidemiological data in Canada shows that HIV/AIDS cases are not equally distributed across all groups. In 2011, the groups most affected by HIV were men who have sex with men (MSM) (46.7\%), intravenous drug users (IDU) (16.9\%), Indigenous people (8.9\%),

\footnotetext{
${ }^{1}$ See Public Health Agency of Canada (2012), there are a total of 71 countries where HIV is endemic. Forty-two of HIV endemic countries are in Africa, 23in the Caribbean, and Bermuda (a British colony). HIV endemic countries also include Honduras (Central America), Guyana and
} 
and men and women from HIV endemic countries (14.9\%). ${ }^{2}$ Based on 2010 statistics, of those living in Ontario from HIV endemic countries, $6.6 \%$ are from the Caribbean and $8.6 \%$ from subSaharan Africa (PHAC, 2014; Remis \& Liu, 2013; Remis, Swantee \& Liu, 2012). In Ontario, $17.5 \%$ of all new HIV cases in 2009 were people from HIV-endemic countries, like places in Africa and the Caribbean. While some people contracted HIV before immigrating to Canada, most Black people ( $>50 \%)$ who are newly diagnosed contracted HIV through heterosexual sex, after arriving in Canada (PHAC, 2009; Remis, et al., 2012). Heterosexual Black men account for $60 \%$ of HIV cases, but they are less likely to be tested for HIV (Remis et al., 2012). Black people accounted for over $10 \%$ of all HIV-related deaths in Ontario, even though they make up only $3.9 \%$ of Ontario's population (Remis et al., 2012). This disproportionate burden of HIV among Black people is a public health concern in Ontario.

While AIDS service organizations (ASOs) like the Africans in Partnership Against AIDS (APPA), Black Coalition for AIDS prevention (Black CAP), and the African and Caribbean Council on HIV/AIDS in Ontario (ACCHO), have responded to Ontario's HIV epidemic in Black communities, their services and programming were mostly limited to Black youth, MSM and women. Further, these HIV services mainly target gay and bisexual youth and youth with addictions issues, who are in need of harm reduction programs. At present, Black CAP has a Community Outreach Program that is tailored to heterosexual people in the Black community, including Black youth between the ages of 16 to 29 (Black CAP, 2017). Also, in response to the emerging needs of heterosexual Black men, APAA developed peer support groups, to engage

\footnotetext{
2 According to PHAC (2014) the number of male versus female HIV endemic cases in Ontario in 2011 were not reported. However, in the Remis and Liu (2013) report, they cited a total of 110 male and 79 female HIV endemic cases in Ontario, in 2010. 
heterosexual Black men in discussion of issues relevant to them. Programs such as these are a good starting point for addressing this population's vulnerabilities to HIV. However, the majority of the existing HIV programs and services are not relevant to the needs of heterosexual young Black men. More research is needed to better understand the HIV issues affecting heterosexual young Black men, to inform programs and services.

In 2011, APAA and other service organizations and researchers collaborated and undertook an exploratory research study called, iSpeak - the only completed Canadian study that focused on the service needs, HIV related challenges, and priorities of heterosexual Black men in Ontario. The iSpeak study used focus groups and individual interviews to engage HIV-positive and HIV-negative heterosexual Black men, AIDS service organizations and researchers, concerned with the health of Black communities. The iSpeak study results showed that heterosexual Black men felt disconnected from ASOs, as there is a lack of programming for heterosexual Black men, as well as, a lack of visibility of heterosexual Black men amongst the staff and volunteers at the ASOs. In the iSpeak study, only one young Black man participated; he echoed similar views shared by other participants, that HIV prevention programs and services were neither inclusive nor welcoming to heterosexual young Black men (Husbands et al., 2013). The results of this study also showed that heterosexual Black men tended to prioritize making a living over engaging with HIV education programs, even though they considered HIV prevention as very important to Black communities (Husbands et al., 2013). In 2014, the results of iSpeak in addition to other research evidence were used to guide the development of weSpeak, a 5-year research program to address HIV vulnerabilities among Black men in Ontario and to 
promote their resiliencies. ${ }^{3}$ In 2015 weSpeak, funded by the Canadian Institute of Health Research, began to engage self-identified heterosexual Black men of all ages in Toronto, Ottawa, London and Windsor, to explore their perspectives about Black masculinities, HIV prevention, health promotion, the conditions that make heterosexual adult Black men and heterosexual young Black men vulnerable to HIV, and the protective factors that promote resilience among this population.

\section{Personal and Professional Interests}

In the summer 2015, I applied for a graduate fellowship with weSpeak and my application was successful. As a weSpeak research trainee, I was mentored and equipped by senior researchers and weSpeak staff, to develop qualitative research skills, knowledge of HIV research and prevention, as well as competencies in community outreach and engagement. The training and direction that I received during my weSpeak fellowship gave me the tools to successfully conduct an independent qualitative study that focused on heterosexual young Black men, under the weSpeak program of research, which looked at Black men of all ages.

My personal and professional interests also led me to focus my thesis on heterosexual young Black men. Growing up as a member of the Black community, I recall seeing young Black men in the media, portrayed in stereotypical and negative images, such as violent gang members, irresponsible fathers or uncommitted partners. Although some positive media images of Black men have emerged in recent years, the characterization of young Black men has largely remained negative and racist. My personal experience with young Black men has been very different from those portrayed in the media. As a Black women from a middle class upbringing, I

${ }^{3}$ In October 2015, I was selected to be a weSpeak Graduate Fellow and had the opportunity to connect my thesis research to the research conducted by the weSpeak researcher and staff. 
have found that the Black men in my life and social networks are family-oriented, thoughtful and hardworking. I also observed that some of them struggle to make sense of who they are and what it means to be a man, amidst a culture that endorses hegemonic forms of masculinity. I attribute these challenges to the structural contexts of young Black men's lives. They are often stereotyped and treated unfairly by society, particularly in lower income communities. It has also been my observation that negative and unsubstantiated judgments and expectations that are imposed on heterosexual young Black men differ based on their socioeconomic status. Similarly, the pressures they face to conform to the stereotypes about them vary based on class. These young men are often blamed for their behaviours without consideration of the systemic oppressions (i.e. racism, sexism and socioeconomic marginalization) that they encounter in their everyday lives. For example, in Ontario, Black people are overrepresented in the criminal justice system as compared to their White counterparts, undergo greater levels of surveillance by police, and experience lower levels of employment (African Canadian Legal Clinic [ACLC], 2011). The historical and colonial legacy of these various forms of oppression in the lives of Black people and in particular Black men, has shaped the context of their lives and in many ways limited the resources and options made available to them.

As a nurse, I am concerned with making explicit the oppressive and limiting environments that have become commonplace for many young Black men and the manner in which these contexts affect their health and wellbeing. In aligning my personal and professional interest with the overall goal of weSpeak, I have been able to undertake a study to explore the phenomena of Black identities, masculinities, and sexualities among self-identified heterosexual young Black men. 


\section{Purpose of the Study}

The purpose of this study is to identify the social conditions that make heterosexual young Black men vulnerable to HIV and factors that contribute to their resilience. Using a qualitative approach, I set out to gain a critical understanding of heterosexual young Black men's perspectives on Black masculinities and sexualities. To adequately explore these phenomena, my research question is: How do the gendered and racialized experiences of heterosexual young Black men affect their vulnerability to HIV and what promotes their resilience? To explore this question, my four sub-questions are: a) How do racialization and hegemonic masculinity intersect to shape heterosexual young Black men's masculine identities? b) How do their racialized masculine identities influence the ways they navigate their relationships with women, men and community? c) What strategies do heterosexual young Black men use to resist racist and masculine hegemonies? d) What are the conditions that promote resilience among these young men? The results of this study are expected to contribute to the larger body of Canadian research in the areas of HIV prevention and health promotion for Black communities. The findings from this study will also be useful for improving program and policy development for heterosexual young Black men.

\section{Summary}

In this chapter, I have presented the contexts and the underlying reasons that motivated me to carry out a study on the gendered and racialized experiences of heterosexual young Black men, and to deepen our understanding of their HIV vulnerabilities and resilience. In Chapter Two, I present current evidence from the literature reviewed on Black men's health, masculinities and issues of race and gender as it relates to HIV vulnerabilities, to provide the 
necessary context and a more comprehensive understanding of concepts and phenomena that I explored in this study. 


\section{CHAPTER 2: LITERATURE REVIEW \\ Introduction}

In this chapter, I present a critical analysis and synthesis of the literature on gender, racialized masculinities and HIV vulnerabilities. My goals are to explore existing knowledge of the complex and intersecting phenomena that shape young Black men's identities and HIV vulnerabilities, as well as to identify gaps in research that impede effective HIV prevention and care, among heterosexual young Black men.

\section{Critical Review of Current Knowledge}

The issues of sexualities, masculinities and vulnerabilities are relevant across social and health disciplines. For this reason, I conducted a literature review using multiple databases including Proquest, CINAHL, and Sociological Abstracts, to access published books and journal articles, on topics related to heterosexual young Black men and HIV vulnerabilities, in Canada and other Western countries that share similar social contexts, as Canada and where racialized and immigrant people reside. Search terms included: 'young', 'adolescent', 'youth', 'heterosexual men', 'male', 'masculinity', 'heterosexual', 'heterosexuality', 'hegemonic masculinity', 'gender', 'immigrant', 'Black men', ‘African American men', ‘African Canadian', ‘Caribbean Canadian', 'Canada', 'United States', “American', 'race', 'racism', 'class', 'socioeconomic status', 'income', 'HIV', 'HIV vulnerabilities', 'vulnerability', 'risk behaviour'and 'resilience', 'resiliency'. Boolean operators included the terms 'AND' and 'OR.' Delimiters that I used included books and peer-reviewed articles published between the years of 1989 and 2016, which was useful for searching a wide range of historical and current research articles, on the subject matter. I searched articles as far back as 1989 because this represents the 
time when the HIV/AIDS epidemic became a prominent issue in North America. The following keywords were used to find articles: 'Canada', 'youth', 'HIV vulnerabilities', 'heterosexual men', 'Black men', 'young heterosexual Black men', 'Black heterosexual' and 'HIV risk.' Searches conducted that included the term 'Canada' yielded one relevant result. ${ }^{4}$ One other Canadian article retrieved was excluded, because it focuses on Muslim and Christian Black teenagers' sexual experiences and did not provide useful information on heterosexual young Black men or HIV. Many of the articles found focused on MSM $(450,120)$ and HIV prevention intervention studies $(348,089)$; and were therefore excluded. A search conducted using terms, ‘youth’ AND ‘HIV vulnerabilities’ AND ‘heterosexual men’ AND ‘Black men’ yielded 886 articles. From these articles only five American articles were relevant to this study and useful for this literature review. A similar search was conducted using terms, 'young heterosexual Black men' OR 'Black heterosexual' AND 'HIV risk', yielded the same five articles. Other articles that were excluded focused on MSM, women, IDUs, or were HIV prevention intervention studies. These studies looked at HIV vulnerabilities and prevention interventions for other populations (e.g., MSM, women and IDUs); they were not used for my literature review, because they lacked applicability to my population and topic of interest, for this study. The total number of articles used for this literature review was seventy-three. However, only 5 articles were relevant to the topic of young Black men's vulnerabilities to HIV.

The literature review showed that there is a paucity of research on heterosexual Black men's HIV vulnerabilities in Canada and the United States. The few articles that have been

\footnotetext{
${ }^{4}$ Baidoobonso, S., Bauer, G., Speechley, K., \& Lawson, E. (2013). HIV risk perception and distribution of HIV risk among African, Caribbean and other Black people in a Canadian city: Mixed methods results from the BLACCH study, BMC Public Health, 13, 184-201. doi: http://www.biomedcentral.com/1471-2458/13/184.
} 
published on heterosexual Black masculinities focused on the systemic and structural contexts that influence Black men's HIV risk behaviours and they were from research undertaken by the same authors (Bowleg et al., 2013; Bowleg, \& Raj, 2012; Bowleg et al., 2011; Raj et al., 2013). While there is some local knowledge generated through iSpeak, the number of Canadian research articles on this topic is few. I have relied mainly on American studies and drawn from evidence on related topics (e.g., gender, racialized masculinities, etc.) to construct a picture that provides the social contexts of HIV vulnerabilities, among heterosexual young Black men in Canada.

\section{Definitions}

Two of the main concepts of this research study are HIV vulnerabilities and resiliencies. Vulnerabilities and resiliencies are interrelated concepts about individual and collective

challenges and strengths; they are useful for critical discussions about heterosexual young Black men and the Black community in terms of identifying HIV risks, and strategies for prevention and health promotion.

\section{Vulnerabilities}

The term vulnerability has its origin in the Latin word 'vulnerabilis,' which means to wound or to be prone to injury (Purdy, 2004; Rogers, 1997). It has also been defined as being at risk of disease or harm, or open and susceptibility to injury or loss (Purdy, 2004; Rogers, 1997). The word vulnerability is often used interchangeably with the word 'risk" (Rogers, 1997, p. 65). While there are many similarities between these terms, vulnerability and risk are conceptualized differently based on whether the factors involved are external or personal. Rose and Killen (1983) differentiate the two; they explain external and environment factors that have the 
potential to harm a person, as being a risk, while defining a person's experience of risk as vulnerability.

The attributes of vulnerability include one being exposed or open to something, being a liability or having a chance of something (Purdy, 2004). Similarly, according to Dorsen (2010) vulnerability can be classified in terms of 'activities' or 'deficiencies' (p. 2823). He suggests that a person's engagement in risky sexual behaviours (e.g., survival sex, having multiple sexual partners, or having sex at an early age) could increase their risk of getting a sexually transmitted infection or HIV (Dorsen, 2010). As it relates to deficiencies, a person could be considered vulnerable because of the inaccessibility or unavailability of resources they need, like social support, health care, financial resources, employment or educational opportunities (Dorsen, 2010). Although Dorsen (2010) talks about activities and deficiencies as separate, they can be interrelated and should not be viewed in isolation, as a person's deficiencies (e.g., lack financial resources) can shape their activities (e.g., engagement in survival sex).

In the context of HIV, discussions about vulnerabilities are also useful for understanding HIV transmission. Unfortunately, much of the HIV prevention discourse has focused on curbing people's sexual behaviours, in order to minimize their exposure to HIV (Gould, 2005). One example of this is when some international agencies and national governments in Africa, have tried to manage the spread of HIV by primarily encouraging people to change their risk behaviours (Gould, 2005). In Uganda, the 'Abstinence, Be faithful to one sexual partner, and use a Condom (ACB)' approach was used to try to persuade people that lowering HIV rates was a matter of them changing their individual behaviours (Gould, 2005). Notwithstanding that there may be some validity to this approach, it does present a limited and insufficient understanding of 
HIV vulnerabilities because it puts the blame of HIV infection on individuals, but fails to acknowledge the contextual factors that contribute to the disease, including gender, race and class.

According to Rogers (1997) some populations in society are more vulnerable than others to health issues because of their social conditions. People can experience greater vulnerability to health problems because of structural barriers associated with their race, gender, age, income, education, or social networks (Rogers, 1997). For example, Black and Hispanic people in the United States have a higher mortality rate than other races and people with a low income are more vulnerable to die earlier than people with higher incomes (Rogers, 1997). The examination of risk and vulnerability discourse is also applicable to the sexual health of heterosexual young Black men; these young men's vulnerabilities to HIV cannot be conceptualized solely in term of their engagement in 'risk' behaviour but a more comprehensive understanding about their vulnerabilities requires that their environmental and social conditions be considered.

\section{Resiliencies}

Another concept that is important to explore when looking at young Black men's lives is resilience. The concept of resilience is connected to the concept of vulnerability (Manyena, 2006). As mentioned, vulnerabilities can be based on social factors like education, income and social support; however, they can also include an individual or communities' resiliencies (Manyena, 2006). That said, the notion that vulnerability is directly equivalent to a person's exposure to an adverse event or situation is incomplete, as an individual's resilience can help to mitigate vulnerabilities. Thus, a clearer understanding of resilience offers a more comprehensive understanding of vulnerability (Manyena, 2006). 
One of the most common definitions of resilience is the ability to "bounce back", that is, to effectively cope with challenges despite substantial adversity (Rutter, 1985). These challenges and adversities can be found in the natural environment (e.g., a natural disaster), in the community, or can be a person's physical condition (Manyena, 2006). Merriam-Webster's (2017) dictionary also defines resilience as, "the capability of a strained body to recover its size and shape after deformation caused especially by compression stress" and as the, "ability to recover from or adjust easily to misfortune or change." Some of the attributes of resilience include: having a high self-expectation, being flexible, having a sense of humor, the ability to rebound, a sense of self-efficacy and having positive relationships and social supports (Earvolino-Ramirez, 2007)

Resilience has it roots in the Latin word 'resilio', which means to 'jump back' (Manyena, 2006). The concept of resilience became popularized in the field of psychology with the study of children, when psychologist examined the vulnerabilities of children for developing psychological disorders, because of their exposure to traumatic life experiences (e.g., the divorce of parents, poverty or having a parent with a mental illness) (Earvolino-Ramirez, 2007; Manyena, 2006). Early studies of resilience were focused on the personal characteristics of resilient people and how these personal characteristics acted as protective factors in the face of adversity. Luthar (1996) labeled this type of resilience as 'ego-resiliency,' which is based on a person's attributes of resourcefulness and character. One of the major criticisms of this understanding of resilience is that it emphasizes individual traits and fails to acknowledge that for resilience to take place, some type of challenge or adversity must be present (EarvolinoRamirez, 2007). Another problem with resilience being defined as personal agency is that it does 
not explain how individuals or communities can be resilient, if they do not 'innately' possess the qualities of resilience (Khanlou \& Wray, 2014). In other words, resilience based on character or personal agency neglects the social factors that can help individuals and communities to be resilient (Khanlou \& Wray, 2014). For example, Black communities could engage in a number of health promotion activities that advocate for access to key social determinants, like education and social support, to increase their resilience and reduce their vulnerabilities to HIV or other community health issues. Within the ecosystems approach, resilience can be understood as both an outcome and the processes leading to an outcome (Khanlou \& Wray, 2014); that is, resilience can be the outcome of a person's or community's ability to, “cope, bounce back, withstand, or absorb negative impacts" as well as, a set of social factors (i.e., individual, familial or community) that protect one from vulnerabilities (Manyena, 2006, p. 438; Khanlou \& Wray, 2014).

As it relates to heterosexual young Black men, both vulnerability and resilience are key concepts for understanding the ways that this population's experiences of race and heterosexuality make them vulnerable to HIV and shape their personal and collective resiliencies.

\section{Gender Matters}

A gendered approach to examining health issues like vulnerabilities to HIV is important because it allows us to better understand the unique ways that men and women are affected.

Gender can be defined as the socially constructed differences in perceptions and behaviours that are deemed "appropriate" and "desirable" for men and women (Everitt-Penhale \& Ratele, 2015). These differences are not based on biological differences between men and women but ascribed 
social rules that define certain roles and behaviours as either masculine or feminine (EverittPenhale \& Ratele, 2015).

The study of gender has often been considered synonymous with the study of women. This is because men historically have held positions of power and privilege over women, and were therefore considered to be the norm or standard against which others are measured. Men have also been the central figures on which much of our knowledge of history and society is based. For this reason, men and the ways that men live their lives as gendered, often go unnoticed (Connell, 2014). Women's studies, as a part of gender studies, is concerned with examining the power relations between men and women and unveiling the systematic oppression and marginalization of women that result from men's position of privilege (Connell, 2014). While many men hold positions of dominance in society, not all men hold similar power and privileges. The importance of studying masculinities is that it helps to better understand men's varying degrees of privilege in society, the normalization of hegemonic forms of masculinity and other masculinities that have been marginalized.

\section{Masculinities}

Existing literature shows that there are multiple masculinities. Masculinity is a fluid concept that reflects power relations in society and can change with time, place and context. It often refers to men's ways of being, social identities, worldviews and practices (Connell, \& Messerschmidt, 2005; Everitt-Penhale \& Ratele, 2015). Hegemonic masculinity is an important concept used in gender analysis; it denotes an ever-changing configuration of discourses and practices that legitimize patriarchy, male dominance, and unequal power relations that are perpetuated through classism, homophobia and racism (Carrigan et al., 1987; Connell \& 
Messerschmidt, 2005). Hegemonic masculinity is a system of practicing "superior" manhood that reproduces White middle-class heterosexual men's power and domination over women and other men of subordinated positions, i.e., racialized, transgender, and/or gay men (Brod, 1994; Connell \& Messerschmidt, 2005; Everitt-Penhale, \& Ratele, 2015).

Hegemonic masculinity, as a relational practice, promotes certain gendered traits, roles and practices as "the" norm or standard of manhood: pursuit of achievement and social status, being the 'breadwinner', male dominance, suppressing emotion, being 'tough', exhibiting selfconfidence and aggressiveness, heteronormativity, and not displaying effeminate behaviour (Levant et al., 1992; Thompson \& Pleck, 1986). Over time, these traits, roles and practices are 'naturalized' and accepted as the ways real men ought to be. Men who do not aspire to or are not able to achieve these masculinist expectations are often marginalized or labelled "failures" as men (Connell, 1995; Carrigan, Connell \& Lee, 1987).

Under hegemonic masculinity, the practices of masculinity among racialized men, men with disabilities, gay men, MSM, working class and economically marginalized men are deemed to be subordinate as these men are not in the position to attain the hegemonic male norms symbolically and material-wise (Everitt-Penhale, \& Ratele, 2015). These 'other' masculinities are placed in the bottom of the hierarchy of masculinities and subordinated to the prototypic male ideal (Connell, 1995). Even though, few men can actually attain hegemonic masculinity, this ideal representation of masculinity is maintained through social institutions (i.e., media, education, heterosexual marriage and family system, law, etc.) to maintain the current power relations whereby some men benefit from the "dividends" of hegemonic masculinity (Connell, 1995). However, as I present in the subsequent sections, when we apply a critical analysis on 
how race, gender and sexuality intersect to (re)produce power relations, we begin to see that men in subordinated positions experience many challenges in obtaining these dividends.

\section{Effects of Hegemonic Masculinity on Subordinated Men}

Hegemonic masculinity has shaped the experiences of many racialized men. For example, through stereotypical media images Asian men have been constructed as effeminate and lacking "real" masculinity (Shek, 2006). Asian men, regardless of their diversity and versatility, are often recognized only for their aspiration to achieve manhood through their pursuit of career success and strong work ethics (Chen, 1999). The stereotypes of Asian men as docile, academically inclined, hardworking, and prioritizing work over romantic relationships has contributed to Asian masculinity being characterized as asexual (Lu \& Wong 2013). Chen (1999) reports that in an attempt to counterbalance some of these negative beliefs, Asian American men have both embodied and purposely dismissed these stereotypes. For example, one Asian American man in Chen's study reported deliberately excelling in school athletics to debunk the myth that all Asian men are docile and could not be aggressive (Chen, 1999). Another Asian American man said that he worked very hard to provide for his family so that his wife could stay home, like the other women in their predominately White upper class neighbourhood (Chen, 1999). However, not all Asian men embrace or feel that they are able to attain some aspects of hegemonic masculine norms. In fact, some Asian men experience psychological distress as a result of trying to meet these standards (Lu \& Wong 2013).

Similarly, Latino masculinity has often been portrayed through the characteristics of the ‘machismo' stereotype. Latino men have been represented as inherently violent, aggressive, commanding the respect of their children, dominant and unfaithful to their wives and having 
many sexual relationships with women (Liang, Salcedo \& Miller, 2011). These stereotypical images of Latino masculinity reflect some of the hegemonic masculinist norms, including the idea that men ought to be dominant and aggressive and reinforce patriarchal hierarchies within their families (Falicov, 2010; Liang et al., 2011). It is important to note that the system of global and local racial domination sets a limit on which aspects of hegemonic masculinity racialized men can aspire to achieve. In actuality, most Latino men do not prescribe to the socially constructed machismo stereotype. Many Latino men consider machismo to be a false depiction of masculinity; they define their masculinity more broadly to include ideas about respect for others and family (Torres, Solberg \& Carlstrom, 2002).

As stated earlier, not all White men enjoy the same privileges within the hierarchy of hegemonic masculinity. For instance, White working class men are limited to pursue certain aspects of hegemonic masculinist ideals, i.e., engaging in manual labour that typifies masculine toughness and physical strength (Connell, 1995). However, with economic changes facilitated by neoliberal policies and the post-Fordist era, many working class men have had to move into service oriented jobs, which often require emotional labor, i.e., workers are required to present themselves in ways that meet the expectations of their manager and solicit satisfactory emotional responses from the customers they serve (Roberts, 2012). In response to these new labour demands, some working class men reject all service work and become further marginalized (Lindsay \& McQuaid, 2004; Nixon, 2009) while other men reconstruct their work in ways that are congruent with their ideas of masculinity, by taking up jobs that are more physically demanding, such as stocking the shelves or give them an opportunity to demonstrate their knowledge and expertise (Roberts, 2012). 
As hegemonic masculinity is not a set of fixed attributes but power relations and struggles to acquire or maintain a position of domination, some men working in the service sector have argued that masculinity is not about the nature of the work, but about having a job at all (Roberts, 2012). In the absence of physically laborious jobs and with the shift towards service work, working class men have adjusted their perspectives about employment in the service sector, to demonstrate that men can take up various forms of work and that masculinity is not only tied to physical labour. Nevertheless, hegemonic masculinist ideals are produced and reproduced through time and social change, to reinforce a hierarchy that continues to subordinate marginalized men, who are often caught in the precarious space of adoption and resistance of this hegemony (Chen, 1999; Roberts, 2012; Torres et al., 2002). In the space of resistance, many racialized and working class men choose to perform their masculinities based on being honest, respectful towards oneself and others, caring for others, and valuing interdependence between men (Nonn, 1995).

\section{Black Masculinities}

Black masculinities are often deemed inferior within the context of anti-Black racism and White Eurocentric and Anglo-American hegemonic masculinities (Mankowski \& Maton, 2010; Wolf, 2003). Some scholars suggest that Black men engage in traditionally prescribed male roles, characterized by seeking achievement, providing for one's family, being competitive, suppressing emotion, exhibiting toughness, power and gender related dominance in interpersonal relationships, anti-feminine behaviour and aggressiveness, to a greater extent than White men (Thomas \& Pleck, 1986; Wade, 1995, 1996). They postulate that since Black men experience racial oppression and economic marginalization that limits their possibility of achieving 
hegemonic masculine status, that many endorse these traditional male role characteristics to establish their masculine identities (Levant et al., 2003; Pleck, Sonenstein \& Ku, 1993; Wade \& Rochlen, 2013).

Further, some Black men define manhood in ways that challenge the dominant hegemonic understanding. Cazenave (1984) found that some Black men believed that masculinity entails being gentle and being able to cry. Other Black men define masculinity as being able to show affection and emotions to women; this is one way that some Black masculine practices differ from traditional hegemonic masculinist who identify manliness with stoicism and emotional control (Hammond, 2012; Wade, 1995). Other Black masculinities that are not commonly associated with hegemonic masculine norms, are a connection to one's racialized identity, drawing support from community and family, and practicing spirituality (Pierre, Mahalik, \& Wooldland, 2001). These alternative Black masculinities may be based on traditional African values, which center on: spirituality or the belief that spirit is the center of all things; collective cooperation and responsibility that is greater than one's responsibility to self and; knowledge of one's ethnic identity and awareness of self (Cokley, 2005). These alternative constructions of masculinity based on an African worldview, may not coincide with hegemonic masculinity based on the conventions of Eurocentrism and heterosexuality, but represent Black men's attempts to assert themselves as distinct and to resist and liberate themselves from the dominant societal systems that disempower and oppress them.

Black men's ideas about masculinity and what it means to be a man are not solely based on White masculine prototypes; for this reason, it is necessary to critically examine the prevailing notion that hegemonic masculinity is the normative form of manhood that all men 
aspire to. Black men adhere to a variety of masculine identities that have been shaped by their experiences of racism and socioeconomic status. Griffith, Gunter, and Watkins (2012) indicate that Black men draw on parts of hegemonic masculinity and combine this with their own meanings of manhood to reformulate and redefine masculinity, in ways that include attributes and abilities that Black men believe they possess. Some Black men reject White hegemonic masculinity and establish alternate practices of masculinity that reflect their identities and realities (Coles, 2008). Many Black men have developed their own protocols for manhood that are based on the options and limitations presented to them, as a result of the structural and systemic oppressive forces that shape their lives. For example, in some lower income communities Black men are economically challenged by a lack of access to employment, which restricts their opportunities to gain adequate financial income to support their families (Pieterse \& Carter, 2007). In Black communities, structurally oppressive systems like racism have been tied to lower socioeconomic status (Clarke, Anderson, Clark, \& Williams, 1999). In the presence of these systems, Black men's opportunities to demonstrate various aspects of hegemonic masculinity, e.g., being the 'breadwinner, having material items, etc. are limited and constrained (Pieterse and Carter, 2007).

Thus, it is important to examine Black masculinities in the context of Black men's experiences with racism and discrimination that have existed since slavery and colonization (Pierre et al., 2001). Although less overt today, racism continues to be embedded in the structures of society, including social policies and institutions. As a result, racialized people experience discrimination in their individual everyday lives (Clarke, Anderson, Clark \& Williams, 1999; Reed et al., 2012). While both Black men and women experience racism, Black 
men experience racism in different and often more intense ways (Pieterse \& Carter, 2007). For example, in Canada, Black men are one of the most disadvantaged groups in the labour market. Between 2001 and 2015, Black men in Canada had a lower average income $(\$ 31,233)$ than nonracialized men (\$45,327) (Block \& Galabuzi, 2011). In Ontario between 2005 and 2010, 23.5\% of Black men experienced low incomes compared to only 10.9\% of non-racialized men (Block, Galabuzi \& Weiss, 2014). The unemployment rate for Black men was also $73 \%$ higher than for non-racialized Canadians, based on 2006 statistics (Block \& Galabuzi, 2011). Further, Black men from middle and upper socioeconomic groups have reported that experiences of racism and discrimination have negatively impacted their psychological well being and levels of stress (Pieterse \& Carter, 2007). Although these Black men have attained some level of career, financial and material success, they have not gained access to the social status associated with hegemonic masculinity, in White dominant societies. Hegemonic masculinity is not a simple set of criteria that once attained, grants Black and other subordinated men entrance to "manhood"; rather it is a complex set of social relations defined by power and domination that restricts and exempts Black men from manhood, even when their educational, career, financial and other achievements are comparable to White middle class men. Black masculinities, like other forms of masculinities (e.g., other racialized and working class men) continue to be subordinated (Chen, 1999; Coles, 2008; hooks, 2004). Consequently, Black men's attempts to execute these standard forms of masculinity are unrealistic and actually endorse and reinforce the structures and systems that have been designed to oppress them. 


\section{Racism and Health}

The effect of racism on the health of Black men is also an important consideration. In Canada, health disparities exist between Black Canadians and White Canadians. Veenstra and Patterson (2015) report that Canadian born Black people are more likely to report lower health outcomes for body mass index (i.e., a measurement used for obesity), self-reported health, diabetes and heart disease, than their White Canadian born counterparts. Canadian born Black people were overall more likely to have poorer health, that Canadian born White Canadians (Veenstra \& Patterson, 2015). This study showed that some of the lower health outcomes reported by Black Canadians could be attributed to lower socioeconomic status. Although, this study did not examine the connection between racism and the poor health outcomes of Black people, it acknowledged that racism likely has some effect on these health disparities (Veenstra \& Patterson, 2015).

With the limited research on racism and health of Black people in Canada, I drew on the research evidence in the United States. Research shows that racism, as perpetuated through institutions and in culture, is a main social determinant of health for Black people in the United States. Racial discrimination negatively affects the health of Black and other racialized groups, on both an intermediary level and as a primary cause of health problems; it worsens other social risk factors for health by limiting people's access to economic and social resources and its presence can also be the primary cause of health problems (Williams \& Mohammed, 2013). For example, racial discrimination has been tied to stress and also impacts people access to employment, income, housing and adequate medical care (Williams \& Mohammed, 2013). Evidently, racism affects Black men in the United States, as they face greater health disparities 
than their White counterparts. Black men living in America are found to have life spans that are seven years less than White American men (Bharmal, Tseng, Kaplan, \& Wong, 2012). The health disparities experienced by Black men are related to a variety of biological, psychological and social factors. For example, Black men report higher levels of discrimination by the police, in hiring practices, in their places of employment and in receiving medical care (Kwate \& Goodman, 2015). Racism and discrimination are not isolated to Black men living in America. For example, in countries like New Zealand, there have been a growing number of complaints by the African community that Black youth are being over policed (Hill, 2016).

Experiences of racism over time have been found to negatively affect the mental health of Black people, resulting in distress, depression and poor mental and physical health (Clarke et al., 1999; Kwate \& Goodman, 2015). Black men, in particular, reported increased levels of depression and anxiety that paralleled their increased experiences of racial discrimination (Banks, Kohn-Wood, \& Spencer, 2006). Their increased mental health distress may be related to the gendered ways that Black men restrict their emotional responses to stresses like racism; that is, many Black men adhere to traditional masculine expectations of stoicism, emotional control, self-reliance, and avoidance of behaviours deemed feminine (Hammond, 2012). Similarly, some young Black men conceptualize masculinity as the ability to manage their own emotional problems, and may choose not to seek help for mental health issues (Lindsey \& Marcell, 2012). In fact, young Black men are less likely to seek professional help for mental health problems because they are socialized to manage their own problems (Watkins \& Neighbors, 2007). This is concerning, as young Black men account for $80 \%$ of all suicides amongst Black people, and they are less likely to access mental health resources (Lindsey \& Marcell, 2012). Furthermore, young 
Black men may draw on coping strategies that put them at risk for other health challenges such as HIV infection or substance use (see next section for details).

Research seldom explicitly discusses racism as an influencing factor of the mental health challenges and help-seeking behaviors of young Black men (for example, Lindsey \& Marcell, 2012; Watkins \& Neighbors, 2007). In failing to acknowledge and explore the impact of systemic factors, like racism, sexism and economic marginalization, on young Black men's mental health and access to services, the notion that this is an individual problem and not a broader social issue of structural oppression and marginalization, is further perpetuated. A more equitable approach to examining health disparities amongst Black men requires that the social factors, that dominate and marginalize Black men also be considered.

\section{Racism and HIV Vulnerabilities of Heterosexual Black Men}

As I presented in Chapter One, Black communities in Ontario bear a disproportionate burden of HIV. However, there is a paucity of research that examines the structural factors that influence heterosexual Black men's vulnerabilities to HIV. The spread of HIV in Black communities has often been blamed on Black men, who have been accused of engaging in 'risky' sexual behaviours (Bond et al., 2009; Bowleg, 2004; Halpern et al., 2004; Pleck et al., 1993). Within a dominant White racist worldview, Black men are portrayed as irresponsible, having many sexual partners, risk taking and dominant towards women (Fleming, Lee, \& Dworkin, 2014). Mainstream media has falsely caricatured heterosexual Black men, as a type of 'King Kong,' barbaric in their approach towards women and as problematic to White social order, if left unrestrained (Dines, 1998). In Canada, these negative media discourses and stereotypes are reinforced by the legal system. In the 1990s, people living with HIV became 
legally obligated to disclose their HIV positive status to their sexual partners, before having intercourse; failure to do so has the potential to result in criminal charges under Canadian criminal law (Canadian HIV/AIDS Legal Network, 2012). This law has disproportionately affected Black men in Ontario (African and Caribbean Council on HIV/AIDS in Ontario, 2010; Wilson, 2013). In Canada, by the end of 2015, 88\% of people charged for HIV-non disclosure were men and $68 \%$ of these men were charged for not disclosing their HIV status with their female partner (Mykhalovskiy, Hastings, Sanders, Hayman, \& Bisaillon, 2016). Similarly, in Ontario, $65 \%$ of the people charged with HIV-non disclosure were men who had not shared their HIV status with a female sexual partner (Mykhalovskiy, 2011). Between 1989 and 2009, of one hundred and four cases, there were ninety-eight people charged in Ontario, for non-disclosure of HIV. Black men comprised 50\% of those charged for HIV non-disclosure between 2004 and 2009 (Mykhalovskiy, 2010). News reporting of HIV non-disclosure cases unfairly portrayed the men as careless, sexually promiscuous and violent (DiManno, 2009; Wilson, 2013). Moreover, the reporting of these cases tended to focus on Black men (Mykhalovskiy, 2011; Mykhalovskiy et al., 2016). Of all racialized groups, Black people were more likely to be reported about in mainstream newspapers with regards to criminal cases for HIV non-disclosure; Black immigrant male defendants represented $76 \%$ of the cases that were reported. Black men were also represented in $92 \%$ of all newspaper stories of racialized people, living with HIV, who were being charged for non-disclosure (Mykhalovskiy et al., 2016). For a population that is disproportionality affected by HIV and that has been further marginalized by racisms and other forms of oppression, the move toward criminalization of HIV non-disclosure is concerning because it puts Black men at risk of being further oppressed. Thus, the intersections of race, 
gender and heterosexuality must be considered when examining HIV non-disclosure as it relates to heterosexual Black men because of the disproportionate effects of both HIV and HIV nondisclosure on this population.

Similarly, there is evidence to suggest that HIV related health disparities experienced by heterosexual Black men are related to their experiences of oppression and marginalization. For instance, Black men's experiences of racism have been found to positively correlate with an increase in the number of sexual partners, a decrease in condom use, increases in selling sex for drugs and giving drugs or money for sex (Reed et al., 2012). Black men who reported higher rates of racism were more likely to report more than 4 sexual partners in one year and having unprotected sex with a female partner (Reed et al., 2012). For some Black men, having multiple and concurrent women sexual partners may be considered as a form of compensatory masculinity, as Black men with multiple sexual partners are sometimes treated with respect and admiration by other Black men who equate having multiple sexual partners with being "a real man” (Bowleg et al., 2011). Likewise, many Black men equate masculinity with heterosexuality. Men who have sex with men are considered to be effeminate, weak and lacking in masculinity (Lemelle \& Battle, 2004). These studies suggest that some Black men adhere to more hegemonic male norms, as it relates to sexuality (Bowleg et al., 2011). Coles (2008) argues that while men may agree to and perform some aspects of hegemonic masculinity that coincide with their own abilities and opportunities, all men do not consider the mainstream form of masculinity to be superior. In fact, some men hold alternate forms of masculinity in higher esteem, even when they are incongruent with the dominant ideas about what constitutes manliness (Coles, 2008). Faced with racism and economic marginalization, Black men who have limited access to hegemonic 
masculine capital (e.g., social status, employment and income), may take up other aspects of hegemonic masculine practices (e.g., sex and sexual relationships) to establish their masculine identities (Coles, 2008).

Heterosexual young Black men's ideas of masculinity and sexuality are also shaped by their experiences of marginalization. One study reported that young Black men, who perceived a greater degree of racial discrimination at the ages of 10 and 11, were more likely to engage in risky sexual behaviours, such as having unprotected sex and multiple partners at 18 and 19 years of age (Roberts et al., 2012). Other studies suggested that young Black men are also more likely to engage in sexual intercourse at a younger age than young Latino or White men, and are more likely to have had 6 or more sexual partners in the past year (Bowleg, 2004). However, without detailed investigations of the structural influences on young Black men's pathways to sexual practices, these research results often serve to reinforce stereotypes about young Black men as hypersexual and anti-social.

\section{Summary}

In this chapter, I have presented research evidence that provides important and relevant contexts to the exploration of the HIV vulnerabilities of heterosexual young Black men, in Toronto. I have also documented the research gaps and illustrated the urgent need for research that examines the individual and structural factors that shape how heterosexual young Black men construct their masculine identities and take up practices that may increase their vulnerabilities to or protect them from HIV and other sexually transmitted infections. The results of this literature review also suggest the need for prioritizing HIV research for heterosexual young Black men in Canada, as very few studies exist for this population. Further, this study will contribute to better 
understanding issues of racism, gender and class, as it relates to young Black men and how HIV prevention strategies can be tailored to meet the needs of this group. In Chapter Three, I focus on the theoretical frameworks and methods that I employed to conduct this study. 


\section{CHAPTER 3: METHODOLOGY}

\section{Introduction}

In this chapter, I look at the theoretical frameworks and concepts that were used to guide this research study. I draw on critical social perspectives of intersectionality and critical race theory (CRT) and explain how they apply to understanding HIV vulnerabilities and resiliencies

for heterosexual young Black men. This chapter also outlines the methods I used in gathering, analyzing and interpreting data collected, in this study.

\section{Theoretical Framework}

There is a plethora of theoretical frameworks that can be used to examine the concepts of vulnerability and resilience, as it relates to HIV and Black men. The research question that I used for this study was: How do the gendered and racialized experiences of heterosexual young Black men affect their vulnerability to HIV and what promotes their resilience? This question provided a starting point for investigating young Black masculinities and the process of addressing this question helped me to understand the complexities of race, masculinity and heterosexuality, as it relates to this population. Using the critical social perspectives of intersectionality and Critical Race Theory (CRT), I examined and challenged the stereotypes and commonplace views reproduced in culture and institutions, about HIV and Black men. These theoretical approaches provided a framework for critically analyzing issues of race and racism, as they intersect with gender and class, to shape young Black men's HIV vulnerabilities, resiliencies and life experiences. Within these theoretical approaches, one recognizes that the stories shared by people about their lives are often a reflection of larger social phenomena and a window into understanding the structural determinants of social and health inequities, that are often invisible. 
Therefore, in examining complex social issues, critical researchers do not accept explanations at 'face value' based on linear and simplistic rationalizations; rather, they apply critical theories to investigate power relations in society and uncover inequities that stem from systemic oppressions. In this study, I applied the theories of intersectionality and CRT to uncover power relations and associated outcomes that are often taken for granted or concealed.

\section{Critical Social Theories}

My research was guided by the broad perspectives of Critical Social Theories (CST), a subset of social theory, that is concerned with critical examination and reflection on existing social institutions and ideologies, to expose the ways that domination and oppression are produced, reinforced and normalized (Agger, 2013; Harrington, 2005). One of the aims of a critical social perspective, is to liberate people from accepting the hegemony that endorses unequal power relations, reproduced through social discourse, practices, institutions, and culture (Agger, 2013; Harrington, 2005). Unlike the positivist tradition, in which society is assessed and explained using strictly objective means, knowledge within critical social perspectives is assumed to be subjective, socially constructed, and laden with values. For example, using a critical framework, HIV among heterosexual young Black men cannot simply be explained as a consequence of behaviours, but the intersection of a variety of social factors. Moreover, CST scholars argue that, it is possible for social structures to be transformed through individual and collective political and social actions that bring about liberation and social justice (Agger, 2013; Browne, 2000; Patton, 2002).

Within CST, I applied intersectionality (using the concepts of race, gender and class) and CRT, as my analytical lenses. Intersectionality is a dynamic theory that can be used to critically 
analyze people's multiple situational social identities, that inform their social positioning and also shape their everyday experiences of privilege and/or marginalization (Crenshaw, 1989, 1991). This theory helped me to analyze the complex gendered and racialized identities of heterosexual young Black men and how these exist simultaneously, to inform their experiences of social marginalization and oppression. Similarly, I also used the theoretical lens of CRT, which allows a critical analysis of how the concept of race has been constructed through power relations, to reinforce and justify historical and existing social injustices, oppression and marginalization (Delgado \& Stefancic, 2012). By using CRT for this study, I investigated the various ways that racism is embedded in society, through discourse, culture and institutions and how this affects heterosexual young Black men's ideas about who they are. In using intersectionality and CRT together, I uncovered the experiences of oppression and the strategies that heterosexual young Black men use to overcome challenges in their lives, their perspectives about their racialized, gendered and classed identities, and how their social positions affect their access to societal resources and determinants of health. I was also able to explicate how racism, hegemonic masculinity, heterosexual norms, and other dominant social norms shape Black men's masculinities and heterosexual sexual practices. As analytical frameworks, these approaches guided me in making sense of the narratives shared by the study participants about HIV vulnerabilities and resiliencies. 


\section{Intersectionality}

Intersectionality is a theoretical approach that originated in the third wave of feminism ${ }^{5}$ and challenged the status quo notion that all women's experiences of oppression and their quests for greater equality were the same. It is an analytical framework, couched between critical race theory (CRT) and critical feminist theory, which critiques second wave feminists for failing to accurately represent the challenges faced by racialized women, particularly Black women (Crenshaw, 1989, 1991). Within this theory, first developed by Kimberle Crenshaw, she argues that even though second wave feminists fought to abolish the ways that women had historically been discriminated against, that this understanding of discrimination based solely on gender, was limited (1989; 1991). Trying to 'fit' Black and other racialized women's issues into the existing analytical framework of feminism was problematic because these frameworks were largely based on White middle class women's thoughts and experiences. Further, anti racism was treated as a separate issue and also lacked a gendered perspective (Crenshaw, 1989). Thus, in maintaining a "race-less" framework for feminism and "gender-less" anti racism, racialized women were further marginalized because they were left behind by people who enjoy the privileges of Whiteness and maleness (Crenshaw, 1989). In other words, White women would be privileged amongst all women within feminism and men would take on dominant positions in the anti racism movement, while those who were excluded based on race, gender, class and other

5 Third wave feminist refers to theories and discourses that criticized $2^{\text {nd }}$ wave feminist of failing to respond to the concerns of women of multiple social identities, including racialized, working women and women with diverse sexual expression. Third wave feminists argued that $2^{\text {nd }}$ wave feminists narrowly represented the concerns of White, Eurocentric, middle and upper class women and marginalized other feminist voice that represented minority and working class women (Crenshaw, 1991; Kinser, 2004). 
marginalized positions were further oppressed.

Crenshaw (1991) problematized the notion that people should be seen through the lens of a single social identity and that their experiences of marginalization be relegated to a onedimensional view of the social constructs about people's identities. In seeing the world through the lens of intersectionality, researchers are better able to acknowledge that a multiplicity of social identities can and do co-exist within a single individual, without being mutually exclusive (Crenshaw, 1989). It is the complexity of the social categories that provides the basis for intersectional analysis; one social category does not become a background issue to the analysis of the other (e.g., race as central and gender as contextual) (McCall, 2005). Rather, it is where these social categories meet that they present a unique set of realities for people (including power and privileges, as well as marginalization and disadvantages) that cannot be accounted for as a singular category or the addition of categories (Crenshaw, 1989).

Although intersectionality was an approach used to explore the social oppression of women, it has application to heterosexual young Black men because of their multiple social identities. Intersectionality was an appropriate theoretical lens for me to use with my study, as my understanding of race, in the context of the everyday experiences of Black men was deepened, when I also critically examined how these experiences are simultaneously gendered and classed, and shaped by other relevant social positioning (Corlett \& Mavin, 2014; Hunting, 2014; Lutz, Vivar, \& Supick, 2011; Nash, 2008; Shields, 2008). It was in the plurality of these identities that I could look at how their personal stories of life challenges, such as being unemployed, being negatively typecast by teachers, or being over policed, as the reflection of their collective struggles of systemic discrimination and structural violence, resulting in racist 
stereotypes, high rates of poverty, over incarceration and experience of everyday

microaggression (African Canadian Legal Clinic, 2013).

\section{Critical Race Theory}

Race as a social construct has been used to produce racism, i.e., the oppression and marginalization of racialized people by the dominant racial group (i.e., Whites) who hold power in society, resulting in tangible and real experiences of inequities, that fuel health disparities and increase vulnerabilities of racial minority groups (Haney-Lopez, 1994). For young Black men, racism can be experienced as everyday microaggressions - being stopped by police on their way home from school (Rankin \& Winsa, 2012), or being devalued by the education system (Gordon, 2017) - that are normalized and legitimized by dominant social institutions of education

(Delgado \& Stefancic, 2012). Critical race theory is a framework and social movement that grew out of critical legal studies and radical feminism in the 1970s, that is mainly concerned with issues of race, racism and power (Delgado \& Stefancic, 2012). From a CRT perspective, race is defined as a social construct that has no real objective or biological basis; it is constructed with a hierarchy of social categories that are used to propagate the idea that specific groups of people possess inherently good or bad traits (e.g., superior or inferior intelligence, or superior or inferior morality) to justify unearned privileges among the dominant groups and reinforce race-based economic and social marginalization, of racial minority peoples (Delgado \& Stefancic, 2012; Haney-Lopez, 1994). For example, dominant popular images and discourses about Black men have shifted during different periods in history, to justify White supremacy and dominance, socially and economically. When imagined as "good men", Black men have been depicted as hardworking and subservient to Whites. Alternatively, when Black men challenge or resist 
oppression and marginalization, they are stereotyped as animalistic, dangerous, violent and in need of being controlled (Cooper, 2005).

CRT scholars are concerned with challenging the existing social order, and examining both the individual and collective lived experiences of racialized people in the context of racism and race relations. They critique institutions and social systems that are built on values that negate racial diversity and are founded on White supremacy, presented as dominant universal truths through discourse, culture, systems and institutions (Delgado \& Stefancic, 2012; Graham, Brown-Jeffy, Aronson, \& Stephens, 2011). In other words, CRT scholars argue that racism is not a rarity but commonplace in society, making it difficult to address because it is seldom acknowledged as an issue (Delgado \& Stefancic, 2012). In many ways, the liberal ideology and dominant discourse of liberalism, based on the notion that the individual is most central and that each individual enjoys equal rights, regardless of their race, promotes a colour-blind society (i.e., the notion that race is irrelevant) (Graham et al., 2011). The refusal to recognize that race and racism limit the liberties and opportunities of racialized people and privileges Whiteness, makes challenges to racism and changes to social structures embedded with White supremacy, difficult (Delgado \& Stefancic, 2012; Graham et al., 2011). CRT is not only concerned with uncovering stories of racism and social inequalities based on people's experiential knowledge, but also using social action to address and eradicate these forms of oppression (Creswell, 2013; Graham et al., 2011).

In this study, I drew on CRT to examine how race and racism operate in the daily lives of heterosexual young Black men. I looked at ways in which young Black men's ideas about masculinity and sexuality are derived from dominant racialized stereotypes and images about 
Black men. In particular, I used CRT to examine how young Black men internalize hegemonic forms of masculinity, as they navigate their everyday lives, and to examine their narratives about their racialized identities and individual and collective experiences.

\section{Qualitative Approach: Narrative Inquiry}

Narrative inquiry is an approach used in qualitative research to understand people's lived experience and is also concerned with the study of narratives (Caine, Estefan \& Clandinin, 2013; Clandinin \& Caine, 2008). Narrative inquiry as a research methodology, is a structured approach to understanding people's lives, how they understand themselves and others, as social beings, and their experiences. Within this approach, stories are examined, as they relate to the storyteller's social context, the past, present and future events and the location or place where the inquiry takes place. Narrative inquiry is about studying people's experiences as stories, as the central means of understanding people's experiences (Connelly \& Clandinin, 1999; Clandinin \& Caine, 2008; Caine et al., 2013).

Narratives are a way of describing the human experience - a continuous process through which people live their storied life and share their stories with others. Personal stories are often reflective of the storytellers' lives, situated within the broader narratives of society, family, culture and institutions (Caine et al., 2013; Connelly \& Clandinin, 1999). As life itself is relational and ever changing, the stories that people tell about their lived experiences are hardly ever the same and changes with each retelling. Thus, narratives are said to be in many ways, "selective, partial and contextually constructed" because people are always growing, adapting and making new meaning of their life stories, the stories of others, and the stories of their social environments (Richardson, 1997, p. 6). 
Although stories about people's lived experiences are central to narrative inquiry, the use of narratives is commonly used in other disciplines, such as the arts and literature, as well as the fields of psychology and biology (Connelly \& Clandinin, 1999). It has also been used as a form of data and for various types of data analysis, within different research methodologies. For example, narratives can be used for thematic or linguistic analysis within ethnographic studies; they can also be used as data within other research methodologies, such as phenomenology and case studies (Caine et al., 2013). Stories can be effective tools for the sharing of research findings, in knowledge translation and dissemination (Caine et al., 2013).

Within the methodological tradition of narrative inquiry, are a number of methods that can be used to solicit the stories of others, including interviews and/or conversations, which can be told by participants, or observed (Clandinin \& Caine, 2008). As the researcher listens to the stories of participants, they can record in their journal or write field notes, which will reflect their thoughts and perspectives about their experiences in the field and any challenges or complications encountered (Clandinin \& Caine, 2008; Savin-Baden \& Van Niekerk, 2007). For researchers that use these methods of narrative inquiry, it is important to examine the ways in which the stories shared are embedded in the broader narratives found in social, cultural and institutional contexts (Clandinin \& Caine, 2008).

One of the aims of narrative inquiry is not to focus on discovering and establishing truths but on making meaning of the stories of people's lived experiences (Bailey, 1996; Clandinin \& Caine, 2008). Notably, it is also a methodology marked by the relationship between the researcher and the participants of research and the ways that they co-construct meaning. While the participant inherently reconstructs their stories as they tell them, by interpreting them in ways 
that make sense and providing significance, the researcher also plays a role in making meaning of the stories shared (Bailey, 1996). Thus, the main concern of the researcher is to recognize the importance of their presence as a researcher and of the participant-researcher relationship, and to retell the participants' stories, in a way that is as close to the participants' meaning as possible (Caine et al., 2013). This also means that narrative researchers have a responsibility to retell difficult stories and resist the temptation to domesticate them, in attempts to make them more palatable (Caine et al., 2013). Even when stories seemingly lack coherence, i.e., they do not present in a linear fashion or chronologically with logical beginnings, middles and endings, the researcher has a responsibility to refrain from retelling the participants' stories in ways that disallow interruptions, inconsistencies and bipolarities (Savin-Baden \& Van Niekerk, 2007). Rather, researchers are to embrace these stories and recount them in ways that give meaning to the stories and the world around them (Riessman, 2002). In other words, throughout the process of storytelling, both the participant and the researcher engage in the co-creation of stories, as they also engage in meaning-making of the participant's storied life (Creswell, 2013).

Within the narrative approach there are a number of ways that the data can be analyzed, including: thematic, structural, interactional and/or performative analyses. First, a thematic analysis is concerned with the story being told, the "what" of what is shared, rather the way in which the story is shared. This type of analysis requires conducting interviews with many participants so that the researcher may review them and inductively develop categories of themes that can be further classified and used, for the purpose of discussing their meaning (Creswell, 2013; Riessman, 2005). Second, a structural analysis focuses on the way that the stories are told, with attention paid to syntax and the patterns, intonation and rhythms of language. Structural 
analysis is less useful with case studies because of the level of detailed analysis required; it is more useful for the theoretical development of language and meaning (Riessman, 2005). Third, the interactional analysis examines the relational aspects of conversation between the listener and storyteller. While it does not negate the importance of thematic and structural forms of analysis on stories, its key emphasis is on the process of story co-construction, that is, how people interact in conversation in different social settings (Riessman, 2005). Fourth, a performative analysis looks at the way in which the storyteller "does" or performs storytelling, that is, how the storytellers position themselves, in the context of social identities and positioning, within the specific setting of where the stories are shared and how the listeners respond to the storytellers' performances. Performative analysis focuses on both the listeners and storytellers and is useful for examining the ways through which both the listeners and storytellers perform their social identities (Riessman, 2005). In addition, one important approach in narrative analysis is to examine people's stories, as experiences or events. In experience-centered narrative research, the stories shared can include personal stories of realization, life changing moments of personal crisis that help storytellers to reach self-understanding and reflection on the social contexts of their lives and identities, that enable them to act as social agents (Squire, Andrews, \& Tamboukou, 2008). Alternatively, event-centered narrative research focuses on a sequential and historical account of an event that a person experienced (Squire et al., 2008). In practice, the combined use of these different strategies enable the researcher to make sense of the narratives of the participants, of diverse lived experiences. 


\section{Narrative Inquiry and This Research}

I have chosen to use narrative inquiry to understand heterosexual young Black men's vulnerabilities to HIV for a number of reasons. First, narrative inquiry is aligned with the ontological assumption of critical social research, i.e., there are multiple realities about social life and that these realities vary with time, place and context (Streubert \& Carpenter, 2011). Unlike the positivist tradition that emphasizes a single objective reality, narrative inquiry is centered on the notion that reality is fluid, interactional, and ever changing, based on one's relations with others, their physical setting, social location and social environment (Creswell, 2013; Caine et al., 2013). Second, researchers of narrative inquiry recognize that knowledge production is subjective and that, for this reason, the values and viewpoints of the researcher are not separated from any aspect of the research process (Streubert \& Carpenter, 2011). They presuppose that meaning is co-constructed between the researcher and the storytellers and hold this as one of the approach's main tenants (Creswell, 2013). Relationship and interaction is key to narrative research in a way that the storytellers are central figures and researchers are there with the participants, as they tell their stories (Clandinin \& Caine, 2008). Third, narrative research is useful for this study because it seeks to situate each narrative within larger social narratives, like family and culture (Caine et al., 2013). For these reasons, narrative inquiry fits well with my theoretical lenses of intersectionality and CRT, as these social theories help to contextualize and conceptualize the narratives of young Black men, about their experiences with racism, heterosexuality and class. While I drew on the different strategies of narrative inquiry, I focused on using an experience-centered narrative approach to better understand the individual and collective experiences of heterosexual young Black men. I focused on narratives about their past 
experiences and hopes in the future, their stories about themselves, their peers, the Black community, and how they understand themselves and others, in the context of their everyday social realities.

\section{My Study within A Research Program}

As a Graduate Fellow with weSpeak, I worked with the weSpeak research team to engage selfidentified heterosexual young Black men to explore their vulnerabilities and resiliencies to HIV. The weSpeak project is a 5-year program of research and related activities, that seeks to engage men of all ages, living in Windsor, London, Toronto and Ottawa, on issues of HIV prevention and health promotion, in Black communities. My training as a Graduate Fellow was specifically placed with the Toronto site team and as a novice researcher, I actively took part in community engagement and participant recruitment. As described in Chapter One, my thesis research was approved as one component of the fellowship training program. I have chosen to focus on heterosexual young Black men between 16-24 years of age, living in Toronto, based on my personal and professional interests. My thesis research was guided by and fits within the overall research program of weSpeak, but conducted independently as partial fulfillment of the Master of Nursing degree. With ongoing direction from my thesis supervisor and committee and support from weSpeak staff, my independent research included recruitment of participants, data collection, transcription, data analysis and interpretation, and writing of this thesis.

\section{The Research Processes}

In this study, I have taken on research processes that were aligned with narrative inquiry, from identifying my research question, to recruitment, data collection and data analysis. In the following section, I will outline the steps I took to engage in this research. 


\section{Identifying a Research Question}

Developing a research question is a central part of any research project. In qualitative research, the purpose is to focus on a number of questions that will address the purpose of the research (Creswell, 2013). Similarly, in narrative inquiry, the aim of a research question is to explore participants' experiences through their stories (Creswell, 2013). In this study, I wanted to gain a better understanding of heterosexual young Black men's perspective on Black masculinities, sexuality, and vulnerabilities and resiliencies, to HIV, through their stories. To adequately explore these phenomena, my research question was: How do the gendered and racialized experiences of heterosexual young Black men affect their vulnerability to HIV and what promotes their resilience? To adequately explore this question, my sub-questions were: a) How do racialization and hegemonic masculinity intersect to shape heterosexual young Black men's masculine identities? b) How do their racialized masculine identities influence the ways they navigate their relationships with women, men and community? c) What strategies do heterosexual young Black men use to resist racist and masculine hegemonies? d) What are the conditions that promote resilience among these young men? These questions were useful in guiding me throughout all steps of my research and thesis writing.

\section{Participant Selection}

As stated in the previous section, this study was a sub-study within the weSpeak project. My study focused on young men, and the participation criteria included the following: individuals who self-identify as heterosexual, male, African, Caribbean or Black, between the ages of 16 and 24, and live in the Toronto or the Greater Toronto Area (GTA). Guided by critical social theories and using a qualitative approach, I used purposive sampling in this study, which complements a 
narrative study design, i.e., the participants recruited represented the specific population of interest, based on the research question (Creswell, 2013; Streubert \& Carpenter, 2011). Purposive sampling is useful for qualitative research for locating individual or groups of individuals who are familiar or have some experience with the topic of study, and who are willing and available to participate in the study (Palinkas et al., 2015). Within purposive sampling, I also used snowball sampling, that is, I invited study participants to refer other potential participants from their social networks, to join the study. Snowball sampling was useful within purposive sampling because it helped to build up a potential participant pool, that met the participation criteria and shared some common experiences (Palinkas et al., 2015; Streubert \& Carpenter, 2011).

Study participants were recruited from two different settings: one from a youth drop-in center in a low-income priority neighbourhood in eastern Toronto, and the other at a local university in northwest Toronto. These different research locations were chosen deliberately, to allow me to talk with youth of diverse socioeconomic backgrounds and experiences. My goal was to conduct 2 focus groups and 5 individual interviews for this study (see Chapter Four on results). This number of focus groups and individual interviews was conducted because it allowed me to hear the stories of many participants and have a sufficient number of narratives to develop themes and ascribe meaning (Creswell, 2013; Riessman, 2005).

\section{Recruitment (Outreach and Engagement)}

During recruitment, I took on the role of a student researcher, as well as, the role of a weSpeak Graduate Fellow. Thus, sometimes I was the leader of recruitment (e.g., in eastern Toronto) and sometimes I worked with weSpeak project staff to carry out recruitment, as a team. 
Throughout the recruitment process there were a number of challenges. One of the major challenges included finding participants who were willing to participate in a study about HIV because of the stigma that exists about HIV, in the Black community. It was also challenging to find the places where young Black men frequented and to provide a brief synopsis of the study, in a way that engaged them and adequately demonstrated the importance of the study, for Black communities.

To recruit participants for my thesis research, I connected with individuals accessing and working in community organizations. To enhance successful recruitment, I undertook various strategies, including visiting community spaces where I knew young Black men would gather, such as drop-in centers, in eastern Toronto. I also spoke to the individuals responsible for the community space about my thesis and weSpeak. After obtaining permission from these individuals, I spoke to young Black men on a group and one-to-one basis; I shared about weSpeak, the research I was doing for my thesis and asked for their participation in the study. For some participants, I obtained their contact information and presented them with a small card with information on weSpeak. Also, after speaking to some young men, I conducted screening immediately in a private room in the drop-in center. I also provided these potential participants with the date and the location of the upcoming focus group. Having collected the contact telephone numbers and/or email addresses (stored in a password protected document) of the young Black men that I met, I either called or text them a few days prior to and on the day of the focus group, to remind them that it was taking place and to indicate that they were welcome to attend.

The recruitment process showed that snowball sampling was very useful for this study. 
Many of the young Black men that I engaged with at the drop-in center attended the focus group and also brought their friends, some of whom participated on a voluntary basis, if they met the inclusion criteria for the study. Snowball sampling was also used to recruit young Black men for the other focus group, at a local university. Recruitment for the individual interviews consisted of contacting young Black men and arranging a mutually convenient time to meet. Three of the young Black men that participated in an individual interview had previously participated in a focus group. The other two young men that participated in the individual interview were recruited through my connections to community workers in the Black community.

\section{Data Collection}

Following outreach and engagement, I worked independently and with the weSpeak research team to collect the data, which mainly consisted of semi-structured focus groups and individual interviews. The interview guide was developed by the weSpeak research team and approved by eight ethics review boards to be used for focus groups and individual interviews (see Appendixes D, E and F). In both the focus groups and individual interviews, semi-structured interview guides were used. These focus group and individual interview guides consisted of seven to ten questions, with a number of sub-questions and probes that reflected the overall aim of the study. Probes were used throughout the interview to delve deeper into the study topic; this interviewing strategy is helpful for obtaining a more detailed response and allowing participants to elaborate and clarify their thoughts (King \& Horrocks, 2010).

Also, having an interview guide was helpful, as it gave me the structure I needed to ask questions in an organized way, to ensure that I was asking similar questions to each participant and moving the conversation in a particular direction, so that I covered the topics identified in 
the weSpeak research purpose (Stewart, Shamdasani \& Rook, 2007). The focus group interview guide helped to limit the amount of variation between me and the other interviewer, during the interview process (Patton, 2002). At the same time, since the focus groups and individual interviews were semi-structured, I was able to ask open-ended questions to promote a deeper conversation, encourage participants to answer questions, based on their lived experiences and using their own words, and eliminate any unnecessary barriers for meaningful participation (Patton, 2002).

As a weSpeak graduate fellow, I co-facilitated two youth focus groups with another member of the weSpeak research team. Each focus group lasted approximately one and a half hours and was audio recorded; individual interviews were also audio recorded. The weSpeak ethics protocol of participant safety required that two interviewers be present during all focus groups. Having two interviewers present allowed for unanticipated needs; for example, one interviewer was always available to attend to the unexpected physical or emotional needs of any individual participant, while the other interviewer could stay with the rest of the focus group participants (see more details in section on Ethical Consideration).

\section{Data Analysis}

The focus groups and individual interviews were transcribed verbatim and verified by a weSpeak team member. In doing data analysis, I read the transcripts and listened to the audio recordings of the focus groups and interviews multiple times, to familiarize myself with the data. This process made it easier for me to identify and highlight ideas and themes that were present in the participants' narratives. I then created a table to organize these themes into a coding tree with major codes and subcodes (e.g., within the code of masculinity, I created a subcode of Black 
masculinity). I also used the computer program, NVivo, to organize the data by entering the codes and subcodes into the program (Bazeley, 2010). NVivo was a useful tool for organizing data because it allowed me to retrieve the different perspectives shared by different participants under the same theme or code.

I conducted data analysis using both an inductive and deductive approach. To begin the process, I initially did open coding and used an inductive approach to thematic analysis (Braun \& Clarke, 2006; Patton, 2002). This means that I started the data analysis process without first ascribing any codes or categories to the data. To achieve this, I read the transcripts and listened to the audio recordings of the individual interviews and focus groups repeatedly, to familiarize myself with the data, so that I could discern commonalities and patterns with recurring words, phrases, ideas and experiences that could be coded into themes and categories. In using an inductive thematic analysis as the first step to data analysis, I uncovered the themes, patterns and categories that are derived from the participants' narratives using an open coding method (Braun \& Clarke, 2006). During the thematic analysis, I paid particular attention to how my understanding of the research topic and the key themes were influenced, by my prior understanding of the subjects of HIV, masculinities, Black communities, and the theoretical underpinning of CRT and intersectionality (Bazeley, 2010).

During data analysis, I also used a deductive approach by examining the data through the theoretical lenses of CRT and intersectionality. Both CRT and intersectionality helped me in making sense of the participants' narratives, in the context of historical and the current social environment. The deductive approach also enabled me to identify the themes relevant to the research questions and other theoretical concepts (Patton, 2002), which helped to illuminate the 
complexities and structural influences, on the participants' vulnerabilities to HIV and the protective factors that promoted their resilience. For example, CRT and intersectionality guided me to critically examine the data, for narratives about racism, social and economic oppression, stereotypes about Black masculinities and sexuality, how young Black men shape their identities about who they are and how this understanding contributes to their vulnerabilities to HIV. In addition, CRT and in particular, intersectionality helped to elucidate the multiple social identities that heterosexual young Black men hold, and the ways in which these young men are oppressed and marginalized in mainstream society.

During the writing phase of this study, I also took an active role in "restorying" the narratives of each of the research participants, by taking the stories of the participants and organizing them in ways that enables the readers of this thesis to gain a reasonable understanding of the participants' perspectives and experiences, without having to read all the interview transcripts (Creswell, 2013). Using a thematic analysis approach, I identified key themes and categories throughout the interviews, and situated the participant's narratives within the broader social context of their collective lived experiences, challenges and resilience.

\section{Researcher Reflexivity}

In research, it is important for the researcher to look both 'inwards' and 'outwards', and to interrogate their prior biases, assumptions, ideas, experience and position as a researcher, in relation to the study and the participants (King \& Horrocks, 2010, p. 125). In qualitative research, the subjectivities of both the researcher and the participants are recognized as an integral part of the co-creation of stories, such as in narrative research (King \& Horrocks, 2010). Reflexivity is a particularly important part of qualitative research and it is expected that the 
researcher approach his or her study from a particular perspective or framework that he or she will use to interpret and ascribe meaning to the findings. The view that the researcher helps to shape the research, requires that the researcher think about how they might position themselves in relation to the study. For example, the researcher's ideological convictions, gender-related, cultural, political, socio-economic and other relational perspectives, will shape various parts of the research process and it's therefore necessary for these stances to be made explicit to the readers of their work (Patton, 2002).

Throughout this research, I frequently engaged in reflection about my social position. My social identity, as a middle class young Black Caribbean woman and a student researcher, put me in an interesting position, as both an 'insider' and an 'outsider.' First, being a member of the Black community, I could be considered an 'insider,' that is, a person who is from the same community, as the participants of the study and shares in some commonalities in terms of culture, language or experience (Dwyer \& Buckle, 2009).

Being an insider in research can be advantageous, as it helps participants to open up in the interview and share information that they may not have otherwise shared (Dwyer \& Buckle, 2009). Throughout the interview process, I found that being a Black woman helped me to develop a rapport and sense of trust with the participants, which is a key to success in research (Dwyer \& Buckle, 2009; King \& Horrocks, 2010).

At the same time, being a woman researcher and from a middle class background, I could also be considered an outsider. As a woman, I was concerned that some of the young men might feel uncomfortable talking to me or that I could not understand their lived experiences as young men. However, in my experience with the two focus groups, I found that the participants were 
very open and explicit in sharing their views. My experience of being able to engage young men meaningfully in research was shared by other women researchers, interviewing Muslim young men (Archer, 2002). Also, my ability to understand the daily challenges of young Black men's lived experiences was likely limited by class. Some of the participants may have come from communities where they experienced poverty, i.e., food scarcity, low employment rates and income. While I could certainly be open to listening to the stories of the young men who lived in these conditions, my life as nurse from the middle class has been one of privilege; I enjoy the economic and social benefits of a middle class income. Therefore, while I aimed, as both a researcher and a Black woman to represent the narratives and experiences of the study participants with authenticity, because of social position, I could not fully appreciate the difficulties that some young Black men faced in their lives, beyond my ability to sympathize and retell their stories with respect.

\section{Ethical Consideration}

To maintain ethical practice in this study, I completed the Tri-Council Policy Statement: Ethical Conduct for Research Involving Humans Course on Research Ethics (TCPS 2: CORE), as required by Ryerson University's Research Ethics Board (REB). Also, as a weSpeak Graduate Fellow, I adhered to the research ethics protocols of weSpeak, as approved by Ryerson University's Research Ethics. I have also signed an agreement with the weSpeak team, which outlines the agreement that I would only use data I collected, for the purpose of fulfilling my graduate thesis. The consent forms that I used for data collection were modified (as recommended by Ryerson's Research Ethics Board) to reflect the fact that I would be using the data collected for my thesis, as a partial fulfillment of the Master of Nursing degree. 
To ensure safety and access to participate, all of the focus groups and individual interviews were purposely carried out in locations that were convenient for the participants, that is, in a meeting room at a local community centre or a meeting room at a local university. I went through the consent form and answered any questions that participants had. I also emphasized to participants, the voluntary nature of the study and that they could leave the focus group at any time, without questions. With the permission of the participants, all interviews were digitally audio-recorded. Before starting the interview and turning on the audio-recorder, I explained to the participants that the recorder was being used for the purpose of being able to accurately transcribe the interviews. All focus group participants also signed a confidentiality agreement during the consent process, to indicate their commitment to respect each other's anonymity and privacy. At the same time, I emphasized that since focus groups would involve sharing their perspectives and experiences in a group setting, absolute confidentiality could not be guaranteed and encouraged participants to decide on what and how much information they would feel comfortable to share. I also explained to all participants that their names or any identifiable information would be removed from the research data. All participants received a $\$ 30$ honorarium and a light meal, regardless of whether they chose to leave the focus group early.

During data management, I removed all the identifying information from all the focus group and individual interview transcripts. All documents were password-protected and audiorecordings were stored on encrypted computers. Throughout the data analysis phase of this study, I maintained my ethical obligation as a researcher, to apply the critical theoretical frameworks (described explicitly above) to analyze and interpret the participants' stories. The application of critical social theories enabled me to provide plausible explanation and 
interpretation of the young men's narratives - some of which reflected misogyny and/or reinforced dominant discourses of oppression - in the context of structural forces, without further stereotyping the collective identities of the participants. My goal was to accurately examine each story and make meaning of these stories, in constructive and equitable ways. Caine et al. (2013) suggests that narratives should not be "tamed" or "sanitized" or made to fit a certain ideology but that researchers have an obligation to represent and retell participants' stories in ways that seek to emancipate people, by challenging status quo power relations in society (p. 581). Certainly, in my study with young Black men, they shared stories about their experiences that were emancipatory; they also shared stories that could be misinterpreted as supporting existing deleterious notions about Black men's masculinity and sexuality. In using critical social theories such as CRT and intersectionality, I analyzed their stories in the contexts of racism, classism and sexism, and retold these stories in meaningful ways that question the power relations that exist in society, based on these social categories. 


\section{CHAPTER 4: RESULTS}

“We have awakened. We will not sleep anymore"

- Kwame Nkrumah

\section{Introduction}

In this study, I sought to answer a complex question - how do the 'gendered' and 'racialized' experiences of 'heterosexual' young Black men affect their 'vulnerability' to HIV and what promotes their 'resilience'? Teasing out the complexities and presenting the perspectives and experiences of the young men in this study, had proven to be both challenging and rewarding. It has been challenging because social identities are dynamic (forever changing), simultaneously imposed (by society and self) and embodied (in thoughts, emotions, and practices $^{6}$ ). Further, social identities are situational, that is, we demonstrate our identities differently, in different contexts or situations.

To present the perceptions, perspectives and experiences of the participants in a way that honours their sharing and at the same time, answers the complex research question, I have chosen a puzzle building method, that is, I present the different themes and narratives in a way that highlights different but important aspects of their identities and experiences. As illustrated by the young men's narratives, the gendered, racialized, sexual and classed aspects of their social identities cannot really be separated in a 'neat' or 'tidy' way because they are integral and embodied. However, the puzzle building method, at the risk of being artificial, provides one way

\footnotetext{
${ }^{6}$ In this chapter, 'practices' refer to what participants do in all aspects of their lives (e.g., how they interact with peers, how they present themselves to others, what do they do to demonstrate their masclinities, etc.)
} 
of looking at how participants' vulnerabilities to HIV are enmeshed in their social vulnerabilities, produced by structural conditions that shape their social identities, experiences and practices.

Guided by the intersectionality and CRT approaches, I present key themes derived from both the focus groups and individual interviews, with heterosexual young Black men. These themes illustrate how participants viewed their identities as heterosexual young Black men, in the contexts of 'gender', 'race' and 'socioeconomic' status. I will also present the participants' perspectives about the ways that they are vulnerable in society and to HIV, the strategies they employ to become resilient and their suggestions for improving HIV prevention, for heterosexual young Black men.

\section{Study Participants}

I conducted 2 focus groups (FG) and 5 individual interviews (IDI). The first focus group consisted of thirteen heterosexual young Black men; twelve of the participants were between the ages of 16 to 18 years old and one participant was 23 years old. Eight of the participants selfidentified as Caribbean, one as African, three as Black Canadian and one as African Canadian. This first focus group took place in a community setting in a low-income neighbourhood in Toronto East, where residents experience frequent community violence, stigma, and inequitable access to resources. In the second focus group, there were five participants whose ages ranged from 19-25 years old; two participants self-identified as African, two as Caribbean and one as African-Canadian. Participants were either in university or had completed their coursework, awaiting graduation. This focus group took place in a meeting room on the campus of a local university in Toronto Northwest. Since the participants do not necessarily live in this area, it is worth noting that the location represents their engagement in higher education and potential 
upward social mobility. The five young men, who took part in individual interviews, ranged between the ages of 16 and 25 years of age. In summary, participants in this study all selfidentified as heterosexual, and they represented a group of young Black men of diverse educational levels and socioeconomic statuses. Throughout this chapter, I inserted the geographic location of the focus groups, to provide the socioeconomic contexts of these young men. Young men in the Toronto East FG were from a socioeconomically disadvantaged neighbourhood, and young men in the Toronto Northwest FG were in university and living in different neighbourhoods.

\section{Perspectives on Black Masculinity}

The identities and social positions of heterosexual young Black men are often defined through the socially constructed categories of race, gender, sexual orientation, socioeconomic status, etc. Heterosexual young Black men hold a variety of social identities that are situational, depending on the temporal and spatial contexts they are in.

\section{Being Black Men: Masculine Expectations of Black Men}

Many participants in this study perceived Black masculinities in terms of their gendered role as providers for their families and others. For example, Eaze and Isaac from the Toronto East focus group commented that Black men have to "grind" (i.e., work hard) to take care of their families. In particular, Isaac defined Black masculinity as a man working hard and doing what is necessary to ensure that the financial needs of his family are met. Eaze agreed with what Isaac shared about Black men having to work hard and expanded on this point:

Eaze: ...to be a Black male, to consider yourself Black, you have to work hard and provide for your family and take care of other people around you.

Isaac: Regardless of the situation.

Eaze: Regardless of how hard you have to work to get it. 
Isaac: Yeah.

Eaze: Regardless of what you have to do to get it.

Isaac further emphasized that Black men should be financially independent and not take handouts (i.e., money) from others.

[Black men] support others, the ones they care about, their family, without having to be dependent, like not dependent, like they don't look, how do I say this? Like, they're not depending on someone to give them something. They're the person being depended on.

Another participant by the name of Quincy, who also participated in the Toronto East focus group, said that even when a young Black man is confronted with a situation that he did not foresee or plan for, that he should be prepared. Quincy echoed the views of other participants, by saying that heterosexual Black men need to be "financially prepared for anything that happens." He further qualified his statement by saying that a young Black man needs to be able to provide financially for his child, in the case that his girlfriend or sexual partner becomes pregnant.

Other participants in the Toronto East focus group spoke about what it meant to be heterosexual young Black men living with socioeconomic limitations. They pointed out that they did not have the privilege of asking their parents for money because they were aware of the challenges that their parents face, in meeting the financial needs of the family. They suggested that some young Black men living in financial hardship might feel compelled to engage in illegal activities, to contribute financially towards their families' household expenses.

Some people in your situation can't just go to their mom and say - can I get \$5 for lunch anytime they go for lunch. People out there that would like, outside selling drugs until 2 o'clock in the morning just to provide for their sisters or whatever. It's just different. (Isaac, aged 17, Toronto East FG). 
The notion that a Black man should be a provider and financially responsible was also discussed, in terms of the limitations and barriers that Black men face, including access to gainful employment.

I think to be a Black man, you have to understand that certain opportunities aren't going to be given to you, like others will be. And you have to be, understand that you're going to have to work harder and do certain things to the status quo, just to get as successful as others. Almost like how a female has to work harder, to get the same pay as a man. (Eaze, aged 16, Toronto East FG).

In further discussion, Eaze expanded on his statement to say that young Black men's

opportunities for employment and ability to achieve economic success were constrained because of the way that society stereotypes young Black men.

Because once you are a Black male, you're already perceived in negative ways. And like, this is from personal experiences... like cops and stuff, they'll just see you and they automatically assume you are doing something wrong when you're living in a certain area and you're a Black man. So, you have to understand, to be a Black man you have to understand that you're going to have to face certain problems and you're going to have to work harder just to get where a White male will be or an Asian male. Like you just have to understand that. You're going to have to work harder. And you have to take a lot of, a lot of stuff from people cause the way you're perceived in the eyes of the world. (Eaze, aged 16, Toronto East FG)

Participants also discussed Black masculinity, in terms of taking responsibility for one's personal actions. When I spoke to Eaze in an individual interview, he indicated that masculinity is about accepting the consequences of one's actions, even when the consequences are negative. He said thoughtfully, "Like, if you make a mistake, don't try and deny it. Take ownership of the mistake you made and try to correct it or be a man about it."

Similarly Quincy shared that he thought Black masculinity was about being a responsible individual. Quincy used the example of following through on commitments and keeping one's word to others, as important characteristics of being responsible. He also said that accomplishing 
one's goals, which may be as simple as providing for one's family, is an important aspect of Black masculinity.

Some young Black men also spoke about Black men's roles as a decision makers and an authority, in their homes. In the Toronto East focus group, a few young men used terms such as alpha male, top dog, and head honcho, to refer to their fathers because they felt that their fathers had the final say with regards to the decisions made within their homes, and their fathers commanded the respect of the household when they spoke.

Isaac: Like, often in a family structure, like the male, the dad's going to obviously be the top alpha dog... your dad's like the stable guy in the house and you're going to look at him to see if like, like if everything's straight [okay].

Eaze: Like you know if your dad's breaking down then there's a problem.

Isaac: There's something super wrong. Yeah, if your dad breaks down something's wrong.

Other participants suggested that fathers played an important role in supporting them in making decisions and keeping them on the right path. At the same time, they recognized that not all Black children and youth grew up in a two-parent household.

A lot of us live in families where it's not a typical nuclear family. You have a lot of us Black males who just live with their mothers or grandmas, aunts. A couple will live with their fathers and mothers. There is a lot of families that are broken up. (Todd, aged 22, Toronto Northwest FG)

Eaze from Toronto East also reflected on the family structures of other young Black

people, living in his neighbourhood.

Because like a lot of people in these areas, not to say, I feel like I'm just judging, but like I'm saying it from like people I know. You don't have the father figure a lot of times. So you're growing up with a mom, so you just have to kind of make that decision for yourself and try and learn those [male] attributes by yourself. (Eaze, aged 16, Toronto East FG) 
In discussing male role modeling for young Black men, some participants spoke about Black men and their expressions of emotions. Some suggested that Black men rarely express emotion, i.e., they were seldom seen smiling, crying or stressed. Josh shared that he had never seen his father cry, except for when his parents were getting a divorce.

That's the first time I seen him like, be vulnerable and it was shocking. It was really shocking. It's like, “Wow, you can do that?" Cause like, I never seen a man cry before. (Josh, aged 20, Toronto East IDI)

Josh described this experience as being an enlightening moment for him, to make sense of the vulnerability of his father and other Black men. He suggested, many men did not want to share their feelings because expressing emotions was considered uncharacteristic of Black masculinity. Other participants shared similar perspectives:

Eaze: You normally don't see a man in a household show a lot of emotion. You know what I'm saying? I don't know, from my personal, my dad...

Isaac: Won't smile.

Eaze: He don't smile, like you know, he's just straight. Like you'll rarely see him, like, you don't see them cry.

Overall, participants in both the focus groups and individual interviews shared both similar and different views about Black masculinity, in terms of provision for their family, financial independence, and fulfilling responsibilities, in the context of the marginalized and disadvantaged social positions held by Black men.

\section{Being 'Straight': Heteronormative Expectations of Young Black Men}

During discussions about the heterosexual masculinity of Black men, participants suggested that society has constructed and propagated stereotypes of heterosexual Black men, as uncommitted, irresponsible and hypersexual. Paul, a university student from the Toronto Northwest focus group, expressed his frustration over the media images of heterosexual young 
Black men, as gang members or womanizers (i.e., men that have relationships and sex with

multiple women). He shared his contempt towards the consequences of these stereotypes.

I feel like if you're a Black man and you're straight, there are two expectations, like, you have to be a thug, or like you have to be living that gangster life and you have to be a player, right. So if you're not talking to like twenty different girls at one time then, like you're waste [useless]. (Paul, aged 19, Toronto Northwest FG)

Paul disagreed with these views about Black men's heterosexuality and said that he had

personally tried to dispel these beliefs, with other young Black men in his family, but he was met with little success.

If you're not in the streets, you know, in the hood doing whatever you need to do, like you're not hustling, you're a waste of life. Even my younger cousins, I talk to them but they're like, "I'm talking to twenty different girls, blah, blah, blah." I'm like, "Yo, you don't need to do that. It doesn't matter what other kids say about you. Like you don't need to be doing that." They're like, "Nah, nah, nah, like I have to blah, blah, blah, blah." I'm like, "Yo, that's not what you need to be doing, right, like you need to be in school. No, you don't have to be on the block like." It's just like, like those are the expectations that I see all the time, like on the media, in life. Like you have to be in the club popping bottles for all these women, you know, have to be in the strip club spending thousands, like you know, that's what people expect of Black men these days and I just, I don't agree with that. (Paul, aged 19, Toronto Northwest FG)

Jack, in the same focus group expanded on Paul's point about stereotypical Black

masculinity and sexuality. He felt that society was responsible for "oversexualizing" the ways

Black men are portrayed in the media and that within the Black community, these stereotypes

were reinforced through peer pressure. Further, he thought that some Black men bought into

living up to the images of being hyper-heterosexual and hyper-masculine, because of

homophobia and the fear of appearing to be gay.

Jack: You know, these expectations are forced on us, in terms of hypersexualizing our identity. It's even, when we grow up, even within our families, within like cultures, specifically Caribbean cultures, like we tend to fit those stereotypes in terms of getting as many women as possible. Right. You know flashing out, you know, and flashing out all, like you know flossing... 
Todd: Mmmhmm

Jack: You know, looking good for the women like...

Todd: Gold chains

Jack: Gold chains, all of that stuff. And the fear of like being, like you know, it's all about the fear of homosexuality. Like all together, that has a big role too, especially in our communities... basically demonstrate extremity of our sexual nature... society uses that against a Black man, or the Black male identity and they assume oh, the Black male is usually the one that tends to go after the women, they tend to be dogs, they tend to be rapists and that type of mentally, that society basically perpetrates through these stereotypes... like especially with the Black women right, it basically tells the Black women that okay, Black men are dogs and a lot of Black men are not honorable in their actions... cause women see that in the media, women see that in their communities, probably cause many men are fitting these stereotypes and they don't realize it. And also this cultural expectation that they may grow up seeing in their household. Like especially in the Jamaican household, you know I could say, I can speak for that. Like, we're kind of pressured to talk to as many women as possible to be honest because of the fear of homosexuality. That comes into play a well.

Other participants agreed that there are dominant discourses in Canadian society and within Black communities, to characterize Black masculinity and hetero-sexuality as: men having many sexual partners, never refusing sex, being exceptional in their sexual performance and possessing certain physical attributes, such as having "big penises." Josh emphasized that these myths are unfounded and few heterosexual young Black men fit with these stereotypes.

Josh: Stereotypes that a Black man has a big penis. Big, you know. There's that stereotype as well, if you're a man... and you don't have that, are you less Black? Do you know what I mean? Are you less of a man? So like they say Black men can jump. If you're Black and you can't jump, are you less of a Black man?

KimB: What do you think?

Josh: Ah, I don't think it matters cause it's just like some Asians aren't good at math. Are they not Asian anymore? Who's to say? It's crazy... if you're Asian and you have this stereotype that you're supposed to be - good at math. You're supposed to be smart, all this stuff, you got to be a doctor, all these things and then if you don't live up to the expectation, are you a failure? Maybe. But if you're a Black man, for example if you're not super athletic, super strong, have a big this, um, have a strong body, like can perform well in bed and all that stuff, it's a lot to live up to and like some people can and some people can't. 
Marcus, a business student shared similar dismay and resentment about the portrayal of heterosexual young Black men's sexuality in society.

I feel like the expectation that's placed on males in society is that we have to be the dominant race because we're the most favored and we get the most girls. We're the most popular. And the whole stigma around Black males and the over sexualization of Black males, especially in society through the media is disgusting. Ah, it's very repulsive. I feel like Black males are discriminated against a lot compared to other races because of institutional racism. I feel like Black males are being degraded every day and we see it as a whole but we don't do enough [to challenge it], which I feel like we should. (Marcus, aged 23, Toronto Northwest FG)

Kadeem from Toronto East shared a different perspective. He postulated that Black masculinity and sexuality could be connected to the history of Black people and that the stereotypes imposed on heterosexual young Black men, by society, are rooted in the legacies of slavery. Kadeem explained that many families were separated during slavery and that Black men were used like "animals" to "breed" (i.e., impregnate) different women simultaneously to increase the number of slaves available for labour; and that some Black men today continue to internalize these stereotypes and engage sexually with multiple women. He suggested that the way that Black men's sexuality has been negatively typecast today in society, is very much connected to slavery and these depictions have been damaging to Black families and communities.

Kadeem: I can tell you what society makes me feel like. It makes you feel like you got to be like the sex symbol. Like, when you are out there, like everybody seems to be looking up to you to, I don't know, to just always have girls all the time. Girls will be after you; you are supposed to dog [cheat] them all. Just, I don't know, being committed, I feel like that's not something that, as a straight Black man, you are not supposed to do. Society and us internally, we have this mind-set where being committed to one person is not part of our repertoire.

KB: Okay. Is that reality, all those things that you mentioned? Is that the reality of straight Black men or is that imposed?

Kadeem: I think largely it's imposed, but I feel like that is something that kind of came with us to society, as we found our place. Because I feel our history, you know like we 
have a whole history of slavery and just the way the family dynamics worked back then. I feel like it had an impact to a certain point but now, I feel like it is for us a lot of times a reality because we make it a reality for ourselves. I feel like we have the potential to not be like that, to not do those things, but I don't know what it is about us or about other people or about other things that are going on, but it's really hard to just not do what is expected of you.

In Kadeem's perspective, heterosexual young Black men are not obligated in any way to internalize negative stereotypes and act them out. However, he believed that many still do so because of societal pressures.

\section{Racist Stereotypes of Black Men: Internalization and Resistance}

In talking to heterosexual young Black men they also shared their thoughts about how they are stereotyped by society in other areas of their lives, like at school. Participants responded in a variety of ways; some young men shared stories about how they have embodied stereotypes about Black men and education while others expressed how they used education to resist these stereotypes.

Josh from Toronto East shared that he often found himself frustrated at school by his Black male peers, who failed to participate in class and lacked enthusiasm towards learning and education. Josh said that there was a belief among his peers that young Black men should not be educated and knowledgeable.

They're like proud of not knowing things. They feel like "Oh, like yo, I don't know about that. Like de, de, de."... it's like an American thing too. It's like, they like to act like Americans and that's a whole stereotype of American Black men... You're not supposed to know things, you're not supposed to have like an education and all this stuff and you're not supposed to know what's going on in society, what's going on in the world of politics... Like that's what comes with being a Black man. That's what people expect you to be, ignorant and not know things that go on. (Josh, aged 20, Toronto East IDI)

Josh felt that many heterosexual young Black men were quite capable of being successful in the education system, but that some chose not to because of peer pressure and so that they could fit 
in with their friends. Josh gave an example from his personal life, about a time when he diminished his own academic capabilities in the presence of his classmates because he did not want to be criticized, by other young Black men.

Like in elementary school I would be goofy, I would fool around, wouldn't take class seriously, even though in class, I raised my hand and answered almost every question correct. I'll still be a goofball on the side and that was part of my personality as well, just to maintain that, you know. Maybe cause, if he's always a smarty pants and de, de, de, de, and even like when I raised my hand, answered almost every question, no matter what the teacher asked me, like some of my friends [would say] like, "Oh, you're trying to show off ..." and they'll bring me down. So then, I started dumbing myself down to their level, so I could also have friends. (Josh, aged 20, Toronto East IDI)

On the other hand, some participants gave examples of how they resisted these stereotypes and used them to their advantage, rather than conforming to society's negative expectations. In the individual interview, Eaze expressed his disgruntlement with being stereotyped by teachers, as being a troublemaker before they had the opportunity to appreciate his academic abilities or get to know him, as an individual. Despite these unpleasant experiences he did not let the teachers' comments deter him from achieving academic success.

Eaze: I went to a classroom, and um, first day the teacher's like, "Oh, you're going to be a bad one." I was like confused, I was like, "Why you saying that to me?" You know, like I didn't even really sit down yet. The first thing she said, "You're going to be bad."

KimB: Wow.

Eaze: And like, she just, straight out the bat. And I sat down and I thought and I even told my mom... My mom was so upset but I told her just leave it. And by the end of the year, I had like an eighty in that class and then I changed her whole entire perspective on things and she was like, "Oh."

KimB: Yeah.

Eaze: Like in grade eight for example, another one. We got a new principal and my pants were low too. Like that was like my transitional year. Like I kind of changed a bit that year... She was like, "pull up your pants." And I was like, "Leave me alone." Ok, I got kind of defensive. So, I'm like, "Just let me wear my pants like this, that's how I like it." Then she starts "Oh, you're going to be in the office all of the time, I can already see that. You know, you're a bad kid." And she just judged me off of that. You know how many times this has happened? I can tell you how many times this has happened to me, 
someone told me that I'm bad, straight off the bat. And like I said, by the end of the year, she's one of the people who picked the awards. I got three awards.

KimB: Wow.

Eaze: And she chose me to apply for a scholarship at like um, a private school. Out of the kids, she chose me.

KimB: Right.

Eaze: And at first, she said I was going to be the worst. But I ended up being the president of that school and being one of the best students in that school.

For Eaze, encounters of negative comments and stereotypes from those in positions of authority

within the education system became a catalyst for him to resist.

You know, I hate when people try to tell me I can't do something because of the way I look or I can't do something cause of a certain situation. Like, if I want to, I can do anything I want, you know. And I love beating people's expectations. That makes me so happy. Like, when someone judges me at first and I show them up, I show them different and make them feel stupid. That's something I love to do. I mean, it happens all the time now. (Eaze, aged 16, Toronto East IDI)

Jack from Toronto Northwest spoke about his concern with literacy and education in the

Black community. In his opinion he felt that Black people did not engage in reading and

education as much as they should because media repeatedly portrayed Black people in stereotypical and limited roles, that is, in sports and music.

KimB: Do you think that amongst Black people, Black men, do you think that we have a bit of a literacy problem?

Jack: Hell yeah! I can agree with you on that, like. Literacy for both. Like school literacy and then there is financial literacy, which I am trying to like advocate and so forth. But of course, because a lot of us do not want to read, a lot of us do not want to develop because you do not see that in the community, they just want to play basketball you know, or throw a football, grab a mic, right? Or slang dope [sell drugs], simple! So that's what you see.

KimB: Why do you think we gravitate towards those...?

Jack: Because that's what the media tends to show about what Black masculinity means. And like I said before, images have a huge effect on people's psychological realities and so forth and that stays with them their whole life and so forth and then people try to basically try to imitate that image in one way or another, right which I try to - which I sometimes do with the people who I read about in the books, like I read. So, and it just comes subconsciously, so. 
Jack further explained that the commonly depicted views of heterosexual young Black men in media, as rappers or athletes, limits what young Black men think is possible for their futures. He suggested that young Black men internalize the stereotypes about who they can be and what they can do, and this puts heterosexual young Black men at a disadvantage, for pursuing education and careers, outside of the imposed stereotypes.

Jack: There's professions too like accountant, or doctor, or like you know, or like, what else? There's accountants, there's doctors, engineers, there's teachers, you know. Those jobs too, it's easier to become that than to become a rapper or athlete. I'm just being honest.

KimB: Yeah. Okay. And as you mentioned, some of the challenges that Black men face. Jack: Yeah so, like I said, it comes down to education, it comes down to learning, right. So a lot of the Black men are not properly educated at home before school, right? Because schools, the information you are exposed to the most, is the information you basically live off of. And people do not understand that concept. So a lot of Black people, they do not read in their homes, so as a result you have these schools who are basically educating, it's usually White women, who are educating these Black boys and Black females, and then they [Black students] basically learn according to the school's curriculum and then a lot of them are pushed out of school because they can't connect to what a lot of the schools are teaching them. When you cannot connect, when you cannot relate... that kind of limits someone's ability to critically think and critically assess what they are... being taught.

In our conversation, Jack shared his observations about the ways that education and media are used to shape the lives of heterosexual young Black men. Likewise, he also told me his own personal story of resisting the norms in education. Throughout our conversation, Jack expressed many times his love of reading. He said that it was both his enjoyment of books and his attending university that allowed him to see a variety of educational and career possibilities, for him, as a young Black man.

But it wasn't until I came here. When I came to University, and when I started to see like Black people do great things, like Black entrepreneurs and so forth. So I really started to push myself to stay focused, I started reading books. I started taking school really seriously and so forth, you know. I took school seriously when I was growing up but I really took school seriously because I feel like it is a tool that can liberate me in some 
way or another. I feel like there's many factors towards what helped me thrive under the system because you know. Because it was a bumpy ride, I can tell you that much. (Jack, aged 20, Toronto Northwest IDI)

Notwithstanding the ways that heterosexual young Black men are typecast and negatively judged in social spaces, like in the education system, many participants demonstrated that they could and did resist internalizing these stereotypes. In fact, some of them used education as resistance to conforming to the norms set for them in society, and used this to thrive in the midst of circumstances and systems, that tried to limit them.

\section{Perspectives on Social and HIV Vulnerabilities}

\section{Being Vulnerable}

In both the Toronto East and Northwest focus groups, I provided a short definition of vulnerability - being at increased risk of harm or having a decreased capacity or ability to protect oneself - to stimulate discussion. Then I invited them to brainstorm what 'being vulnerable' meant for young Black men. Most of the participants did not provide their own definitions of vulnerability. Instead they spoke about their perceptions and experiences. Some young men from the Toronto Northwest suggested that their personal sense of vulnerability could be both positive and negative. For example, Arden from Toronto Northwest spoke about vulnerability in terms of being, "open", "telling your truth" and being "true to who you are." Other participants, like Marcus added that being vulnerable is to be "transparent". Some went further to say that being vulnerable was necessary for growth or that vulnerability could give rise to new opportunities. Todd gave the following example:

Vulnerability does involve taking risks and a lot of times in business transactions or even when people don't know enough about a certain case or matter and they need information or education, there needs to be someone to take that leadership role to... do what it takes to get the information and then all of a sudden that person has the know how or that 
person has experience because they took the risk. (Todd, aged 22, Toronto Northwest IDI)

Participants acknowledged that feeling vulnerable could also have negative outcomes, such as being dishonest with oneself and others, avoidance that could result in not getting help or support, and having unresolved problems. For some participants, it was the first time they had a chance to contemplate and reflect on the topic of 'being vulnerable' even though they had experienced many moments of vulnerability.

\section{Social Vulnerabilities}

Although I set out to talk to the participants about HIV vulnerabilities, all of them wanted to talk about their experiences of social vulnerabilities, which could not be separated from their social identities and sexual practices. In this section, I present the young men's narratives of social vulnerabilities, which shed light on their HIV vulnerabilities, presented in the subsequent sections.

\section{Social vulnerabilities: Race and class matters.}

Eaze from Toronto East said that young Black men are negatively judged in society as being "troublesome" which makes them vulnerable to unfair treatment by law enforcement.

I was walking on the street with my girlfriend one time. It was, I was just walking regularly, hand over her shoulder, cop pulls me over, he's like, "Oh are you harassing this woman? How old are you?" ... he asked for my ID and I told him that I don't have any ID. He asked for me name, my address, everything, pulled me up in the computer and there was nothing there and then he asked me my age and I was like "Oh I'm only fourteen," I was fourteen at the time. And he's like "Oh ok fine" and he drove away. But he pulled me over. Made me come to the car, everything. Looked me up on the system, everything. (Eaze, aged 16, Toronto East IDI)

Josh from Toronto East shared a similar perspective about young Black men's vulnerability to police. 
...Then police will stop you and want to question you, "Hey why you did this, why you did that?" And it's just like, I find people of different races do the same things and they don't get in trouble for it. Because like "Oh, they're just trying to be Black, he's not really about all that stuff. He just wants to be Black." And they don't get in trouble for it. Or it's just like "Oh, he's just in a phase." (Josh, aged 20, Toronto East IDI)

Todd shared a similar perspective about the power and privileges granted to members of society, from certain races and social positions that allowed for young Black men to be vulnerable and oppressed.

Black men? I can just talk about policing... A Black person can be driving the same kind of car as another member [of society] that isn't a visible minority and if a police stops, not even whether they get charged within an offense, but if the police stops a Black person, people, onlookers, will look and they will be like, "Oh yeah, that seems about right" or "That Black person probably did do something." There is a tendency for Black people to be presumed as troublemakers or law breakers or up to trouble. And if it's a White person, because of... how many White people are in positions of power here, they fly right under the radar. I think personally they get away with a lot of more than anybody else here... because daddy's a police officer or uncle is a police officer or daddy is a lawyer. It is a sense of untouchableness because of who has the power in the system here and as a result if there is ever an instance where they could get into trouble... they're more likely to get off because of the networks that they have. (Todd, aged 22, Toronto Northwest IDI)

Some participants from Toronto Northwest spoke about how mental health challenges

further increase young Black men's social vulnerability.

Depression is a real thing. It's a real thing that a lot of Black people, the Black community doesn't talk about it because a lot of situations where Black men get into certain problems with police officers or someone on the street, it could result from them going through something but we don't know. We only hear about the after effects of this; such and such person got into an altercation and the end result was that it cost someone a life. But we don't know what such and such person was going through ... And that's the sad part about it. (Marcus, aged 23, Toronto Northwest FG)

In addition, some young men spoke about how economic disadvantage experienced by young

Black men and communities increased their social vulnerabilities.

So when you are able to record data on the present times and kind of connect it to the past, you start to get a bigger picture of questions that you might have, that you didn't 
have answered. Like, why is my mom everyday working, you know a 9 to 5 , why can't she just take a day off, why can't she just relax for a bit? Then you learn with time about minimum wage, and bills and all these things that are a reflection of where you live right now. Because back home, a lot of us immigrants who are coming from different places in the world, they do not have that system where we have to grind [work] so hard just to cover a couple of expenses here, you know. A lot of us have homes in foreign places where we do not have to do that, you know, life is a lot more relaxed. It's just a matter of where we are here and who has power here. So, I think trying to understand these things just makes you a more enlightened, you know, a more aware person. (Todd, aged 22, Toronto Northwest IDI)

Other participants from Toronto East said that young heterosexual Black men encountered difficulties with finding employment because of the way that they are negatively perceived in society, which made it challenging for them to get ahead financially

Eaze: ...Like I said like, it's a lot easier for certain other males to get certain jobs. You know I would change that just to make life easier. ... Like if we [young Black men] didn't have to work so hard.

Desmond: If what?

Eaze: If Black males didn't have to work so hard to become successful.

Desmond: You would change that?

Eaze: Yeah, if they [young Black men] were given the same opportunities, like that would be bless [great]...

In discussing their social vulnerabilities, produced by anti-Black racism and marginalization in Canadian society, some participants also brought out an interesting observation. Their narratives suggest that young Black men's HIV vulnerabilities are embedded in their social vulnerabilities.

In the Toronto East focus group, participants talked about how heteronormative masculine expectations varied across different social and spatial locations. Eaze shared his observation that there seemed to be less social expectation and peer pressure on teenage heterosexual young men, living in predominately White and higher income communities, to engage in sex.

I have a cousin and he hangs with a lot of White people. Like he lives in (name of community) and he's still a virgin and he's seventeen. And he doesn't really find it that 
weird and a lot of his friends are virgins... I mean that's not the expectation in other places. But like, with a lot of Black men, that's an expectation. (Eaze, aged 16, Toronto East FG)

Eaze made explicit the different expectations of Black masculinities and sexualities based on social locations, defined by socioeconomic status and class. He went on to share that within his neighbourhood, if a sixteen-year-old heterosexual young Black man remained a virgin or did not engage in sex, his sexuality would be in question.

I mean if you were, in my experience, a sixteen-year-old boy and still a virgin in my friend group? It's kind of like, well, "Yo fam, you gotta do something some time, come on, hurry up." It's kind of frowned upon, I'm not even going to lie. It's kind of like, "Yo, you don't get girls?"... Maybe you're not even ready. Then it's like "whoa, what's wrong with you fam?" Like, if you were to say like, "oh, fam, I'm not ready to have sex with a girl," people will be like "Yo fam, you're gay." Ya, I'm going to be honest with you. I've seen, I wouldn't even say it to one of my friends because one of them only just did it with a girl. And I was like, "Oh fam, what took you so long?" Like, he's like, "I don’t really know.” But I guess, maybe he wasn't ready. (Eaze, aged 16, Toronto East FG)

Eaze's observation suggested that Black young men's HIV vulnerabilities, presented in the next subsection, needs to be understood in the context of social vulnerabilities and marginalization.

\section{HIV vulnerabilities: "It ain't going to happen to me."}

Participants in both the focus groups and individual interviews were asked to share their thoughts about heterosexual young Black men's vulnerabilities to HIV. Many of the perspectives shared were similar but there was variation on the topics of condom use and HIV education. Participants from the Toronto East focus group said that Black community members and heterosexual young Black men seldom discussed HIV, which continues to be considered as a "gay" man's disease. 
Others from Toronto Northwest commented on the need for discussion about sexual health, amongst Black community members and suggested, a reason why these conversations often do not take place.

Marcus: It's a real problem. We don't talk about it but having a STI is a problem. But again, in the Black community we don't talk about it. We don't talk about it as much as we should because there could potentially be cures, we can push for cures for this but we don't talk about it. You rather be like, bun dat [forget that].

Jack: That can't happen to me.

Marcus : Bun dat [forget that]. Bun dat [forget that]. It ain’t going to happen to me.

Participants from Toronto East were aware that they could contract HIV through

heterosexual sex and that they were more vulnerable to HIV, if they engaged in condomless sex.

Nevertheless, they stated reasons other than preventing the contraction of HIV, as their primary reason for using a condom.

Dully: If you wear a condom, less chance of the next girl catching HIV.

KB: Or getting pregnant.

Dully: Or getting her pregnant.

KB: Or getting her pregnant?

Eaze: Yeah

KB: That's the ultimate.

KimB: That's the ultimate?

Isaac: That's the ultimate fear.

Another participant from Toronto East, Quincy provided insight about heterosexual

young Black men's concerns about pregnancy.

Let's say. Let's say I get a girl pregnant and I'm not financially prepared how am I going to take care of the child, you know? That's why in that case I should be financially prepared to have money. (Quincy, aged 17, Toronto East FG)

Likewise, participants in the Toronto Northwest focus group said that they used condoms to prevent pregnancy and STIs, but that they sometimes preferred not to use a condom at all.

I can say that I've used condoms and I've not used condoms and obviously there's a preference for not using condoms because it's raw [sex without a condom] ... as 
uncomfortable as condoms are they protect you from ... having a STI and potentially getting a girl pregnant. (Marcus, aged 23, Toronto Northwest FG)

Pressures from society, media and the Black community, to embrace and impose stereotypes about Black masculinity, were also identified as making heterosexual young Black men vulnerable to HIV. One participant said that he felt that heterosexual young Black men had to show themselves as "sex symbols" to be considered heterosexual men. Other participants spoke about the pressures that young Black men face to demonstrate heterosexuality and masculinity, through their sexuality.

Black males in specific are expected to fit a social norm or to fit certain expectations to basically act in a hypersexual way or to be able to like demonstrate or prove to our bredrin [friends; peers] or prove to like people you know, we're really masculine. Right, and I feel like that's a cultural dynamic that exists in many different Black communities. (Jack, aged 20, Toronto Northwest IDI)

Other participants also said that heterosexual young Black men feel pressured by their

peers, to accept sex from females and that they are often chastised for refusing sex.

Getting this girl and then you finally get that chance like, do you really want to turn it down? So there's that. It's a lot of temptation as well...like how can you say no to that? And then like your boys [friends] will tell you..."Like yo I had a chance to have sex with like, Jaydeen... "Yo, I said no." I'm like "Yo! You said no! Man if I was you I would have did this! I would have did that! I'm like yo, are you moving waste [you are useless], like what are you doing?"...You feel like you're less of a man. Like what are you doing? Like, you're a punk and they'll punk you on that. So, you're like "man you're right, you're right, you know, if I get a chance again I'm gone do it." So then another girl comes around... and they're like "Yo, I'm definitely hitting it this time" and then they do it. Because peer pressure. (Josh, aged 20, Toronto East IDI)

Furthermore, Josh commented that heterosexual young Black men feel compelled to engage with multiple partners to fulfill the stereotypes about Black masculinity and sexuality, and to meet the sexual expectations of their female partners.

Josh: So then it's (sex) just going to keep coming to me because if I do well then... it's like, experience. It's definitely like experience in being good at that thing that you're 
doing, if like, so many different girls, different types of girls, different shapes, different sizes, then you're gaining that experience so then you're going to perform well.

KimB: Right

Josh: Like, it sucks too for people that are Black males and are virgins and are...doing it for the first time, with someone who's done it multiple times before. They're expecting you to do certain things like, freaky stuff...

KimB: Yeah.

Josh: But like freaky stuff and then and you knowing how to use your penis.

KimB: Yeah.

Josh: Right, they expect that and if you don't then you're not living up to that standard.

KimB: As a Black guy? As a Black man?

Josh: As a Black guy, yeah.

Perspectives about negotiating condoms use and HIV testing varied amongst participants.

Some said that negotiating with their female partners about using a condom was challenging and unsuccessful, while others did not experience any issues with this.

Some participants stated they continued to have sex without a condom because it was more enjoyable, despite knowing that this made them vulnerable to HIV. Other participants suggested that they are challenged by their female sexual partners, not to use a condom.

KimB: Do women pressure you not to use protection?

Kadeem: Yes! Yes.

KimB: Can you talk about that a little bit?

Kadeem: Yes. Okay. It's like, what do they say...most of the time what you hear is like "Oh it feels different", or "It doesn't feel as good" Or "You do not need to use that with me, I'm good". Or, "Why are you using that? What are you trying to say? Like you are trying to say something about me, like you do not trust me?"

It was also suggested that negotiating condom use with a female partner was difficult, particularly when in a relationship because it can be interpreted as a sign of disrespect or imply mistrust.

KimB: Some of the other young guys that I have talked to have spoken about the fact that women sometimes get offended if you, you know...

Kadeem: They do. They do get offended like they take it as some type of diss [insult] or something. I don't know why but they do.

KimB: Okay. 
Kadeem: And sometimes like, as a guy in your head, you are like "no" but then at the same time, like, in the moment you are not necessarily thinking straight.

KimB: Okay, so would a guy initiate that, would a guy bring that up? You would be the one to say, "Oh let's use protection."

Kadeem: If a guy is not going to use protection like we just won't use it. Like we just won't. But I guess if - I know certain guys when they are in a certain level of relationship where it's expected, then like sometimes they (female partners) try to persuade you like, "No I don't need one tonight" whatever, and you just talk to him a certain way. But as far as I know, as far as like my experience and anybody else that I know, it's always been the females that are like "Naw, don't use it."

The pressure of not using a condom also existed for heterosexual young Black men, who had multiple sexual female partners; their HIV vulnerabilities were amplified because they were not using a condom with their girlfriends or other young women that they had sex with. Kadeem talked about the desire to be committed to one sexual partner and the reality about condom use with multiple partners.

KimB: So, in your circle of friends, are many of them in committed relationships or are many of them with multiple people, like multiple women? Is there that pressure to be with multiple women?

Kadeem: Yeah, yeah. And especially that because when we were younger like, obviously we used to just do our own thing. And now like I guess when you are trying to change and try to be committed, everyone (guy friends) still remembers what you used to do and trying to talk about it, "Yeah remember when you were like this, what happened to you?"... And then they're telling you their stories you feel like you are missing out. But, yeah, you are right. In my circle of friends, most of them are in committed relationships but they are not committed in those relationships.

KimB: So they have somebody who is their main person and then other people kind of like on the side?

Kadeem: Yeah.

KimB: Okay, alright. I've heard like in other interviews like some guys say you would use protection maybe with other girls that are not your main girl but with your main girl you would just do it "raw."

Kadeem: Hmm!

KimB: Is that the case?

Kadeem: That's the thing. Like, it depends. Normally, that's what happens like for guys, well I'm talking about my circle of friends. Black men, we feel like if we're with somebody, we do not need to use protection. But if it is somebody else, then we're going to use it. However, then, there is this other portion where sometimes you just don't. And 
there are times where like, yeah this is your main girl and this is your side, but then you stop using protection with your side [girl], right?

Participants from the Toronto East focus group faced similar challenges with trying to talk to their girlfriends and sexual partners, about using a condom because the young women felt like they were being accused of being dishonest. Eaze from Toronto East said that for this reason, he sometimes refrains from discussing condoms.

Eaze: ... When you're put in a sexual situation with a girl more times [often] you don't want to say how you're feeling, like you kind of just do what she wants cause you don't want to like lose the chance...

Isaac: Yeah you don't want to lose the chance with her. You don't want to say the wrong thing and mess everything up.

Eaze: So if she's like "Oh baby, like let's have sex raw" and you're like "Naw, I don't trust you", she's going to be like "what's wrong with you? You're dissing me. What, you think I have diseases or something?" ... If she cuts [leaves], you're going to be like... "Next time we do, it we're going to do it raw."

In the Toronto Northwest focus group, participants said that they did not consistently wear condoms during sexual intercourse because they enjoyed the sensation of sex without a condom. They also suggested that if they were in a serious relationship that they were less likely to use a condom.

Some mans [guys] just like going in raw [sex without a condom]. Like you know. A lot of mans, like especially if they're with someone for a long period of time or if they really love that person, they just like, they don't use the protection. (Jack, aged 20, Toronto Northwest IDI)

Marcus from the same Toronto Northwest focus group said that he almost consistently wore condoms during sexual intercourse, but that he also regularly got tested for HIV. Marcus provided the following rationale for getting HIV testing.

...I usually get tested on my own. Like every time I'm sexually active, usually about, every three and a half to four months I get tested. Even when I'm with the same person, I get tested because I love my life. I'm trying to live as much as possible... when I get into a relationship with someone, sex is not the initial aspect of it but it's going to happen, 
right. I can't say that I'm going to put all my eggs in one basket and be like "Oh I trust you and we're going to have sex." But I'm not watching you twenty-four seven, I'm not with you all the time right. But there's times where like, like in my past relationships I've gone, having unprotected sex and then like literally a month later I go and get tested cause like, I don't know who they're sleeping with. (Marcus, aged 23, Toronto Northwest FG)

Marcus acknowledged that talking about HIV testing was not always well received by his female partners, but that he had these conversations because he thought it was important.

...Whenever I get into a relationship with someone, I usually tell the person straight up, I got tested before... I tell them. And I'm one hundred percent honest... when we have sex, after we have sex, I'm getting tested. I tell them. A lot of women look at me like I'm crazy. I'm like, "I don't care, like I'm being tested! Like I don't know who you've been with in the past, you don't know who've I've been with so let's just avoid the mess. I'm going to my own testing and I would like you to get your test too." And so far, every single relationship I've gone into, I've done the test for them, they've done the test for me. (Marcus, aged 23, Toronto Northwest FG)

On the topic of HIV testing, participants from the Toronto East focus group had a different perspective and said that discussing this with their female sexual partners was difficult because, much like discussing condom use, it could be interpreted as disrespectful and accusatory, by their girlfriends.

Eaze: That's the thing, I think I would be too scared to ask a girl to get tested, to be honest.

KimB: Why would you be scared?

Eaze: I think she would take it as an insult. I don't insult a girl because I think people look at AIDS as a bad thing, like "Oh, I'm a hoe, like I had too much sex with too many people."

In other words, asking a female sexual partner to get tested for HIV was described by participants as blaming or questioning a woman's sexual history or practices; this often left participants feeling vulnerable. One participant said: "So I guess that's a risk right there. Being like, not having enough courage to ask someone to be tested before you do anything." (Eaze, aged 16, Toronto East GP). 
As indicated by the young men's narrative, negotiating condom use or discussing HIV testing was challenging for some young men, but not all.

\section{Reducing HIV Vulnerabilities: Personal Strategies}

Participants in the Toronto East focus group said that one of the main strategies they used to address their vulnerabilities to HIV was to use condoms, particularly with new sexual partners. One participant explained that he used his own condoms, when having sex with young women that he did not know well because he feared that his partner's condom could be ineffective (i.e., the condom was expired or defective).

Eaze: ... don't ever trust a ting [girl] with a condom.

Isaac: Actually naw, naw, naw, naw. No girls bringing a condom to me. It's my condom. Eaze: Cause you don't trust that.

KimB: So you don't trust a girl if she brings a condom?

Isaac: Unless that's my girl, unless it's my girl.

Being able to trust their sexual partners was also an important aspect of sex, for

participants; trust was said to develop over time and with experience.

If I see a really good looking girl and she's like, "You want to have sex?" Like, I can't just say, "Yeah I want to have sex." Like I don't even know you... I don't know your past, I don't know who you've been with. I don't know your brothers. Like I don't know you. (Isaac, aged 17, Toronto East FG)

In the Toronto Northwest focus group, participants said that using condoms protect heterosexual young Black men from getting and spreading HIV. This group also expressed greater confidence in negotiating condom use and discussing HIV testing, which were strategies they used to be resilient, in the context of Black men's HIV vulnerability.

Jack from an individual interview in Toronto Northwest spoke about choosing his sexual partners carefully because he felt that they had the potential to jeopardize his career and personal goals. Jack's strategies for social resilience included finishing his university degree and pursuing 
a career in business. Furthermore, he said that having been exposed to a university education, helped to broaden his outlook for his future, which changed the way that he approached his sexual relationships.

Jack: It [university] opened my eyes a lot actually. And then I met people and I did my own business and so forth. I had a marketing business, not really like a big business where I opened like a shop, but it's like an online type of business. A direct sales business.

KimB: Okay. Nice.

Jack: I did that for a little bit. So that kind of opened my eyes too, right? But it's not easy. And because of that now, that lifestyle that I have (focusing on school and being selective about relationships), it scares a lot of people. It scares a lot of girls that I deal with because they can't handle that. And for me like I am not going to lie to you. It's not easy for me because sometimes I had regrets and sometimes I have - I have regrets of like, "What am I doing? Is it right?" and so forth. "Is it going to pay off?" You know? Or like, I miss parties and so forth. It's not easy at all, you know. I have to pass, you know, I have to pass, I have to pass down on like sex and so forth you know, it's not easy.

\section{Reducing HIV Vulnerabilities: Access to Effective Sex Education}

Participants from Toronto East and Northwest said that heterosexual young Black men needed more information and education about HIV, to improve sex education and HIV prevention. In the Toronto East focus group, participants suggested that the sex education that currently exists in schools (e.g., elementary and high schools) needed to focus more on HIV and STIs prevention.

Give more sexual information. Not just like about AIDS but more just about being safe when it comes to sex in general. You know, talk about those things. Schools should be getting into it, well they get into it early but they only talk really about like puberty. They should be talking about AIDS from the time you're like in grade five so...you know what it is, you already know all the facts, you're good. You're not making mistakes when you're like in grade six (Eaze, aged 16, Toronto East FG).

Other participants suggested that the sexual education provided in public schools need to be more comprehensive and more forthright about HIV transmission. 
Arden:... I think the main thing is just there's been no education. There's been like studies done where if you teach a community about it, like the rate of infection, or the amount of people who have it like, it decreases drastically, like huge amounts...

Desmond: So lack of education, a need for education on STIs.

Arden: Yeah.

Desmond: So if you don't have that it could make you vulnerable to HIV?

Arden: Yeah, yeah.

Marcus: ...the education that I received on HIV and STIs and AIDS is so watered down to make it like friendly, like a, b, c, it's just, it happens, like you know, it happens.

All you have to do is like put a condom on and you're going to be good. And you know no, it's not like that. It's not easy.

Participants said that meeting with and hearing from people living with HIV in the Black

community, would be one strategy to increase heterosexual young Black men's knowledge about HIV, because learning from the experiences of others would help to bring the issue of HIV to life. As Eaze (aged 16, Toronto East, FG) shared, 'I don't think I've seen anyone with HIV. So how can I say anything if I have no experience?”

Other ideas presented to improve sex education in schools included delivering sex education to students at an earlier age (i.e., grade 5) and ensuring that the information shared provided students with statistics, on the rates of HIV infection in the Black community.

\section{Reducing HIV Vulnerabilities: Meaningful Engagement}

In the focus groups and individual interviews, participants recommended various engagement strategies to get heterosexual young Black men involved, in HIV prevention programs and accessing services. One participant said that programs and services needed to be delivered in community settings, alongside other activities (e.g., sports), with a focus on mentorship, as these activities would motivate young Black men to attend.

... But if it's a program where they play basketball or where they hang out with their kids, or like a program that motivates these kids to come play sports and they'll learn something while playing sports. There's certain programs in the United States, where in New York they have... this basketball program, it's for two and a half hours, an hour and 
a half into the program they literally stop playing basketball and they take these kids to the classroom and they sit them down and they literally talk to them... ask them how it's going, "How's school going? How's things with girls going? This is the way you should deal with this, how you should deal with this." These are grown men sitting down with these kids and letting them know in their experience, "In my opinion when I was your age, this is what I was doing." It's a back and forth communication, open communication. There's grown Black men sitting down talking to these kids and then after an hour, after discussion, they go back and playing their basketball... you don't use the power specter, you talk to them like you would talk to your friends. (Marcus, aged 23, Toronto Northwest FG)

Eaze from the Toronto East focus group also said that it is important for heterosexual

young Black men to be able to talk to and hear from someone that they can relate to.

I think it would be good, if there was a man, that would be... in the community to talk to like that. That's a good role model... someone who grew up kind of in the same situation as you. You can look to and see that he has [some] kind of resemblance. (Eaze, aged 16, Toronto East FG)

For participants, improving HIV programs and services was not only a matter of having mentors and role models in the community but also about engaging neighbourhood social and health related agencies. One participant suggested that it was necessary for agencies to be proactive about building relationships with heterosexual young Black men in their communities, instead of waiting for young Black men to take the initiative, to access their services.

The only time that ... we actually go after help is when help was already shown to us first. Like if you are shown, "Yo, you can get help here for whatever it is you're dealing with." Like, it might take months, a year, it might take weeks, hours, days, whatever, depending on the circumstance, but if you really need help and it's shown, you can come and get this help and there's no strings attached. You do not have to worry about it, no one has to know about stuff like that. Then, there's a chance that we might go down that avenue but most of the time, there's nothing else that will really get us to go seek help because we don't. We feel like we can handle things on our own. Like you can't really show anybody any type of weakness. (Kadeem aged 25, Toronto East IDI) 
In addition to the notion of relationship building, as a form of engagement, Kadeem

recommended that there be greater emphasis on having clear goals and objectives during these activities and events.

There has to be a balance because I know sometimes you go to an event and it just ends up being about the food and the games and like people talking, and the information that is supposed to be given to you is just put on the table and people can just pick it up at the end. There's some other times where it's all about the info and you are just like, "No I'm not taking anything, let me just cut [leave]." And then you don't learn anything. I mean there has to be a little bit of both; enough engagement that gets you interested but enough information that ensures you feel like there's something. (Kadeem, aged 25, Toronto East IDI)

Thus, according to the participants, effective HIV prevention education is about engaging heterosexual young Black men in meaningful but fun learning activities and providing mentorship and support.

\section{Against All Odds: Building Social Resilience}

Resilience was one of the key topics that was discussed in the focus groups and individual interviews. The working definition of resilience used to stimulate the discussion was: "The ability to overcome or bounce back from challenges or difficulties in life." Again, participants did not add to this definition but they shared their experiences of resilience, as heterosexual young Black men. Many participants spoke about being resilient to the social conditions in their lives; they talked about how they overcame challenges, such as personal loss, economic hardship and negative stereotypes about them. Some participants spoke about using their social support networks, goal setting and pursuing education, to help them stay resilient.

KimB: What would help Black men to be resilient? ...

Jack: What would help?

KimB: Yeah!

Jack: Oh my God yo! It's not easy! It's not easy because it has to come down to...there are so many factors to it. 
KimB: Yeah.

Jack: It comes down to like the closest 5 people you hang out with the most. Like for me too, I'm very selective of the friends I keep around. I'm very selective of who I let into my life and the energy that they bring in...

For Jack, having the support and encouragement of adult mentors and friends kept him resilient and helped him to decide to pursue a university education.

Jack: I didn't know I was going to come to university until the second semester of grade 12. So a teacher told me to apply to university and I did... I didn't think I was going to university, to be completely honest. I thought I was going to go to college and do justice studies or do like those youth programs, whatever or those little, programs. But it's just a great decision that I came here.

KimB: So you had a teacher who...?

Jack: Pushed me a lot, a teacher. She pushed me to go to university...

Others from the Toronto East focus group spoke about being able to observe and learn

from their family members, as a way to successfully deal with problems in their lives and to be resilient to HIV.

KimB: ... What do you think is needed to help Black men to be more resilient and to reduce their vulnerability to HIV?

Eaze: Ah, family life.

KimB: Family life.

Eaze: The way you grew up.... if you see people giving up all the time...

Isaac: You're a product of your environment.

Eaze: Yeah like you're going to give up too. But if you see people that are always, things hit them but they get back up and they keep trying, then you're going to be like that too.

Eaze from Toronto East spoke about the importance of having people in his life who were role models for him, offering him guidance and being someone that he could talk to, about difficult topics.

Eaze: Having a lot of role models, like male role models...

KimB: Male role models.

Eaze: ...Will help out, I think, a lot. Having someone to talk to about those things, like males. Like, I know I can bring anything to my dad. Like I can talk to him about anything, with a girl... He's had conversations with me about like AIDS and stuff. He'll tell me, you always use a condom, doesn't even matter. It's not even about having babies, 
be careful... So I guess like for people who don't have that person to talk to, they should have that, because honestly, it does help.

Similarly, participants said that role models helped them to know how to handle different situations in life and provided them with someone to look up to and pattern their lives after.

Like people, men in my life, that have had other people to show them. Cause like, you see the way they handle situations and it changes the way you handle it... growing up as a kid, you want to act like the older men, you want to act like a man. So you're going to see what they have, the way that they react to situations and you want to act the same way. And it kind of shapes who you are and how you act in situations. And it shapes you into a man. (Eaze, aged 16, Toronto East IDI)

Other participants said that the support of siblings, friends and other family members,

like uncles, helped them to be resilient and to develop a sense of identity, as a young Black man.

My father is a big influence on me. I try to mirror the qualities of him that I like. Uncles. Uncles, because they are just family friends but you grow up calling them uncles. My guy friends; the qualities that I like from them, they make sure that I do not get into much trouble and I keep a good head on my shoulder and whenever I'm contemplating a big decision, they are the guys who will tell me when I'm doing something wrong or when they don't agree. And you need people like that in your circle. You don't, just be a "yes men" will just say "yeah, yeah, do that." I wouldn't do that to my friends if I thought they were going to do something crazy. Yeah, so my guy friends, my father, my father's friends and whether this is a bad thing or a good thing, role models in the media. (Todd, aged 22, Toronto Northwest, IDI)

Other participants suggested that social support helps young Black men to get through

difficult and challenging circumstances, such as a loss. Josh explained a time when he faced

multiple losses.

Like when I was sixteen, like I was going through some really tough challenges. When I turned sixteen, actually, I was fifteen at the time and like basketball season was starting and I was really excited for the season...I made the cut and later on down the road my teacher, he got sick and our principal took over and was taking care of the game. I've been asking like what happened to (name of teacher)? Like what happened to him? Like where is he? And he's (the principal) like, "Oh he's just sick, he's in the hospital, he's not feeling well."... And that's when I found out like on the day of my birthday, that he passed away from, from cancer. And a month later...I got evicted from my apartment, had to live in a shelter, a homeless shelter then my father passed away. And then I had 
exams as well, I had a math exam, like just exams. All in the same week and I was able to persevere. Ah, I thank God, like I have a, I believe in God and never once did I curse God during all those experiences and I think that if I didn't have a strong faith that I wouldn't be able to get through that situation. (Josh, aged 20, Toronto East IDI)

During this time Josh said that it was the encouragement of his brother that helped him to look at how he could learn from his adversities and use them to better himself.

...When I was being evicted and I had to move everything, my brother told me, "Learn from this experience, don't let this stress you out." So there was that, I kept that in mind. Helped me get through it. (Josh, aged 20, Toronto East, IDI)

The words of advice spoken by his brother prompted Josh to pursue his passions for art and to start a t-shirt company, in honour of his father. Josh said that having a personal goal and working towards it, kept him from making decisions that he described as being destructive to his future.

It's very important because if I didn't have a goal that I wanted to achieve, if I didn't have something like art or basketball or whatever, a goal, ambition in general, if I didn't have that, then I'll be doing all of this foolishness. Like I'll be, maybe smoking weed [marijuana] on the corner all day or something. Chasing girls... chasing girls, how much money I can make in a day, how many girls can I get, which girl I can get. I'll be like, I'll be ambitious, in the things, of obtaining things, even material things, that cause me harm, to myself... Maybe looking for comfort in like a woman, alcohol, drugs...Y You know, I don't do that to feel calm, I just do something else. I do something more positive...just having goals, just kept me from like self-destructing really... (Josh, aged 20, Toronto East IDI)

Reflecting on his personal challenges and the strategies that he used to be resilient, Josh summarizes his thoughts about goal setting and how this has helped him:

Life comes with challenges and you need to be doing something. You need to have a goal. You need to have a purpose because that goal and that purpose makes you want to wake up early in the morning. Makes you want to go to school on time, makes you want to go to work on time, makes you want to, you know, just be better. Be better. (Josh, aged 20, Toronto East IDI) 
Alternatively, other participants suggested that while social supports were necessary for resilience, that they were often limited or non-existent for heterosexual young Black men, in the Black community.

What helps us to bounce back is a support system. I feel like that most of the time we do not have that. Whether it's people at home, we do not have it with or like, people to just chill with, you don't have it. We do not really have a support system. So if something happens and we get set back, most of the time we just sit back until we've managed to sort it out ourselves, if we manage to sort it out ourselves. And like I see that for a lot of my friends, I know, I've been there myself, and I see now with like, you know, even some other people that have just grown up just watching, you know, just doing certain things. Even my own dad, like, he went through certain things you know, like he was always trying to do things on his own and he was always trying to handle it on his own, when it would have helped if like, he had a support system, he could have relied on to help him get there. Alright. So yeah. I feel like it's difficult for us to have resilience within ourselves, just on our own. I don't know why but I just feel like, it's just like that. (Kadeem, aged 25, Toronto East IDI)

Kadeem suggested that heterosexual young Black men could be supported both informally and formally.

Like first and fore most, family, friends to an extent but also what is really important is like, resources or supports that are just in the community that are available. Those honestly, like, I know myself and I know other people they've been like to different programs and different things, and different social workers that come through or different community workers and you develop a certain relationship with them and you are able to show them, "You know I am trying... or you know this is happening that's good." If something bad happened, you can talk to them and be like you know what, "Here this is what you can do to help you with that" or even if they were just able to listen to us and just hear us out. You know, it just helps having that there. (Kadeem, aged 25, Toronto East IDI)

Another important factor that Kadeem felt contributed to his resilience was education and information about how to navigate through difficulties. He suggested that having the necessary information and educational resources could help young Black men to solve problems and successfully overcome obstacles. 
KimB: Are there other things that would help guys to come back, make a come back from the things that they face?"

Kadeem: Yeah, other things?

KimB: Other ways that Black men, or the Black community could be resilient or could demonstrate that or things that would help them to be resilient?

Kadeem: I think we have to unify. And just educate ourselves. And I feel like when you do not know any better, it's going to be hard for you to do any better. Like you have to know and you have to know that, even if you know, when something bad happens, like say you don't get into the program you are trying to get into, or you don't get the job or you get kicked out or you get fired from your work place... even when things like that happen, if you know, like there's ways to come back from that....This is not the end of the world, if this doesn't go through I can always come back and do something else.

Likewise some participants spoke about the importance of education in their personal journeys and growth and as a way of seeing new opportunities for themselves.

Other young men, like Paul from the Toronto Northwest focus group, also spoke about education, as a means for improving the social and economic situations of young Black men and something that would help them to explore other possibilities for their lives, outside of the stereotypical roles, imposed on young Black men.

I just stay in school. I just do what I feel I need to do to make my life better for me and my family. So if I don't see something as positive or beneficial to me, I simply won't do it. Like, I don't see selling drugs, hustling, anything, I don't see that to be beneficial to me or anyone. So I don't do it. I see going to school, getting an education and then trying to make a name for myself in a positive light, I see that as being beneficial for me and like my family, other Black men too, so like they can see there's not like only one or two ways to make it out the hood and to make it in the world. There's like several different ways you could do like, it could be positive instead of negative. (Paul, aged 19, Toronto Northwest FG)

As participants from the focus groups and individual interviews shared their thoughts and experiences, there were many ideas expressed about how heterosexual young Black men have been resilient to the various social conditions in their lives; having social supports, pursuing personals goals and education are a few factors that have contributed to them overcoming challenges. 


\section{Summary}

In this chapter I have presented the results from the focus groups and individual interviews that were conducted for this study. I have identified major themes of HIV and social vulnerabilities and resilience, for heterosexual young Black men. Themes about vulnerabilities included peer pressure from sexual partners, pressure to conform to sexual stereotypes, limited knowledge about STIs and unfair treatment from police and teachers. Major themes about resilience included, having social supports, education and personal goals, as strategies to help overcome adversity. Participants also recommended that male mentorship and education in the Black community are tools that will help to improve HIV prevention and sexual education programs. In Chapter 5, I present a critical discussion of the participants' narratives, based on my application of the intersectionality framework and critical race theory (CRT). 


\title{
CHAPTER 5: DISCUSSION
}

\author{
"You may write me down in history \\ With your bitter, twisted lies, \\ You may trod me in the very dirt \\ But still, like dust, I'll rise" \\ - Maya Angelou
}

\section{Introduction}

I began the journey of my thesis with the goal of gaining a better understanding about young Black men's heterosexual masculine identities and HIV vulnerabilities. After my engagement in discussion with the participants and immersion in their narratives, I have come to realize that young Black men's social identities and HIV vulnerabilities can only be understood in the context of their social vulnerabilities, produced and reinforced by structural anti-Black racism and everyday mircoaggressions, experienced by Black men, especially young Black men. In this chapter, I present my interpretation and understanding of the gendered and racialized experiences of heterosexual young Black men and how these experiences converge on many levels, to shape how young Black men understand themselves and how they interact with the world around them. I begin with a discussion of the social vulnerabilities of young Black men, followed by how these social vulnerabilities shaped their identity construction and HIV vulnerabilities.

It is important to note that what these young men have shared cannot be easily delineated into neat and tidy themes and discussion points. Rather the essence of their narratives overlaps and intersects in ways that demonstrate the complex realities of the human experience. As such, a discussion about the HIV vulnerabilities of heterosexual young Black men, cannot simply 
entail descriptions of their 'risky' behaviours, but requires an understanding of how heterosexual Black masculinities are constructed, through social relations and structural conditions. My interpretation is guided by the theoretical frameworks of intersectionality and CRT presented in Chapter 3. Again, intersectionality is useful for examining how the interlocking systems of oppression based on the socially constructed categories of race, gender and class shaped the experiences of young Black men. Likewise, CRT is useful for analyzing how anti-Black racism affects myriad aspects of Black men's lives.

\section{Social Vulnerabilities of Young Black Men}

As identified by many participants in this study, one of the key systematic barriers experienced by Black men in Canada is economic marginalization. Many participants believed that it is much more difficult for Black men to obtain gainful employment and to access the same level of economic prosperity, that White men enjoy. They suggested that anti-Black racism and the negative stereotypes about Black men have continued to fuel prejudice and misconceptions, that prevent Black men from securing higher paying jobs. They expected to have to work harder than their non-Black counterparts to obtain an income sufficient to support themselves and their families.

Anti-Black racism is the systematic discrimination of Black people based on stereotypes and has been perpetuated throughout many generations (Feagin, 2001). The participants' subjective perceptions of the economic marginalization of Black men have been substantiated by research. In Canada, the unemployment rates of second generation Black men between 24-54 years old is at $9 \%$ compared to second generation White men, who experience $3.8 \%$ unemployment (Statistics Canada, 2015). Black men also experience unemployment at a rate that 
is $73 \%$ greater than non-racialized Canadians (Block \& Galabuzi, 2011). Within the labour market, Black men have lower average annual incomes $(\$ 31,233)$ than non-racialized men $(\$ 45,327)$ (Block \& Galabuzi, 2011) and there are a greater percentage of Black men (23.5\%) who experience lower incomes than non-racialized men (10.9\%) (Block, Galabuzi \& Weiss, 2014). Despite "working hard" to become "successful," the majority of Black men face lower wages, higher rates of unemployment and a lack of access to high paying jobs (Block \& Galabuzi, 2011). Studies also suggest that Black men experience unfair and discriminatory hiring practices (Feagin, 2001; Vijaya, Eshleman, \& Halley, 2005) and that the majority of professional and managerial positions are held by White people who, when hiring, are more likely to employ people that share their racial and cultural backgrounds (Vijaya, et al., 2005). These racist practices often go unchallenged and perpetuate the dominant discourse that employment is always given to the most qualified individuals. This claim of "colour-blindness" in hiring practices, that is, race is not a consideration and that everyone has an equal opportunity to employment, leaves many young Black men at the mercy of exclusionary practices, deeply embedded in society.

Liberal ideology, in Canada and elsewhere, promotes the dominant and false ideal that every person in society has equal rights and is given a fair chance to succeed (Graham et al., 2011). Along this line of thinking, individuals experiencing poverty or economic marginalization are deemed undeserving or blamed for their own failings. These liberal ideologies ignore the fact that racialized people are systematically marginalized in society, while Whiteness is privileged and embedded in many social institutions (e.g., in politics, media, labour market and education) and White supremacy is operationalized in policies and practices (Delgado \& Stefancic, 2012; 
Graham et al., 2011). As a result of these racist policies and practices, young Black men experience and are vulnerable to many social injustices beyond economic marginalization. In North America, including Canada, racist stereotypes that portray young Black men as lazy, simpleminded, delinquent, dangerous, criminal, and savage are widely circulated in the media and other social spaces (Feagin, 2001; Cooper, 2006; Milner, George, \& Allison, 2016). These racist stereotypical images have created unsubstantiated fear and prejudice among White and non-Black people and prevents young Black men from full participation in society, including access to inclusive education and equitable career development.

For decades, compared to White and other non-Black students, young Black men in high school have experienced disproportionately higher dropout rates, harsher disciplinary actions from teachers, and exclusion from advanced level education required for university enrolment (James \& Turner, 2017). I argue that many of the problems faced by young Black men are related to their experiences with anti-Black racism in educational institutions that prevent them from excelling academically. As reported by many participants, young Black men are marginalized at school by teachers who unjustifiably view them in negative ways, that is, as being "bad", "delinquent" or lacking the intelligence needed to succeed in school. Some of these teachers' perceptions and behaviours reflect commonly held racist stereotypes about young Black men being "troublesome" and "unintelligent." Many participants shared their own experience of having to work very hard to dispel these stereotypes about them and to prove their academic capabilities. These challenges were also found in other studies in which young Black men reported that their teachers often spoke negatively about them, ignored them, or seemed to be afraid of them (Cooper, 2006; Gray, Bailey, Brady, \& Tecle, 2016). Likewise, many young 
Black men receive harsher disciplinary action (e.g., expulsion from school) for what is perceived as "bad behaviour." The experiences of social exclusion and mistreatment among young Black men contribute to their disillusionment with the education system, which fails to provide equitable opportunities for them to succeed (James, 2012).

While some young Black men are able to resist these mistreatments, rise above the exclusive school environments, and turn these barriers into motivation to excel academically, not all young men are able to do that. Despite knowing that they are capable of academic success, some young Black men take on the stance that they are not interested in education, or display a persona of being unknowledgeable, as a form of resistance to White authority. Other young Black men disengage from the education system in order to fit with the dominant discourse and the internalized racist assumptions that young Black men are "naturally" inferior or incapable of achieving career success (Brown \& Segrist, 2016; Gray et al., 2016; Tyler et al., 2016). Arguably, without changes to the status quo, the current educational system will continue to move young Black men from school to the prison pipeline (James, 2012). Within the Canadian federal prison system, young Black men are overrepresented. Between 2005 and 2016, there was a $70 \%$ increase in the number of incarcerated Black people in federal prisons, in Canada (McIntyre, 2016). Data from 2014 suggests that many of these inmates were Black men (95\%) and that half were young Black men under the age 30 (Government of Canada, 2014). I argue that our current education system not only excludes young Black men but also contributes to their disproportionate incarceration. With limited education, young Black men will experience even harsher social and economic marginalization and precarious living that may steer them towards the street economy (e.g., petty crimes, drug deals, or selling stolen goods) and further 
pushes them into the peripheries of Canadian society (Western, Kleykamp, \& Rosenfeld, 2006).

Their increased likelihood of experiencing poverty may also result in their limited access to housing, as they are relegated to neighbourhoods of concentrated poverty that put them at risk of community violence and increased homicide (Khenti, 2013).

In addition to social vulnerabilities associated with barriers to employment, income and education, many young Black men also experience everyday stressors associated with racial profiling and over-policing. Many participants spoke about feeling vulnerable because of being routinely stopped, questioned and treated unfairly by police, based on the popular racist belief of young Black men as "troublesome". Evidence indicates that Black men are three times more likely to be stopped by police than non-racialized people and are disproportionately carded by police (Grewal, 2015). As reported by participants from Toronto East, young Black men from socially disadvantaged communities are even more likely to be racially profiled and stopped by police than any other group (Wortley \& Owusu-Bempah, 2011). The police use of force is 4.3 times greater for Black people, than the national average; Black people are more likely to be harmed by police, and are ten times more likely to experience gun violence, than White people (Wortley et al., 2011). The statistics on over-policing and over-incarceration of Black men, illustrate the social vulnerabilities faced by young Black men and the structural violence that justifies White supremacy, by normalizing the criminalization of Black men as "necessary" to "protect" the public (Gilbert \& Ray, 2015).

As shared by the participants in this study, the everyday experiences of social vulnerabilities related to anti-Black racism, in the form of racist stereotypes, economic 
marginalization, exclusive education, over-policing, and over-incarceration undoubtedly affect young Black men's perceptions and constructions of their social identities.

\section{Black Heterosexual Masculine Identities in the Context of Anti-Black Racism}

As I have stated in the introduction of Chapter 4, social identities are dynamic, situational and complex. The narratives of the participants suggested that their perspectives and experiences were shaped by social forces, such as, hegemonic masculine expectations. Hegemonic masculinity is a relational practice that allows White middle-class and upper-class men to take up dominant positions, to set the standards of manhood in ways that justify the domination of women and marginalization of racialized men and gay men (Connell, 1995). While hegemonic masculinity operates to reinforce unequal power relations, it is often operationalized through men's adoption and pursuits of certain hegemonic masculine ideals or expectations, including: achievements of economic and social status, being a "breadwinner", male dominance, suppression of "feminine" emotions, acting "tough", exhibiting self-confidence and aggressiveness, heteronormative practices, and not displaying effeminate behaviours (Levant et al., 1992; Thompson \& Pleck, 1986). The social forces embedded in hegemonic masculinity are so strong that most men, regardless of their social positions, subscribe to certain dominant ideals and expectations.

Despite being in marginalized positions, most of the participants in this study resonated with some hegemonic ideals of masculinity. Many of them considered masculinity as synonymous with being 'responsible' and emphasized financial responsibility, employment, income, and most of all, being a provider for their families. They perceived that to be a "real" man, one must not be dependent on others and be able to demonstrate self-sufficiency, being 
dependable, and the ability to provide financial support to those they cared about. This finding affirmed the results of other research that showed young Black men considered financial independence and self-reliance as indicators of maturity and attributes of masculinity (Chaney, 2009). However, different from other studies, young Black men in this study also spoke of 'responsibility' in terms of owning one's actions and the ensuing consequences. They shared that being a man required that they stand firmly to face the repercussions of their choices, even when the outcomes were seemingly unfavourable to them. Their desire to be responsible contradicted the stereotype of young Black men as careless and delinquent (Stewart \& Simons, 2010). It also suggested that they had a deep sense of commitment in caring for their families, despite facing many barriers in society that made it challenging for them to provide financial and other support.

It is important to note that structural racism, resulting in economic marginalization and social stigmatization, makes it challenging for young Black men to fulfill the hegemonic masculine norms and expectations. In other words, the hegemonic masculine ideals of economic successes or self-sufficiency are often unattainable for many Black men, especially young men. For the most part, these ideals propagated through the media (Connell \& Messerschmidt, 2005) and other symbolic representations in political and social institutions (e.g., Canadian Parliament, Supreme Court of Canada) privilege White middle- and upper-class men who enjoy access to power and resources, a privilege seldom enjoyed by Black men (Vijaya, et al., 2015). Within Canadian society, Whiteness and maleness often confers one's access to social, political and economic resources, the power and authority for decision-making, and the privilege of being presumed 'the norm' to which women and racialized men are judged and subjugated. These privileges enable White middle- and upper-middle class men to perform and maintain hegemonic 
masculine norms, determine the distribution of social, political and economic resources, and exert power and domination over Black and other racialized men, women and sexual minority peoples (Garner, 2006).

As many participants pointed out, young Black men's lack of access to job opportunities and equitable employment, makes it difficult for them to fulfill their masculine roles as providers. At the same time, when Black men are not able to fulfill the masculine expectations of being "self-sufficient" or the "breadwinner," they are constructed as "failures" or being "irresponsible". Thus, the barriers to employment and lack of access to equitable income do not seem to diminish the desire of Black men to meet the masculine expectation of being providers for their loved ones. While some young Black men may take up multiple low wage jobs to make ends meet, some may feel drawn to engage in the street economy and illegal work activities (e.g., selling stolen goods or drugs) to support their families and themselves. In many ways, young Black men are caught between the lack of access to resources that enable them to fulfill hegemonic masculine expectations and societal pressure to demonstrate successful manhood. Previous studies suggested that some Black men engaged in the street economy or illegal activities to fulfill the masculine expectation of self-sufficiency (Western et al., 2006; Whitehead, 1997), while other research showed that some young men perceived illegal activities as legitimate work because it was the only type of work available to them (Richardson \& St. Vil, 2015). This conundrum presents a double-edged sword for many young Black men; they are marginalized by the structural conditions that steered some of them towards engaging in illegal activities, which in turn are used to justify racial profiling, over-policing, over-incarceration, and the perpetuation of racist stereotypes of young Black men as "inherent" criminals and thugs, in 
society (Cooper, 2006; Haynes, 2000). When the media reports on gang fights or criminal activities undertaken by Black men and racialized men, structural conditions that contribute to these criminal activities are seldom mentioned. The naturalization of racist stereotypes of young Black men as inherently dangerous, anti-social or criminal, takes away the public's attention from holding those in power accountable for addressing issues of social inequities and marginalization.

As some participants indicated, young Black men's identity constructions are also influenced by the media's portrayal of young Black men as glorified "thugs" in music videos and other media forums. When bombarded with these negative images, some participants were able to challenge these racist stereotypes, while others internalized them, as the attributes of being Black men. Arguably, White hegemonic masculine domination, in media and various social institutions (i.e., policing and law enforcement) that vilifies and treats young Black men as criminals (Colpitts, 2017), may have contributed to these young men's internalized belief that Black masculinity is synonymous with being "thugs" and "gangsters." I argue that for some young Black men, especially those living in concentrated poverty, or having minimal access to positive images of Black men, taking on the identity of being a "thug" or being "tough" is sometimes a way for them to establish a sense of social belonging. It is also a way for them to acquire "street credibility" or "street respect", which is particularly important to young Black men with little social and economic resources (Richardson et al., 2015).

For many participants in this study, acting "tough" and "unemotional", even in the face of difficult circumstances, was a demonstration of manhood. They suggested that showing "soft" emotions would be equated with effeminacy and weakness. Feminine attributes, such as timidity 
and dependency were viewed as undesirable and unacceptable for men (Harris, Palmer, \& Struve, 2011). Further, some participants suggested that, in the context of Black men's relationships with women and children within the family, men often took on the role of the "Alpha Male" or "Head Honcho." For many young Black men, failure to demonstrate masculine qualities may result in being seen as effeminate, unmanly, or gay. However, many participants also shared that they felt a variety of emotions, including fear, grief, and sadness but that they are unable to show these emotions to others, for fear of being ostracized by their peers or becoming easy targets for violence. For young men from economically disadvantaged and socially marginalized communities, the internalization of the hegemonic masculine norm of "toughness" is concerning because it may be manifested as violence against other young Black men. In communities where young Black men are systematically marginalized and oppressed socially and economically, violence may be adopted as one way to demonstrate manhood and gain respect and acceptability from other men. Unfortunately, it has been reported that young men who adhere to street codes that endorse violence, are at a higher risk of violence (Stewart, Schreck, \& Simons, 2006); even when young Black men do not want to participate in violence, many must adhere to these street codes, to avoid becoming victims of violence (Richardson \& St. Vil, 2015). Thus, many young Black men are twice oppressed: first, because they are pressured to uphold masculine ideals of economic and social successes that are unattainable, and second, because in fulfilling the hegemonic masculine norm of toughness, they may be at greater risk for violence and victimization in their own communities.

Many participants also shared that their social identities were shaped by existing stereotypes about Black men's sexuality. Historically, there has been a racist preoccupation with 
young Black masculinity and sexuality, as being inherently deviant; this has been pervasive throughout White settler societies in North America, since the Atlantic slave trade (Ferber, 2007). Stereotypical and racist ideas about young Black men's heterosexuality also persist in mainstream society. Arguably, these images portray Black men as hypersexualized, animalistic and unable to control their sexual urges, which have generate fears, misconceptions and adds to the racist stereotypes about Black men. Research evidence suggests that White supremacist cultures and anti-Black racist media images, have propagated the idea that young Black men need to be tamed, in order to protect social order and prevent the violation of White women, (Ferber, 2007). Other common images of young Black men's heterosexuality depict them as carefree and irresponsible, particularly in their relationship with women. Young Black men are portrayed as having an unquenchable sexuality, manifested in being uncommitted in relationships and having many sexual partners (Cooper, 2006; Ford, 2011).

These negative and stereotypical images of young Black men's heterosexuality are false representations. In this study, many participants challenged these stereotypes and expressed their support and commitments for gender equity in thoughtful ways. While some recognized that they had internalized some negative stereotypes about Black masculinity and sexuality, others were able to critically examine and challenge these expectations. Within a structural context, masculine expectations about how young Black men demonstrate their heterosexuality may often differ according to social class expectations. Participants in this study suggested that heterosexual young Black men from the middle-class neighbourhoods, were shaped by a different set of norms that placed the emphasis on education and less so on defining manhood in terms of success in sexual relationships. Arguably, young Black men from middle and upper 
class families are more likely to have the economic means to participate in extracurricular activities (e.g., team sports, private academic lessons, etc.) that are deemed as legitimate ways to demonstrate manhood, and there may also be a greater emphasis and support from parents and others to pursue successes in education. Other research supports the notion that young Black men from middle class families, experience greater support and persuasion from their parents and social networks, to focus on academic achievements, in preparation for the workforce (Weibold $\&$ Spiller, 2017). Within middle and upper social classes, achieving manhood may be understood as requiring young men to focus on completing their high school and college educations, so that they can be better positioned within the labour market, to obtain gainful employment, and be able to provide for their own families, as adult men. In this way, middle and upper class Black families may have reinforced the hegemonic masculine norms of men as self-sufficient, independent, and providers. In contrast to young Black men from socially and economically deprived communities, middle and upper class young Black men may be better able to achieve some of the hegemonic masculine expectations.

Nevertheless, irrespective of class, young Black men from all socioeconomic statuses are subjected to similar structural pressures, to conform to the mainstream racist depictions of Black heterosexual masculinity. As some participants shared, even when they struggled with identifying with these negative depictions, they sometimes felt pressured to behave in ways that mirrored the stereotypes about Black masculinity. For instance, some young men shared that they would be rejected by their peers, if they did not conform to the expectation of having multiple sexual partners, as a demonstration of their manliness. Even for young Black men who do not necessarily desire to fulfill these expectations, the pressures experienced from friends and 
stereotypes reinforced through media, can make it challenging for young men not to follow these conventions. They may feel that if they do not show their heterosexuality in these ways, their sexuality and their manhood will be in question. Similarly, other research suggests that the constant bombardment of 'sex-craved' and 'womanizing' representations of young Black men, in the mainstream media, makes it difficult for them to escape and refrain from assimilating to the expectation (Ford, 2011). It is important to note that the hegemonic masculine norms are so insidious and powerful in our society that many young Black men strive to achieve these standards. This desire among Black men to achieve the hegemonic masculine ideals, despite encountering many challenges, was also found in other studies (Cazenave, 1982; Haynes, 2000). To a certain extent, when young Black men attempt to fulfill these masculine expectations against all odds, they may also have unknowingly taken part in reinforcing and accepting White middle-class domination. Further, in pursuing these ideals, they may also be put into positions that put their health and wellbeing at risk.

\section{Social Contexts of HIV Vulnerabilities Among Young Heterosexual Black Men}

Conditions and factors that affect young heterosexual Black men's HIV vulnerabilities are complex. Contrary to the dominant discourse that HIV vulnerabilities are linked to individual risky behaviours, I argue that heterosexual young Black men's HIV vulnerabilities are socially produced, through their everyday experience of marginalization. As structural racism makes it difficult for many young Black men to fulfill economically defined masculine expectations, some of them may be drawn to demonstrating their masculinity through sexual prowess, male domination, lateral violence towards gay Black men, or acting like thugs. Further, when young 
Black men have to live in the constant fear of police harassment and institutionalized racism, their desire for "trusting" relationships may take on special meanings.

One key aspect of HIV vulnerabilities for heterosexual young Black men is HIV stigma, which is reinforced by homophobia and heterosexist norms. In the Black community, HIV remains a taboo and an unpopular topic of conversation. The misconceptions of HIV as a "gay man's disease" and the consequence of one's immoral or deviant sexual behaviors are still commonly held by many people (Lawson et al., 2006). Many participants in this study were not concerned about HIV and do not participate in HIV testing because they believed that their heterosexuality made them invincible to the disease. Stigma of HIV, as a gay man's problem limited participants' understanding and insight about the HIV risks for heterosexual men and women, including their own risks. Despite education and HIV awareness campaigns, Black communities have been reluctant to acknowledge HIV as a relevant issue for them because they are overburdened by other social problems (e.g., racism, violence, poverty, employment, etc.) that many of them may still be trying to address.

The problem of HIV stigma is worsened by the lack of relevant and adequate sex education. Many participants in this study indicated that the sexual health education provided by the school system did not adequately address HIV risks, based on the everyday social contexts of young people in the Black community. School sex education tended to focus on the biology of sexual health, such as sexual development. Other research suggested that young Black men from lower income groups tended to be less knowledgeable about HIV, than young Black women and other young Black men, from higher income communities (Swenson, Rizzo, Brown, Vanable, \& Carey, 2010). Young Black men's lack of knowledge may be tied to HIV stigma, which 
increases their reluctance to learn about HIV. At the same time, Black youth with less HIV education and knowledge also tend to display increased stigmatizing attitudes towards HIV (Kerr et al., 2014). The lack of comprehensive and relevant sexual health education appears to be a common challenge for racialized young people (Wong, Macpherson, Vahabi, \& Li, 2017).

Other factors that increase HIV vulnerabilities for young Black men include sexual relationships and condom use. Many participants, especially those from East Toronto, suggested that their primary reason for condom use during sex was to prevent pregnancy. Pregnancy prevention was important to these young men because they felt that they were not yet ready to be financially responsible for a family. Although all the young men were aware that condom use could protect them from HIV and other STIs, few of them prioritized condom use for this reason.

In terms of condom use as an HIV prevention strategy, the young men in this study expressed mixed perceptions. Some suggested that the misconception about HIV as a gay disease continued to make Black men feel invincible and therefore condom use for HIV prevention was less of a concern. Others suggested that even when they were aware of their HIV vulnerability, using a condom was not an easy matter. One of the key challenges for young Black men in negotiating condom use with their sexual partners is related to the issue of trust. They shared that the suggestion of using a condom is often interpreted as a sign of disrespect and could signal to one's partner a lack of trust and commitment in the relationship. Some participants felt vulnerable about discussing condom use with their sexual partners because they did not want to offend them. Some engaged in condomless sex because they lacked the skills required to negotiate condom use in a way that demonstrated their commitment to the relationship and their partner's wellbeing. Other studies also found that young Black men had a hard time negotiating 
condom use because their sexual partner considered condoms as a lack of dedication to the relationship (Feldstein \& Ewing, 2015; Civic, 1999). Further, it was also found that young heterosexual men in committed or serious relationships tended to be less likely to use a condom during sex and that condom use decreased with the frequency of sexual intercourse and with increased length of the relationship (Civic, 1999). As mentioned earlier, I argue that "trust" is a valuable asset to many young Black men who live in precarious conditions. Their desire to demonstrate trust in sexual relationships also reflects the dominant middle-class assumption and expectation of sexual monogamy. In this study, participants who had multiple sexual partners were aware that they were at an increased risk of HIV/STIs. At the same time, they spoke of the challenges of being young and being at a life stage when they were not ready to settle into a monogamous relationship. Young Black men with multiple sexual partners started out with the full intention to use a condom with partners outside of their regular relationship, but condom use became less consistent over time, even with their "side" partners as they got to know each other more. The association of decreased condom use with increased familiarity and intimacy was also evident in other studies (Feldstein et al., 2015; Klein Hattori, Richter, \& Greene, 2010). To some extent, the lack of openness in Canadian society to dialogue about consented concurrent sexual relationships and the pressure to demonstrate trust through condomless sex, have contributed to young Black men’s HIV vulnerabilities.

To reduce the HIV vulnerabilities of young heterosexual Black men, more open dialogue is needed to challenge the discourse that trust in a relationship equates to engagement in condomless sex. Regardless of the level of commitment and duration of the relationship, it is important to normalize condom use, as a demonstration of respect and commitment for both 
young Black men and their sexual partners. Strategies that increase young Black men's HIV knowledge and ability to share this information with their sexual partners may be useful for addressing HIV vulnerabilities. Further, as indicated by many participants, the current sexual health education provided in schools is in need of improvement. Effective sex education and HIV prevention programs for young heterosexual Black men must include strategies that challenge dominant hegemonic masculine expectations and address their HIV vulnerabilities, in the context of structural racism and social marginalization. Providing information beyond the physiology of HIV transmission to address the specific vulnerabilities faced by young Black men is critical.

Moreover, to increase the level of interest and relevancy of HIV prevention, the engagement of Black men living with HIV (PLHIV) in facilitating sex education and HIV prevention programs may help to strengthen education, about HIV and address the issue of HIV stigma, in the Black community. Young Black men from the study shared that they had difficulties connecting with HIV messaging and that they mostly had negative images about HIV because they had never met anyone with the illness. Having PLHIV collaborate with schools and lead education sessions could prove a powerful tool for challenging common misconceptions about PLHIV, building supportive social networks, and for normalizing discussions about HIV, in the Black community. Others have found that engaging PLHIV in HIV education has been successful at addressing issues of stigma (Brown, Macintyre, \& Trujillo, 2003; Li \& Wong, 2016)

In addition to education workshops, effective HIV prevention strategies for heterosexual young Black men require a comprehensive approach. Didactic explanations of the mode of 
transmission, personal risks, condom use, and HIV testing may be useful but they can also be limiting in engaging the Black community. Meaningful engagement of heterosexual young Black men and the Black community in HIV prevention requires dialogue about complex issues, such as, the impact of racist stereotypes and hegemonic masculine expectations on the sexual practices of young Black men. Without addressing the issues of racism, hegemonic masculinity and heterosexism, strategies to address HIV will be superficial and will not address the structural conditions that increase HIV vulnerabilities. Open dialogue about HIV stigma and ways to normalize these discussions at the community and familial levels could also be helpful. Greater community involvement in HIV programming and implementation could help to ensure that prevention strategies are accessible and meet the concerns of the community. Others have found that community involvement in HIV prevention has helped to limit the reproduction of stigma in some Black communities (Interagency Coalition on AIDS Development, 2011).

In addition, meaningfully engaging heterosexual young Black men will require existing HIV programs and services to actively conduct outreach activities to meet young Black men in the places where they congregate. Many participants suggested that HIV prevention needed to include activities that are of interest to young men. Therefore, programs and services could be offered in meeting places, such as, barbershops, churches and other service organizations frequented by young Black men. Health initiatives that aimed to increase awareness and health literacy about cardiovascular health have been successfully implemented in places like Black barbershops (Davis, 2011). These strategies could be employed by HIV program and service organizations, to increase heterosexual young Black men's participation and interest in health promotion and HIV prevention activities. 


\section{Building Collective Resilience: Social Support and Education}

In spite of the personal challenges and structural barriers that heterosexual young Black men face, many participants were hopeful about their futures and demonstrated that they were resilient in spite of their setbacks and vulnerabilities. Looking at these young Black men's resiliencies in the context of multiple structural barriers is necessary to understand how these social conditions can be addressed, to improve the lives of young Black men. Delineating possible strategies to improve the social conditions of these young men is equally important in the context of HIV vulnerabilities. Structural barriers like racism, low income, unemployment and underemployment, do not exist in a vacuum. Likewise, the strategies that young Black men use to be resilient in the face of social oppressions are relevant to HIV prevention. The implementation of strategies that improve the social conditions of this group will likely also address their HIV risks.

While some participants suggested that their ability to overcome challenges was the result of their personal perseverance and choices, it would be difficult to imagine that these young men had achieved their goals without the support of others. Accessing both informal (e.g., friends and family) and formal (e.g., community services) social networks has been crucial to the academic achievement and social mobility of some young Black men in this study. Having mentors and other important people, in young men's lives was an important source of guidance for them in making important decisions. Some participants also acknowledged the importance of having other Black men as important role models in their lives, especially during a period of time when they were faced with challenges. They indicated that these mentors helped them to successfully overcome difficult life situations, by presenting them with new ways of problem-solving, and 
encouraging them to seek opportunities or access resources that were previously unknown to them. As a result of their social support and networks, some participants were encouraged to pursue a university education or start a small business. Similarly, other research on young Black men from low-income communities, found that social supports offered young men diverse social networks that developed their life skills, employability and access to job opportunities and extracurricular activities (Wiebold \& Spiller, 2017).

In addition to social supports as a key resource in the resilience of young Black men, education has been an important source of resilience. Some of the young men in this study who attended high schools and post-secondary institutions were able to resist racist stereotypes about their intelligence, by consciously working towards academic excellence, to challenge these stereotypes. Inclusive education promotes resilience in young Black men by broadening their perspectives and horizons. It provides them with new possibilities and opportunities for developing social networks and interests; it also provides them with skills to challenge racist misconceptions about young Black men. For many participants enrolled in university, education exposed them to new perspectives and helped them to develop new skills and increase selfefficacy, which could help them to be more competitive in the job market, despite the constraints imposed by structural racism. As one young Black man expressed, education is a "tool" that can be used to "liberate" young Black men by showing them different possibilities for their lives.

\section{Summary}

In this chapter I have critically analyzed the key themes derived from the perspectives and experiences of the study participants. Using intersectionality and CRT frameworks, I have presented how structural violence and systemic discrimination produce social vulnerabilities, 
which shape the gendered, racialized and classed identities of heterosexual young Black men and contribute to their HIV vulnerabilities. Young Black men face multiple social challenges, such as, racist stereotypes, inequitable access to income, unemployment, underemployment, exclusive education, over-policing and over-incarceration, which are all embedded in anti-Black racism. I have also identified the conditions that promoted resiliencies among the participants, including the development of social networks, seeking mentorship and pursing education. This chapter has provided a broad understanding of young Black men's social and HIV vulnerabilities and conditions that promote their resilience. In the final chapter, I will present the implications and recommendations to inform changes in policy, research and practice, to reduce HIV vulnerabilities and improve the conditions that promote the collective resilience and wellbeing of young Black men and communities. I will also present the limitations of this study and my concluding thoughts. 


\section{CHAPTER 6: CONCLUSION}

\section{We are the ones we've been waiting for \\ We are the change that we seek.}

\section{- President Barack Obama}

\section{Introduction}

When I started this journey, I set out to understand more about young Black men's HIV vulnerabilities - I wanted to know why HIV was on the rise in Black communities and how social contextual factors contributed to this. Initially, I held some of the misconceptions and prejudgments commonly held about young Black men's sexuality however, this journey has taught me that many of these young men face multiple and complex social barriers and oppressions, that shape their identities and the direction of their lives. As a result of this research, I have gained a new perspective, and I am convinced, more than ever that without addressing the structural conditions that oppress and marginalize many young Black men, that they will continue to face health inequities and social disparities. Understanding health problems like HIV requires looking at social factors, such as, racism, masculinities and identities, employment, income and education. Moreover, I am convinced that deciphering how these and other social determinants negatively or positively impact health may hold the keys for narrowing the gap between racialized and non-racialized people, in Canada.

The purpose of this research was to use the lenses of CRT and intersectionality to explore the gendered, raced and classed identities of heterosexual young Black men, as they relate to their HIV vulnerabilities and the resilience strategies they employed, in spite of their everyday challenges. The theoretical frameworks used were useful for uncovering the oppression and 
marginalization these young men endured in their daily lives that were often embedded and normalized, in the institutional and systemic fabrics of society. The use of CRT helped me to highlight the impacts of race and racism in the lives of young Black men, while intersectionality provided me with the necessary approach for examining the complexity of co-existing social identities. To consider HIV vulnerabilities without examining the effects of racism, sexism, hegemonic masculine domination, economic marginalization, etc. would have yielded an incomplete investigation and erroneous conclusions. Furthermore, I have drawn on the methodological approach of narrative inquiry in data collection and analysis. This approach was helpful in promoting open dialogue and sharing among the participants. In analyzing the young men's stories, I was able to explicate how social forces and power relations were embedded in the participants' everyday experiences and how they interacted with their complex social worlds.

\section{Significance of the Study}

This study has contributed to addressing current research gaps, as it relates to HIV vulnerabilities for heterosexual young Black men and strategies that may enhance young Black men's engagement in HIV prevention. It has also generated new and important knowledge on: heterosexual young Black men's racialized and gendered identities, which reflect the push-andpull forces associated with society's anti-Black racist stereotypes and young Black men's own ideas about who they are; how these identities are internalized to influence their thoughts and experiences; and how some young Black men resist social stereotypes. Further, this research has also identified some social conditions that make many young men vulnerable in society and the factors that promote their resilience. Many of the social conditions that oppress and marginalize young Black men have been fueled by racism, which is embedded in social institutions. The 
impact of anti-Black racism for this population is manifested in all aspects of their lives, including challenges with obtaining gainful employment, barriers in the education system, and problems with over policing and hyper incarceration.

In the immediate term, based on the feedback of the participants, the study has provided a rare opportunity, in a safe environment for young Black men to share their perspectives and stories, and to draw strengths and insights from each other's sharing. The focus group also provided an opportunity for them to talk openly about HIV, in the context of their everyday racialized and gendered lived experiences and in relation to Black communities. Participants were able to dialogue about critical social issues, like racism, socioeconomic marginalization, education, peer pressure, community engagement and health. It opened up a space for participants to think collectively and constructively about social injustice and how it related to their lives, as individuals and together, as a community. As a member of the weSpeak team, I am committed to work with my colleagues to return to the community to share our study results with these young men and to work with community organizations, to further establish open space for young Black men to engage in critical dialogue.

In the longer term, this study is significant because it brings to the forefront critical discussions that address the paucity of research on Black heterosexual masculinities and HIV vulnerability, in the contexts of anti-Black racism, classism and heteronormativity. Furthermore, this research adds to the existing body of literature on young Black masculinities, by explicating the ways that structural violence, in the form of sociocultural norms, exerts tremendous pressures for young Black men to fulfill racist stereotypes, constructed through anti-Black racism. In taking this approach, this study has opened up the space for dialogue and debates within the 
research, policy and programming fields and evidence to challenge the unfounded and oppressive misrepresentation of young Black men as 'deviant' and 'lesser' than White men. Lastly, this research highlights strategies, such as, relying on social supports and pursuing education, that many of these young men have used to resist, challenge and defeat the social restrictions placed on them, and considers how various strategies can be used to promote resilience and to improve the social and health outcomes of young Black men.

\section{Implications and Recommendations}

The rich narratives and results of this study have illuminated issues related to Black masculine identities, social and economic oppressions that make young Black men vulnerable in society, HIV vulnerabilities and gaps in HIV prevention strategies. In the following section, I will look at the implications of this research and make recommendations for the development of more effective policies, programs and needs for future research.

\section{Policy}

The results of this study have shown that HIV vulnerabilities do not exist in a vacuum but are produced through power relations and institutionalized anti-Black racism, manifested in exclusionary practices and inequitable resource distribution. In Ontario, the government has devised a comprehensive policy plan for addressing HIV in the province until the year 2026. One of the strategic approaches of this plan includes focusing on populations that are most affected by HIV, which includes Black communities. The approach taken in this policy recognizes the social and structural determinants of HIV, such as racism, gender and sexual orientation (Ontario Advisory Committee on HIV/AIDS, 2016). However, what has been excluded from this provincial strategy is a concrete action plan about how programs and services will address issues 
of racism, which is a major factor in the health of racialized people. While ensuring culturally appropriate services, as the standard of care to be provided at all HIV agencies is critical, it is only a band-aid solution, when the structural determinants of HIV vulnerabilities are not addressed through policy and societal change. A more rigorous policy commitment that challenges social and health inequities related to anti-Black racism, would seek to acknowledge that racism negatively effects and increases the HIV vulnerabilities of Black people in multiple ways, which include access to health care, education, equitable income, housing and social supports (African and Caribbean Council on HIV/AIDS in Ontario [ACCHO], 2013). Without a dedicated policy plan to address these structural conditions, there may be minimal improvement in the fight against HIV in Black communities.

\section{Research}

This research contributes to a better understanding of heterosexual young Black masculinities, heterosexuality, and HIV vulnerabilities. It moves away from individual blaming and risk discourses, that reinforce misconceptions about HIV transmission, in isolation from contextual factors, like racism, sexism, hegemonic masculine domination, economic marginalization, etc. This research also substantiates the need for a more comprehensive examination of the social conditions that increase HIV vulnerabilities among heterosexual young Black men and their communities. From this research, strategies can be developed to build on the existing strengths of young Black men and communities, to improve health outcomes and diminish risk. Future research is needed to explore how access to social determinants, such as, income, higher education, housing, equitable civic participation and decision-making, and 
community building, contribute to the resilience of young Black men to inform comprehensive policy decisions and programming.

\section{Practice}

The results of this study have provided some indication of the importance of comprehensive HIV/STI prevention programs that are underpinned by the principles of social justice and anti-oppression. Further, HIV programs and services need to engage heterosexual young Black men in meaningful ways. Many young Black men are not likely to access HIV health services, for the fear of appearing vulnerable and because of the stigma associated with HIV and HIV service organizations. For this reason, program development and outreach staff must be strategic in creating a welcoming and non-judgmental environment that encourages heterosexual young Black men to uptake their services. Having other Black men in positions of leadership to develop and lead programs, and connect young Black men to Black male mentors, would be one way to reorient healthcare services and make them more accessible. Equally, having HIV-related programs that take place in spaces that young Black men frequent, may also improve access, increase community engagement and decrease HIV stigma.

\section{Limitations of the Study}

This study is exploratory and not an exhaustive examination of the social conditions related to HIV vulnerabilities and the resilience of heterosexual young Black men. Being a small study of 15 participants, the results are not meant to be generalizable. However, the results of this study offer a useful starting point for understanding HIV vulnerabilities in relation to heterosexuality and young Black masculinities and they may be applicable to other young Black men who share similar social and economic contexts. Future research can build on the findings 
of this research by further investigating young Black men's resilience and how their resilience strategies can be developed into effective programs, services and policies that promote health.

\section{Summary}

In conclusion, in this thesis I have presented the voices of one of society's most marginalized and silenced populations. These young men's voices were powerful in that they bring to the forefront counter-stories that challenge the racist stereotypes about young Black men and highlighted the importance of social justice and equity in health and wellbeing. Their voices also represent the voices of the ancestors, generations of strong Black men and Black communities locally and globally, who have experienced various forms and degrees of marginalization and oppression; many will never have the opportunity to share their stories of opposition and overcoming. I hope I have been able to highlight here not only narratives about the numerous difficulties that young Black men face but how they triumph and rise, despite them. I also hope that in reading this thesis, others will join me in taking up new perspectives and engaging in collective action that will challenge the current state of affairs and improve young Black men's social positions and quality of health in society. The power to affect change for the better lies in all our hands and our ability to work collectively and collaboratively with young Black men and Black communities. 


\section{Appendix A: Recruitment Flyer \\ weSpeak: Straight Black Men \\ Building Resilience to HIV in Ontario}

(Recruitment Flyer for Phase One, straight Black men, non-HIV specific]

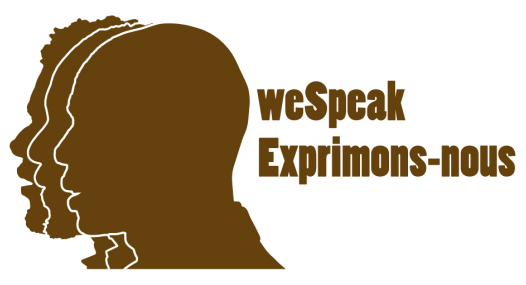

weSpeak is a 5-year research and community engagement project undertaken by a team of researchers and community partners in London, Ottawa, Toronto and Windsor. The goal of weSpeak is to engage straight African, Caribbean, and Black (ACB) men and service providers/decisionmakers to develop effective responses to reduce HIV vulnerabilities and promote resilience among Black men and communities.

Do you identify as:

- A straight Black or BLACK man?

- 16 years of age or older?

- Living in [name of city] i.e. Toronto/Ottawa/London/Windsor

- Fluent in English? [In Ottawa, Fluent in English or French]

If so, we invite you to take part in our study to share your knowledge, insights, and perspectives.

Joining this study will involve taking part in a 2.5-hour focus group. You will be asked to complete a short demographic and health practice survey and join a focus group to discuss issues related to masculinities, sexualities, HIV in Black communities, and access to services and resources.

Your participation in this study is entirely voluntary and private.

- You may withdraw at any time.

- You do not need to provide your real name

- You will receive a small honorarium and a small meal when you attend the focus group session.

- The research team will keep the information you share private. Since a focus group involves many participants, confidentiality cannot be guaranteed. We will ask all participants to honour and respect each other's privacy.

For more information about joining this study, please contact: [Name of project coordinator]

E-mail:weSpeak@ryerson.ca

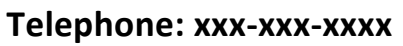

Website: www.we-speak.ca

This project is funded by funded by the Ontario HIV Treatment Network (OHTN) and the Canadian Institute of Health Research (CIHR).

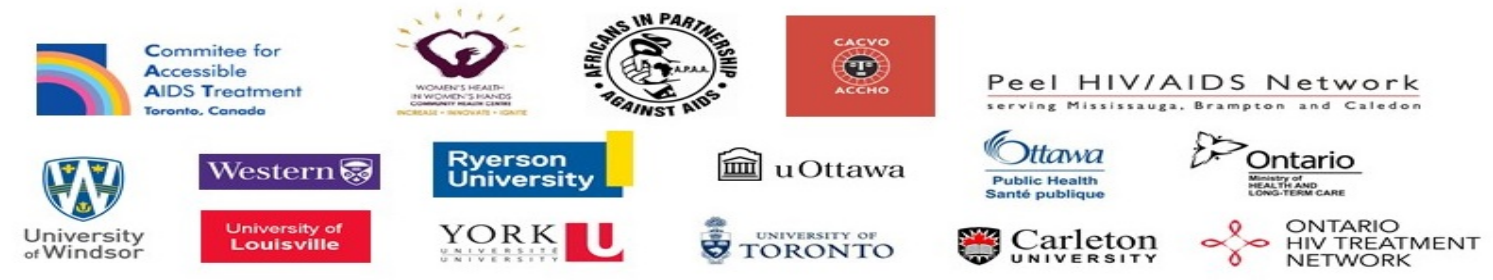




\section{Appendix B: Consent Form (Focus Group)}

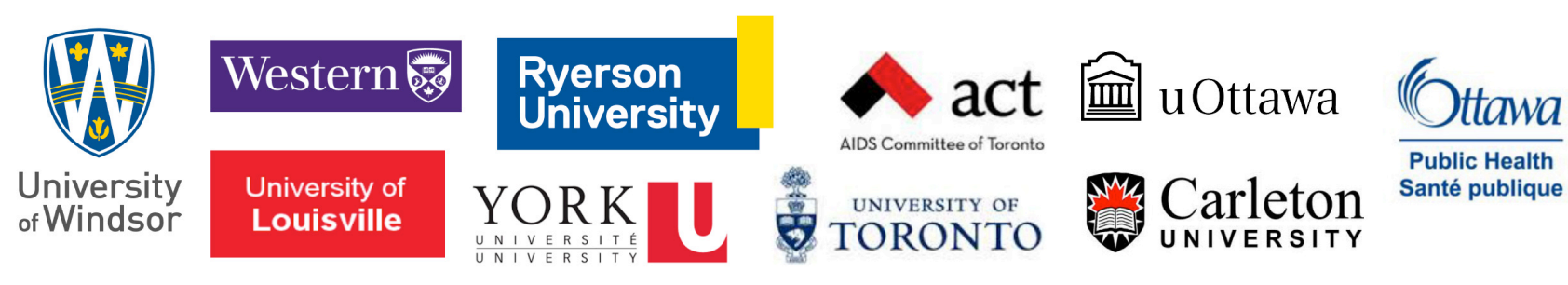

\section{weSpeak: Straight Black Men Building Resilience to HIV in Ontario Project}

\section{Toronto Site - Participant Consent Agreement (Black Men Focus Groups)}

You are being invited to participate in weSpeak, a research project funded by the Ontario HIV Treatment Network (OHTN) and Canadian Institute of Health Research (CIHR). Kimberly Bryce is also conducting this research for her graduate thesis work in partial fulfillment of the requirements for a Master of Nursing from Ryerson University. Please read this consent form so that you understand what your participation will involve. Before you consent to participate, please ask any questions to be sure you fully understand what your voluntary participation will involve.

\section{INVESTIGATORS:}

weSpeak is carried out by a large team of researchers in Toronto, Ottawa, London and Windsor. All team members are listed on the last page of this consent form. The principal investigators of this study are:

- Dr. Josephine P. Wong (Associate Professor, Ryerson University)

- Dr. Winston Husbands (Director of Research, AIDS Committee of Toronto (ACT))

- Dr. Josephine Etowa (Associate Professor, University of Ottawa)

- Dr. Isaac Luginaah (Professor, Western University)

- Dr. Francisca Omorodion (Associate Professor, University of Windsor)

Today's focus group will be co-facilitated by Kimberly Bryce, a weSpeak trainee and nursing student, who will use your sharing and stories (under the supervision of Dr. Wong) to develop her graduate thesis work in partial fulfillment of the requirements for a Master of Nursing degree from Ryerson University

\section{PURPOSE OF THE STUDY:}

The goal of this research project is to reduce HIV vulnerabilities and promote resilience through active engagement of self-identified heterosexual African, Caribbean and Black (ACB) men in community HIV responses, programs, research, and policy. We will engage and mobilize self-identified straight (heterosexual) Black men who are: aged 16 and over; residing in the Greater Toronto Area, London, Ottawa, and Windsor; and HIV-positive, or have never been diagnosed with HIV. We will also engage service providers, policy/decision-makers and other 
relevant stakeholders who work in or with Black communities to address HIV and other related issues that affect the health and wellbeing of straight Black men and communities.

\section{TAKING PART IN THIS STUDY}

Taking part in this study is totally voluntary. You must self-identify as a straight Black man, aged 16 or over, and living in one of the four project cities - Toronto, Ottawa, London, or Windsor. If you choose to participate in this study, you will be asked to do the following:

- Complete a short demographic and health practices survey, which consists of a range of questions about you (e.g., your age, faith/religion, housing arrangement), your sexual practices (e.g., condom use) and your access to health information and services (e.g., whether you have a family doctor).

- Join a focus group discussion to share your ideas about: what being a straight Black man means; intimacy and relationships; gender roles and cultural expectations, challenges and HIV vulnerabilities faced by Black men; and strategies used by Black men to overcome these challenges. Since a focus group involves numerous participants, your agreement to be audio-taped is a criteria to take part in this focus group.

\section{FUTURE PARTICIPATION IN OTHER RESEARCH ACTIVITIES}

If you agree to take part in this study, you will also be asked if you wish to be contacted to take part voluntarily in the following activities at a later date:

- Individual In-depth Interview: This interview will last approximately 60-90 minutes and will be audio-taped with your permission. The interview builds on the focus groups interview to explore issues regarding your personal views and experiences surrounding sexual practices, HIV /AIDS, gender, racial and cultural identity, discrimination and barriers, and other experiences that may affect your health and wellbeing.

- weSpeak Survey of Straight Black men: This survey takes approximately 35 minutes to complete; it will ask questions about masculine role identity, resilience, HIV knowledge and condom use.

- Concept Mapping Focus Group Sessions: This is a series of 4 focus group sessions during which you will work with other straight Black men to draw on the weSpeak study results to develop a best practices model for HIV prevention and resilience promotion for straight Black men and communities.

If you wish to be contacted to take part in the survey and/or the individual interview, you may fill out a separate contact information form at the end of today's focus group.

\section{VOLUNTARY PARTICIPATION}

Taking part in this research study is completely voluntary and you may refuse to participate, refuse to answer any questions or withdraw from the study at any time. Withdrawing from the study will not affect any services that you now receive or will receive from any of the weSpeak partnership agencies (see list of research team members on the last page). Should you choose to withdraw, we will remove your individual research data (demographic and health practice surveys). We will also do our best to remove your focus group data. However, in a focus group discussion, what you share is mixed in with what other participants share. Thus, it may not be possible for us to remove all your data when you withdraw. We will do our utmost to delete your portion as long as it does not lead to the loss of someone else's ideas and sharing. 


\section{CONFIDENTIALITY}

All information you provide during the research will be kept private. Your name will not appear in any report or publication of the research. We will use a study code on all the data we collect from you. The surveys and focus group interview notes will be kept in a locked filing cabinet in a secured office. We will store the consent form and your contact information separate from research data. The audio-recorded focus group interview will be downloaded onto a passwordprotected computer and be transcribed into written texts as a password protected document. Once the transcription is completed, we will store the audio files on password-protected computers. These computers will be stored in a locked filing cabinet in a secured office. Only the research team will have access to this office. All audio files, questionnaires, focus group transcripts and notes will be destroyed 5 years after the study has been completed as required by the funding agency.

The research team will keep what you share in the interview confidential, except in situations where we are required by law to release the information (e.g., if we hear information that a child has been or is being abused; if we hear that you may harm yourself, that is, there is reason to believe that you are at risk to commit suicide; if we hear that an individual who is HIV positive is having unprotected sexual relations without disclosing his status to his partner(s); or if we hear that someone has threatened your life or someone else's life, etc.).

\section{LIMITS ON CONFIDENTIALITY}

Since this focus group involves a number of participants, confidentiality cannot be absolutely guaranteed. Confidentiality is kept only when all of us agree to keep everything that is shared in this room confidential and not share any information with anyone outside of this focus group interview. To protect your confidentiality, we encourage you to think through and decide what you will and will not share in a group setting. To protect everyone's privacy, we will ask each of you to sign the agreement to confidentiality at the bottom of this consent form. You are also encouraged to use a made-up name while taking part in the focus group discussion to enhance your privacy.

\section{RISKS AND DISCOMFORTS}

This study is not expected to cause you or others any known harm. However, you may experience some unexpected emotion or discomfort during the discussion. If you feel upset during the focus group, and you wish to express your discomfort, please feel free to contact any member of the research team. You may also refer to the list of community resources that you received from the research team member. This list contains information on support services in the community that may be helpful to you.

\section{BENEFITS OF THE RESEARCH}

Although you may not have any direct benefit from taking part in this study, your ideas and sharing may help us develop effective programs and policy to improve HIV programs, services and policies for Black men and communities in Ontario.

\section{HONORARIUM}

You will receive a $\$ 30$ honorarium for taking part in this focus group. You will keep this honorarium even if you decide to withdraw from the study at any point in time. A light meal will also be provided. 


\section{RESEARCH REPORT}

You can access our research project results at the weSpeak website (www.we-speak.ca)

\section{QUESTIONS ABOUT THE RESEARCH}

If you have questions about the research in general or about your role in the study, please feel free to contact: Dr. Josephine Wong, Principal Investigator, Ryerson University, at 416-9795000 ext. 6303, or by E-mail: jph.wong@ryerson.ca;

This research has been reviewed by the Ryerson University's Research Ethics Board and conforms to the standards of the Canadian Tri-Council Research Ethics guidelines. If you have any questions about this process, or about your rights as a participant in the study please contact: Research Ethics Board, Ryerson University, at 416-979-5000 ext. 7112, or by E-mail: rebchair@ryerson.ca

** You do not need to use your full name or real name in signing this consent

\section{CONSENT TO PARTICIPATE}

I have read this consent form. I am satisfied with the answers to all my questions about this study. I agree to take part in this study. I have been given a copy of this consent form, and I fully understand my rights as a person taking part in this study.

(Participant's signature)

(Date)

(City)

I agree to be audio-recorded during the focus group.

(Participant's signature)

(Date)

(City)

\section{CONFIDENTIALITY AGREEMENT}

We remind you that since this focus group involves a number of participants, confidentiality cannot be absolutely guaranteed. To protect your confidentiality, we encourage you to think through and decide what information you will and will not share in a group setting. You are also encouraged to use a made-up name while taking part in the focus group discussion to enhance your privacy.

I understand confidential information will be made known to me as (please check all that apply):

[ ] other (please specify) __Focus Group Participant

for a study being conducted by Professor Josephine Wong of the School of Nursing, Ryerson University. I agree to keep all information collected during this study confidential, and will not reveal by speaking, communicating or transmitting this information in written, electronic (disks, tapes, transcripts, email) or any other manner to anyone outside the research team. 
I agree that I will not tell anyone about any of the information that I hear in the group interview today, unless the speaker has told me personally that it is okay to do so.

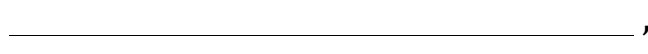

(Participant's signature)

(Date)

(City)

\section{RESEARCH TEAM MEMBER - CONFIRMATION}

I confirm that I have reviewed this consent form with the participant named above and I have answered all questions.

(Research team member's signature)

(Date)

(City) 


\section{Appendix C: Consent Form (Individual Interview)}

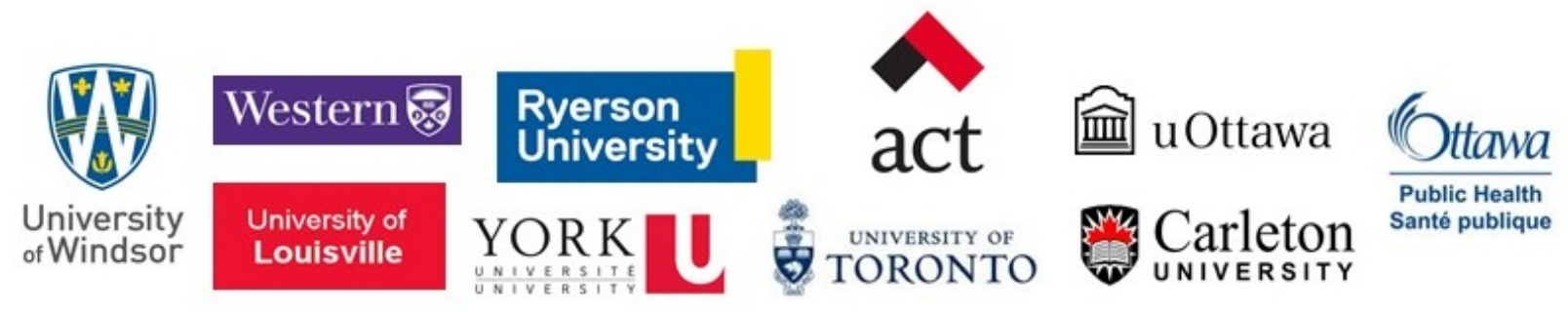

weSpeak: Straight Black Men Building Resilience to HIV in Ontario Project

Toronto Site - Participant Consent Agreement (Black Men Individual Interview)

You are being invited to participate in weSpeak, a research project funded by the Ontario HIV Treatment Network (OHTN) and Canadian Institute of Health Research (CIHR). Please read this consent form so that you understand what your participation will involve. Before you consent to participate, please ask any questions to be sure you fully understand what your voluntary participation will involve.

\section{INVESTIGATORS:}

weSpeak is carried out by a large team of researchers in Toronto, Ottawa, London and Windsor. All team members are listed on the last page of this consent form. The principal investigators of this study are:

- Dr. Josephine P. Wong (Associate Professor, Ryerson University)

- Dr. Winston Husbands (Director of Research, AIDS Committee of Toronto (ACT))

- Dr. Josephine Etowa (Professor, University of Ottawa)

- Dr. Isaac Luginaah (Professor, Western University)

- Dr. Francisca Omorodion (Associate Professor, University of Windsor)

Today's interview will be conducted by Kimberly Bryce, a weSpeak trainee and nursing student, who will use your sharing and stories (under the supervision of Dr. Wong) to develop her graduate thesis work in partial fulfillment of the requirements for a Master of Nursing degree from Ryerson University.

\section{PURPOSE OF THE STUDY:}

The goal of this research project is to reduce HIV vulnerabilities and promote resilience through active engagement of self-identified heterosexual African, Caribbean and Black (ACB) men in community HIV responses, programs, research, and policy. We will engage and mobilize self-identified straight (heterosexual) Black men who are: aged 16 and over; residing in the Greater Toronto Area, London, Ottawa, and Windsor; and HIV-positive or have never been diagnosed with HIV. We will also engage service providers, policy/decision-makers and other relevant stakeholders who work in or with Black communities to address HIV and other related issues that affect the health and wellbeing of straight Black men and communities. 


\section{TAKING PART IN THIS STUDY}

Taking part in this study is totally voluntary. You must self-identify as a straight Black man, aged 16 or over, and living in one of the four project cities - Toronto, Ottawa, London, or Windsor. If you choose to participate in today's interview, you will be asked to do the following:

- Complete a short demographic and health practices survey, which consists of a range of questions about you (e.g., your age, faith/religion, housing arrangement), your sexual practices (e.g., condom use) and your access to health information and services (e.g., whether you have a family doctor).

Take part in an individual interview and share your ideas about: what being a straight Black man means; intimacy and relationships; gender roles and cultural expectations, challenges and HIV vulnerabilities faced by Black men; and strategies used by Black men to overcome these challenges.

\section{FUTURE PARTICIPATION IN OTHER RESEARCH ACTIVITIES}

If you agree to take part in this study, you will also be asked if you wish to be contacted to take part voluntarily in the following activities at a later date:

- weSpeak Survey of Straight Black men: This survey takes approximately 35 minutes to complete; it will ask questions about masculine role identity, resilience, HIV knowledge and condom use.

- Concept Mapping Focus Group Sessions: This is a series of 4 focus group sessions during which you will work with other straight Black men to draw on the weSpeak study results to develop a best practices model for HIV prevention and resilience promotion for straight Black men and communities.

If you wish to take part in the survey and/or the concept mapping focus group sessions, you may fill out a separate contact information form at the end of this interview.

\section{VOLUNTARY PARTICIPATION}

Taking part in this research study is completely voluntary and you may refuse to participate, refuse to answer any questions or withdraw from the study at any time. Withdrawing from the study will not affect any services that you now receive or will receive from any of the weSpeak partnership agencies (see list of research team members on the last page). Should you choose to withdraw within 6 months of your participation, we will remove your individual research data from the study. However, after 6 months from your interview, we may only be able to remove data of your demographic and health practice survey, but not all the ideas you have shared in the interview if these ideas have been integrated into the analyzed and interpreted data of all the study interviews.

\section{CONFIDENTIALITY}

All information you provide during the research will be kept private. Your name will not appear in any report or publication of the research. We will use a study code on all the data we collect from you. The surveys and interview notes will be kept in a locked filing cabinet in a secured office. We will store the consent form and your contact information separate from research data. The audio-recorded interview will be downloaded onto a password- 
protected computer and be transcribed into written texts as a password protected document. Once the transcription is completed, we will store the audio files on passwordprotected computers. These computers will be stored in a locked filing cabinet in a secured office. Only the research team will have access to this office. All audio files questionnaires, interview transcripts and notes will be destroyed 5 years after the study has been completed as required by the funding agency.

The research team will keep what you share in the interview confidential, except in situations where we are required by law to release the information (e.g., if we hear information that a child has been or is being abused; if we hear that you may harm yourself, that is, there is reason to believe that you are at risk to commit suicide; if we hear that an individual who is HIV positive is having unprotected sexual relations without disclosing his status to his partner(s); or if we hear that someone has threatened your life or someone else's life, etc.).

\section{RISKS AND DISCOMFORTS}

This study is not expected to cause you or others any known harm. However, you may experience some unexpected emotion or discomfort during the interview. If you feel upset during the interview, and you wish to express your discomfort, please feel free to contact any member of the research team. You may also refer to the list of community resources that you received from the research team member. This list contains information on support services in the community that may be helpful to you.

\section{BENEFITS OF THE RESEARCH}

Although you may not have any direct benefit from taking part in this study, your ideas and sharing may help us develop effective programs and policy to improve HIV programs, services and policies for Black men and communities in Ontario.

\section{HONORARIUM}

You will receive a $\$ 30$ honorarium for taking part in this interview. You will keep this honorarium even if you decide to withdraw from the study at any point in time.

\section{RESEARCH REPORT}

You can access our research project results at the weSpeak website (www.we-speak.ca)

\section{QUESTIONS ABOUT THE RESEARCH}

If you have questions about the research in general or about your role in the study, please feel free to contact: Dr. Josephine Wong, Principal Investigator, Ryerson University, at 416979-5000 ext. 6303, or by E-mail: jph.wong@ryerson.ca;

This research has been reviewed by the Ryerson University's Research Ethics Board and conforms to the standards of the Canadian Tri-Council Research Ethics guidelines. If you have any questions about this process, or about your rights as a participant in the study please contact: Research Ethics Board, Ryerson University, at 416-979-5000 ext. 7112, or by E-mail: rebchair@ryerson.ca 
** You do not need to use your full name or real name in signing this consent

\section{RESEARCH TEAM MEMBER - CONFIRMATION}

I confirm that I have reviewed this consent form with the participant named above and I have answered all questions.

(Research team member's signature)

(Date)

(City)

\section{CONSENT TO PARTICIPATE}

I have read this consent form. I am satisfied with the answers to all my questions about this study. I agree to take part in this study. I have been given a copy of this consent form, and I fully understand my rights as a person taking part in this study.

$$
\text { (Participant's signature) }
$$

I agree be audio-recorded during the interview.

(Participant's signature)

(Date)

(City) 


\section{Appendix D: Focus Group Interview Guide}

weSpeak: Straight Black Men Building Resilience to HIV in Ontario

Focus Group Interview Guide (Black Men, HIV-, or HIV+)

Appendix 15B (For young men under aged 25) - weSpeak: Straight Black Men Building Resilience to HIV in Ontario

Focus Group Interview Guide Phase 1 (Black Men, HIV- or HIV+)

Pre-survey Focus Group Interview Guide

1. Introduction:

a. Welcome participants

b. Obtain informed consent

c. Review ground rules / guiding principles for group interaction (Appendix 8)

d. Facilitator posts the key topics to be discussed to guide the focus group processes

2. Explore participants' perspectives on HIV and heterosexual Black men:

a. Provide each participant with a sticky note/small piece of paper, and invite the participants to write down: "Three things that come to mind when you hear the topic HIV and straight (heterosexual) Black men." (Facilitator posts this pre-written statement on flip chart to enhance participation.) After a couple of minutes, invite participants to submit their responses into a basket and facilitator saves these responses to guide the discussion later on. Facilitator: "Thank you for all your responses. We will come back to this list in a few moments."

\section{Explore participants' perspectives on the connection between heterosexuality and} masculinity:

Facilitator: "As you are aware, this study focuses on reducing the risk of HIV and how to support young straight black men to bounce back when faced with challenges and difficulties. Before we go on to talk about that, we would like to hear more about your experience as young Black men.

a. What was it like growing up being a Black guy? [Probes: What were the cultural norms and expectations from family, at school, among peers and society? How is being a young black man different from other young men who are not black? How is being a young black man different from young black women? How do other Black men (young or older shape how you think and act as a young black man? Also probe how they resists these norms and expectations.)

b. What was it like growing up being straight? (Probes: What were the cultural expectations on how you act, how you interact with others - peers, other young men, other young women, adults? What about friendships and relationships - with buddies who are men and buddies who are women? Etc.) 
c. How do young black men show that they are masculine or manly? [Probes: What are the cultural norms and expectations? Also probe how they resist these norms and expectations. E.g., How do you feel about the ways you are expected to be manly or fulfill your role as a man that you are experiencing in your life right now? How would you like to change these roles and expectations?)

Note: Encourage participants to provide specific examples based on their own lived experiences or community stories. If participants could not think of examples of cultural norms or expectations, use the following statements to promote discussion by asking - "What is your response to the following statements?"

- Men are expected to provide for their families or girlfriends.

- If a Black man turns down sex from a woman, he must be gay.

- Real men have multiple sexual partners concurrently.

- NOTE: For FG with HIV+ Black men, ask an additional question - How does living with HIV affect your sense of identity as a straight Black men?

\section{Explore HIV vulnerabilities among heterosexual Black men:}

a. Facilitator: "Thank you for sharing your insights and stories about being straight Black men. Now, we would like to focus on HIV vulnerabilities. Before we invite you to share, we will share with you a definition of 'vulnerability' and perhaps it will help us with our discussion."

b. Co-facilitator posts definition: "Being vulnerable = being at more risk of harm, and having less capacity (ability and opportunity) to protect oneself from harm because of individual as well as societal conditions (e.g., peer pressure, racism, sexism, etc.)"

c. Facilitator reads out the posted definition and encourages participants to add their ideas to the written definition on vulnerability. Then, facilitator post the recorded list of participants responses on the "Three things that come to mind when you hear the topic HIV and heterosexual Black men" (taken at the beginning of the focus group) to guide the group discussion on the HIV vulnerabilities of heterosexual Black men by:

i. "Now let us look at what you have written at the beginning of the focus group and talk about these together."

ii. Depending on the age and development stage of participants, facilitator may or may not be able to engage participants in categorizing their responses in terms of individual (physical, mental and interpersonal) and societal (cultural, political, economic, etc.) conditions.

iii. If the participants' list fits with "HIV vulnerability", invite participants to elaborate on what they wrote and encourage them to give specific examples based on their own lived experiences or community stories from their peers. 
- "You have collectively identified many sources of vulnerabilities among Black men, I would now like to hear examples of how these vulnerabilities play out in your everyday life. What are some examples of these different sources of vulnerabilities?"

- "How do these sources of vulnerabilities affect different groups of Black men?" (Probes: young men, immigrants and refugees, older men, etc.)

iv. If the participants' list does not fit with HIV vulnerabilities, move on to discuss HIV vulnerabilities by saying: "You have listed some interesting things here. I now would like to hear from you about:

- What puts young black men at risk of getting HIV? (probes: how individual safer sex practices are tied to other conditions - e.g., cultural norms, expectations from sexual partners, peer pressures, etc.)

- What makes it difficult to talk about HIV among young Black men? (probes: stigmas (negative labels and stereotypes), negative experiences, myths about HIV, etc.)?

- What can we do to promote more open discussion about HIV among young Black men?

\section{Explore individual, group and collective resilience among heterosexual Black men:}

Facilitator: "We have discussed quite a bit on expectations and challenges that put young black men at more risk of HIV and other harms. We would like to take some time to hear your thought about resilience. In general resilience means the ability of individuals and communities to bounce back when they are faced with challenges or hard times. It can also mean people having supportive environments that enable them to get resources to meet all their needs."

- When you or your peers were faced with challenges and hard times, what supported you to bounce back? [Probe: strategies they use, support, personal and community resources, etc.]

\section{Explore participants' perspectives on existing social and structural barriers and pathways for heterosexual Black men to access culturally safe and coherent resources that address HIV vulnerabilities and promote resilience.}

a. What is needed to support young Black men to stay healthy, happy, and reduce their risks of getting HIV? [Probe: what is important to them; what is out there - their awareness of resources, what they want to see happen.]

b. What are the experiences of you and your peers (other young black men they know) in accessing HIV-related health and social services?

c. How can the existing programs /services be improved? What about policies?

7. Facilitators summarize focus group discussion, and invite participants to provide additional comments. 


\section{Appendix E: Individual Interview Guide A}

Appendix 16A - weSpeak: Straight Black Men Building Resilience to HIV in Ontario

Individual Interview Guide Phase 1(Black Men who have not attended any Phase 1 focus groups)

Individual Interview Guide (Black men: HIV-, or HIV+)

\section{Introduction:}
a. Welcome participants
b. Obtain informed consent

\section{I would like to explore your perspectives on HIV and heterosexual African, Caribbean and Black (ACB) men.}

(a) When you hear the topic - HIV and straight (heterosexual) Black men - what comes to your mind?

(b) Interviewer takes notes of what the participant has said and follow-up, and invite participant to say more: Please elaborate on each of the ideas you have just mentioned.

\section{Explore participant's perspectives on the connection between heterosexuality and masculinity:}

As you are aware, this study focuses on reducing the HIV vulnerabilities and promoting resilience among heterosexual Black men. Before we talk about HIV vulnerabilities, I would like to explore something that has not been explored much in research. I would like to hear your perspectives on:

(a) What does it mean to be straight (heterosexual)?

(b) What does it mean to be straight and a Black man?

\section{Probes:}

- How do you define being straight? (E.g., feelings of attraction, cultural norms, sexual and gender practices - sexual behaviours, sexual relationships, intimacy, etc.)

- How do you think Black men's understandings of heterosexuality (being straight) differ from other men, for example, White men or non-Black men in Ontario?

- Based on what you see or experience in the community, what are the different ways that Black men practice being straight (i.e., different Black men may define being straight differently and also interact differently with women and men in different contexts)?

(c) What does it mean to be manly (masculine)?

(d) What does it mean to be manly (masculine) and being a Black man? 
Probes: Encourage participant to provide specific examples based on their own lived experiences or community stories.

(e) How do the ways that Black men are expected to be manly or fulfill their role as a man affect you as an Black man:

- your sense of identity, social status (prestige or reputation) and wellbeing?

- your relationships with women (hetero-social/opposite-sex friendship, heterosocial/opposite-sex social intimacy, and hetero-sexual/opposite-sex sexual intimacy, etc.)?

- your relationships with other men (homo-social/same-sex friendship, homosocial/same-sex social intimacy, and homo-sexual/same-sex sexual intimacy, etc.)?

Probes: Encourage participant to provide specific examples based on their own lived experiences or community stories.

If participant cannot think or is hesitant in providing a personal example, invite him to respond to the following statement by saying: "In Canada society and in the community, we often hear many discourses about Black men's sexualities. I would like to hear your response to the following statements:

○ Black men can't turn down sex

○ Real Black men have multiple sex partners concurrently

Note: For interviews with HIV+ Black men, ask the following additional questions:

- How does living with HIV affect your sense of identity as a straight (heterosexual) Black men?

- How does living with HIV affect your sexual decision-making?

Probes: explore challenges and resilience

\section{Now, I would like to explore your ideas about HIV vulnerabilities among heterosexual Black men.}

(a) In general, vulnerability means being at increased risk of harm, and/or having a less capacity to protect oneself from harm because of biological (physical or related to the body), psychological (related to the mind or mentality), social, political, cultural, spiritual and environmental (built environment or physical surroundings) conditions.

(b) What comes to your mind when you hear the topic HIV and straight Black men?

(c) What contributes to HIV vulnerabilities among straight Black men?

(d) How do some of these factors affect you personally? (Explore participant's own perception of personal HIV vulnerabilities.) 
(e) How do Black men express their vulnerability or vulnerable feelings? What discourages Black men from openly addressing their vulnerability (e.g., stigma, negative experiences, etc.)?

(f) How do you address your vulnerable feelings? When and with whom would it be okay for you to talk about your vulnerability? How do men's interactions with each other facilitate (encourage or promote) or discourage openness about their vulnerability?

\section{Probes:}

- Invite participant to talk about HIV and straight Black in terms of biological (physical or related to the body), psychological (related to the mind or mentality), social, political, cultural, spiritual and environmental (built environment or physical surroundings) sources of vulnerability; and encourage him to provide specific examples based on his own lived experiences or community stories.

- Invite participant to share his own experience of HIV vulnerabilities and what supported him to be resilient; for example, peer pressure vs. peer support; stress and coping; power negotiation, etc.

- Explore with participant how his experience may differ from other straight Black men based on their different life contexts and lived experiences (e.g., age, citizenship and/or immigration/settlement experiences, connection to Black communities, etc.)

\section{Explore individual, group and collective resilience among heterosexual Black men:}

We have talked quite a bit on HIV vulnerabilities. I would like to hear your thoughts about individual and collective resilience among straight Black men. There is not one agreed definition on resilience. In general resilience has been defined as the ability of individuals and communities to bounce back when they are faced with challenges and adversities (challenges or hard times). Another definition of resilience focuses more on what supports people to be well: (a) Individuals know how to obtain resources that they need to be well; and (b) individuals' social environments (e.g., family, school, work, community, society) provide them with resources that meet their physical, social, economic, cultural, and spiritual needs."

(a) Based on these ideas on resilience, what do you think is needed to promote resilience among straight Black men particularly to reduce their HIV vulnerabilities and improve their health and well-being?

(b) What will promote your resilience?

\section{Probes:}

- Explore how the participant copes with adversity - what kind of strategies, narratives, networks, and resources does he draw on to address adversity?

- Also explore resilience in the contexts of family, social networks, Black communities, and society. 
6. Explore participants' perspectives on existing social and structural barriers and pathways for heterosexual Black men to access culturally safe and coherent resources that address HIV vulnerabilities and promote resilience.

a. What do you think are the HIV and health related priority needs of straight Black men?

b. What are your experiences in accessing HIV-related health and social services?

c. What can be done to improve HIV services and programming for straight Black men? What about policy or government responses towards HIV in the Black communities?

Probes:

- Explore the roles of both HIV and non-HIV services in addressing HIV vulnerabilities of heterosexual Black men;

- Explore the participant's awareness of existing services and resources

- Encourage participant's to express new and creative ideas

7. Interviewer summarizes the interview, and invite participants to provide additional comments. 


\section{Appendix F: Individual Interview Guide B}

Appendix 16B - weSpeak: Straight Black Men Building Resilience to HIV in Ontario

Individual Interview Guide Phase 1 (Black Men who have attended a Phase 1 focus group)

\section{weSpeak: Straight Black Men Building Resilience to HIV in Ontario}

\section{Individual Interview Guide (Black Men, have attended focus groups, HIV-or HIV+)}

The purpose of interviewing individuals who have attended a focus group in Phase 1 is to ask more in-depth questions (in the privacy of an individual interview). The interviewer will explore additional ideas and perspectives that the participant has on gender and sexual practices. Interviewer may draw on key themes derived from the focus group interviews to encourage in-depth discussion and sharing.

\section{Pre-survey Individual Interview Guide}

1. Introduction:
a. Welcome participant.
b. Obtain informed consent
c. Interviewer explains purpose of individual interview: Thank you for taking part in this individual interview. The purpose of this interview is to have the opportunity to speak with you more in depth about some of the issues that have been identified by you and other Black men in the focus group.

2. Explore participant's perspectives about the focus group discussion.
a. I would like to start by exploring your thoughts about our focus group discussion.
- What were the key themes and ideas that you remember most from the group discussion?
- What did you want to share but did not have a chance to share at the focus group?

Probes: Were there any topics or issues that you wished we had spent more time to talk about? [Follow-up with participant's identified issues and invite him to share his thoughts and perspectives.]

\section{Explore participant's perspectives on the connection between heterosexuality and masculinity}

a. In the focus group, we had a general discussion about what it means to be straight and an Black man. Now I would like to invite you to share your own lived experience of being a straight Black man.

- What does it mean to be a straight Black man in your everyday life?

- What are the messages you have received about being straight and being a Black man? How do these messages shape your sense of identity?

[Probes: feelings of attraction, cultural norms, sexual and gender practices - sexual behaviours, sexual relationships, intimacy, etc.; and messages about being straight - from family, peers, media, etc.] 
- What do you think are the positive aspects of your life related to being a straight Black man?

- What are the challenges you have faced for being a straight Black man?

- How do these positive aspects and challenges shape your sexual decision-making?

- NOTE: With participants who are HIV+, add questions: What has it been like for you being a straight Black man and living with HIV? How does your HIV+ status affect your sense of identity? How does it affect your sexual decision making?

\section{Explore HIV vulnerabilities among heterosexual Black men:}

a. In the focus group, we discussed how gender role expectations (the ways Black men are expected to be manly) and other cultural and social factors affect Black men's HIV vulnerabilities. I would like to invite you to share how these factors influence your HIV vulnerabilities.

- What are some of the gender expectations (ways you are expected to be a man) you have faced in your everyday life? [Probes: social, economic, cultural expectations from family, friends, co-workers, etc.]

- How do you address these gender expectations (ways you are expected to be a man)? [Probes: coping strategies that are helpful or harmful; peer support, spirituality, alcohol use, substance use, etc.]

- How do these gender expectations (ways you are expected to be a man) affect your sexual decision-making?

b. Who do talk with about your feelings of vulnerability? Who do you wish you could talk to? What would support you in sharing your feelings of vulnerabilities?

\section{Explore individual, group and collective resilience among heterosexual Black men:}

a. In the focus group, we explored the resilience of Black men and how they cope with adversity and challenges. I would like to hear your personal strategies in overcoming challenges in life. (Probes: Invite participant to think of the last time he was faced with a challenge in life, explore with him strategies he used at the personal, family, community levels)

b. What would promote the resilience of you and other straight Black men?

c. Based on your personal experience, what are that strengths and resilience resources of Black communities that you have drawn on to support you in overcoming adversities and challenges? What other resources would you like to see in Black communities?

6. Explore participant's perspectives on existing social and structural barriers and pathways for heterosexual Black men to access culturally safe and coherent resources that address HIV vulnerabilities and promote resilience.

a. As a straight Black man, what are your HIV and health related priority needs? 
b. What has been your experience in accessing HIV-related health and social resources?

[Probes: Explore extent of social inclusiveness associated with sexual orientation, cultures, languages, etc.]

c. What kind of policy, programs and services will reduce HIV vulnerabilities of straight Black men? (Encourage participant to share creative ideas)

7. Interviewer summarizes key ideas from the interview, and invite participant to provide additional comments. 
Appendix G: Tri-Council Policy Statement: Ethical Conduct for Research Involving Humans Course on Research Ethics (TCPS 2: CORE)

PANEL ON

RESEARCH ETHICS

TCPS 2: CORE

Navigating the ethics of human research

\section{Certificate of Completion}

This document certifies that

\section{Kimberly Bryce}

has completed the Tri-Council Policy Statement:

Ethical Conduct for Research Involving Humans

Course on Research Ethics (TCPS 2: CORE)

Date of Issue: 2 October, 2014 


\section{References}

African and Caribbean Council on HIV/AIDS in Ontario. (2010). Criminals and Victims? The impact of the criminalization of HIV non-disclosure on African, Caribbean and Black communities in Ontario. Retrieved from http://www.accho.ca/Portals/3/documents/ACCHO_Criminals_and_Victims_Nov2010_L oRes.pdf

African and Caribbean Council on HIV/AIDS in Ontario (2013). Ontario HIV strategy for African, Caribbean and Black communities 2013-2018. Retrieved from: http://www.accho.ca/portals/3/documents/Black_strategy_web_oct2013_en.pdf

African Canadian Legal Clinic. (2011). ACLC policy papers. Retrieved from:

http://www.aclc.net/wp-content/uploads/Policy-Papers-1-11-English-FINAL.pdf

African Canadian Legal Clinic (2013). African Canadian Legal Clinic: Promoting Justice, Defending Equality, Building community, 2013-2014 Annual report. Retrieved from http:/www.aclc.net/wp-content/uploads/Annual-Report-2013-for-2014-AGM-FINALrevised-Nov-6-2014.pdf

Agger, B. (2013). Critical Social Theories, third edition, New York: Oxford University Press.

Archer, L. (2002). 'It's easier that you're a girl and that you're Asian': Interactions of 'race' and gender between researchers and participants. Feminist Review, 72, 108-132. doi: http://www.jstor.org/stable/1395889

Baidoobonso, S., Bauer, G., Speechley, K., \& Lawson, E. (2013). HIV risk perception and distribution of HIV risk among African, Caribbean and other Black people in a Canadian city: mixed methods results from the BLACCH study, BMC Public Health, 
13, 184-201. doi: http://www.biomedcentral.com/1471-2458/13/184.

Bailey, P. (1996). Assuring quality in narrative analysis. Western Journal of Nursing Research, 18, 186-194. doi: 10.1177/019394599601800206

Banks, K., Kohn-Wood, L., \& Spencer, M. (2006). An examination of the African American experience of everyday discrimination and symptoms of psychological distress. Community Mental Health Journal, 42 (6), 555-570. doi: 10.1007/s10597-006-9052-9

Bazeley, P. (2010). Qualitative Data Analysis with NVivo. California; Thousand Oaks: Sage Publication Inc.

Bharmal, N., Tseng, C., Kaplan, R., \& Wong, M. (2012). State-level variation in racial disparities in life expectancy. Health Services Research, 47(1), 544-555. doi: 10.1111/j.1475-6773.2011.01345.x

Block, S., \& Galabuzi, G.E. (2011). Canada's colour coded labour market: The gap for racialized workers. Retrieved from http://www.wellesleyinstitute.com/wpcontent/uploads/2011/03/Colour_Coded_Labour_MarketFINAL.pdf

Block, S., Galabuzi, G.E., Weiss, A. (2014). The colour coded labour market by the numbers: A national household survey analysis. Retrieved from http://www.wellesleyinstitute.com/wp-content/uploads/2014/09/The-Colour-CodedLabour-Market-By-The-Numbers.pdf

Bond, L., Wheeler, D., Millet, G., LaPollo, A., Carson, L., \& Laiu, A. (2009). Black men who have sex with men and the association of down-low identity with HIV risk behavior. Research and Practice, 99, S92-S95. doi: 10.2105/AJPH.2007.127217 
Bowleg, L. (2004). Love, sex, and masculinity in sociocultural context: HIV concerns and condom use among African American men in heterosexual relationships. Men and Masculinities, 7(2), 166-186. doi: 10.1177/1097184X03257523

Bowleg, L., Burkholder, G. J., Massie, J. S., Wahome, R., Teti, M. Malebrache, D. J., \& Tschann, J. M. (2013). Racial discrimination, social support, and sexual HIV risk among Black heterosexual men. AIDS Behaviour, 17, 407-418. doi: 10.1007/s10461-012-0179-0

Bowleg, L. \& Raj, A. (2012). Shared communities, structural contexts, and HIV risks:

Prioritizing the HIV risk and prevention needs of Black heterosexual men. American Journal of Public Health, 102, s173-s177. doi: 10.2105/AJPH.2011.300342

Bowleg, L. Teti, M., Massie, J., Patel, A., Malebranche, D., \& Tschann, J. (2011). 'What does it take to be a man? What is a real man?': Ideologies of masculinity and HIV sexual risk among Black heterosexual men. Culture, Health \& Sexuality, 13, 545-559. doi: $10.1080 / 13691058.2011 .556201$

Braun, V. \& Clarke, V. (2006). Using thematic analysis in psychology. Qualitative Research in Psychology, 3 (2), 77-101. Retrieved from: http://dx.doi.org/10.1191/1478088706qp063oa

Brod, H. (1994). Some thoughts on some histories of some masculinities: Jews and other others. In H. Brod, \& M. Kaufman (Eds.), Theorizing masculinities: Research on men and masculinities (pp. 1-302). Thousand Oaks California: Sage Publications.

Browne, A. (2000). The potential contributions of critical social theory to nursing science. Canadian Journal of Nursing Research, 32, 35-55.

Brown, D. L., \& Segrist, D. (2016). African American career aspirations: Examining the relative 
influence of internalized racism. Journal of Career Development, 43(2), 177-189. doi: $10.1177 / 0894845315586256$

Brown L, Macintyre K, \& Trujillo L. (2003) Interventions to reduce HIV/AIDS stigma: What have we learned? AIDS Education and Prevention, 15, 49-69. Retrieved from: http://ezproxy.lib.ryerson.ca/login?url=https://search-proquestcom.ezproxy.lib.ryerson.ca/docview/198011581?accountid=13631

Caine, V., Estefan, A., \& Clandinin, D. (2013). A return to methodological commitment: Reflections on narrative inquiry. Scandinavian Journal of Educational Research, 57, 574-586. doi: http://dx.doi.org/10.1080/00313831.2013.798833.

Canadian HIV/AIDS Black, African and Caribbean Network. (2016). African, Caribbean \& Black Canadian HIV/AIDS Awareness Day. Retrieved from: http://www.blackhivday.ca/awareness_day_fact_sheet_2017_EN_final.pdf

Canadian HIV/AIDS Legal Network (2012). Criminalization of HIV nondisclosure: current Canadian Law. Retrieved from: http://www.aidslaw.ca/site/wp content/uploads/2014/09/CriminalInfo2014_ENG.pdf

Carrigan, T., Connell, B., \& Lee, J. (1987). Towards a new sociology of masculinity. In H. Brod (Ed.), The making of masculinities: The new men's studies. MA: Allen \& Unwin Inc. Cazenave, N. A. (1984). Race, socioeconomic status, and age: The social context of American masculinity. Sex Roles, 11, 639-656. doi: 10.1007/BF00288117

Chaney, C. (2009). Boys to men: How perceptions of manhood influence the romantic partnerships of black men. Western Journal of Black Studies, 33 (2), 110-122. Retrieved 
from: http://ezproxy.lib.ryerson.ca/login?url=https://search-proquest-

com.ezproxy.lib.ryerson.ca/docview/200320401?accountid=13631

Chen, A. S. (1999). Lives at the center of the periphery, lives at the periphery of the center: Chinese American masculinities and bargaining with hegemony. Gender \& Society, 13 (5), 584-607. doi: 10.1177/089124399013005002

Civic, D. (1999). The association between characteristics of dating relationships and condom use among heterosexual young adults. AIDS Education and Prevention, 11 (4), 343-352. Retrieved from: http://ezproxy.lib.ryerson.ca/login?url=https://search-proquestcom.ezproxy.lib.ryerson.ca/docview/198000833?accountid=13631

Clandinin, D. and Caine, V. (2008). Narrative Inquiry. In Lisa M. Given (Ed.), The Sage Encyclopedia of Qualitative Research Methods. (pp.542-545). Thousand Oaks, CA: SAGE Publications, Inc. doi: http://dx.doi.org/10.4135/9781412963909.n275

Clarke, R., Anderson, N., Clark, V., \& Williams. D (1999). Racism as a stressor for African Americans: A biopsychosocial model. American Psychologist, 54 (10), 805-816. doi: 10.1037/0003-066X.54.10.805

Cokley, K. O. (2005). Racial(ized) identity, ethnic identity, Afrocentric values: conceptual and methodological challenges in understanding African American identity. Journal of Counseling Psychology, 52 (4), 517-526. doi: 10.1037/0022-0167.52.4.517

Coles, T. (2008). Finding space in the field of masculinity: Lived experiences of men's masculinities. Journal of Sociology, 44 (3), 233-248. doi:10.1177/1440783308092882 
Colpitts, I. (2017, July 28). Suspects sought: Peel police seeking suspects in gas station robbery. Mississauga News. Retrieved from https://www.mississauga.com/news-story/7477149suspects-sought-peel-police-seeking-suspects-in-gas-station-robbery/

Connell, R. W. (1995). Masculinities. Los Angeles; California: University of California Press. Connell, R. W. (2014). The study of masculinities. Qualitative Research Journal, 14 (1), 5-15. doi: 10.1108/QRJ-03-2014-0006

Connell, R., \& Messerschmidt, J. (2005). Hegemonic masculinity: Rethinking the concept. Gender and Society, 19(6), 829-859. doi: 10.1177/0891243205278639

Connelly, F. M., \& Clandinin, D. J. (1999). Shaping a professional identity: Stories of educational practice. New York: Teachers College Press.

Cooper, F. R. (2005). Against bipolar black masculinity: Intersectionality, assimilation, identity performance, and hierarchy. UC Davis Law Review, 39, 853 - 906. Retrieved from https://ssrn.com/abstract=1003000

Corlett, S. and Mavin, S. (2014). Intersectionality, identity and identity work: Shared tenets and future research agendas for gender and identity studies. Gender Management: An International Journal, 29 (5), 258-276. doi: 10.1108/GM.12.2013.0138

Crenshaw, K. (1989). Demarginalizing the Intersection of Race and Sex: A Black Feminist Critique of Antidiscrimination Doctrine, Feminist Theory and Antiracist Politics. University of Chicago Legal Forum, 139-67. Retrieved from http://chicagounbound.uchicago.edu/cgi/viewcontent.cgi?article=1052\&context=uclf Crenshaw, K. (1991). Mapping the margins: Intersectionality, identity politics, and violence against women of color. Stanford Law Review, 43 (6), 1241-1299. doi: 10.2307/1229039 
Creswell, J. (2013). Qualitative inquiry \& research design: Choosing among five approaches $\left(3^{\text {rd }}\right.$ edition.). Thousand Oaks, California: Sage Publications.

Davis, O. I. (2011). (Re)framing health literacy: Transforming the culture of health in the black barbershop. Western Journal of Black Studies, 35 (3), 176-187. Retrieved from: http://ezproxy.lib.ryerson.ca/login?url=https://search-proquestcom.ezproxy.lib.ryerson.ca/docview/1018080494?accountid=13631

Delgado, R., \& Stefanocic, J. (2012). Critical Race Theory: An Introduction. New York: New York University Press.

DiManno, Rosie. (6 April, 2009). HIV-positive man killed with hatred. The Toronto Star. Retrieved from: http://www.thestar.com/opinion/columnists/2009/04/06/hivpositive_man_killed_with_hat red.html

Dines, G. (1998). King Kong and the White woman: Hustler magazine and the demonization of Black masculinity. Violence Against Women, 4, 291-307. doi: $10.1177 / 1077801298004003003$

Dorsen, C. (2010). Vulnerability in homeless adolescents: concept analysis. Journal of Advanced Nursing, 66 (12), 2819-2827. doi: 10.1111/j.1365-2648.2010.05375.x

Dwyer, S. C. and Buckle, J. L. (2009). The space between: On being an insider-outsider in qualitative research. International Journal of Qualitative Methods, 8 (1). Retrieved from http://citeseerx.ist.psu.edu/viewdoc/download?doi=10.1.1.596.4039\&rep=rep1\&type=pdf Earvolino-Ramirez, M. (2007). Resilience: A concept analysis. Nursing Forum, 42 (2), 73-82. doi: $10.1111 / \mathrm{j} .1744-6198.2007 .00070 . \mathrm{x}$ 
Everitt-Penhale, B. \& Ratele, K. (2015). Rethinking 'traditional masculinity' as constructed, multiple, and hegemonic masculinity. South African Review of Sociology, 46 (2), 4-22. doi: $10.1080 / 21528586.2015 .1025826$

Falicov, C. J. (2010). Changing constructions for machismo for Latino men in therapy: "The Devil Never Sleeps." Family Process, 29 (3), 309-329. doi: 10.1111/j.15455300.2010.01325.x

Feagin, J. R. (2001). Racist America: Roots, current realities and future reparations. New York: Routledge.

Feldstein Ewing, S. \& Bryan, A. D. (2015). "A question of love and trust? The role of relationship factors in adolescent sexual decision-making". Journal of Developmental and Behavioral Pediatrics, 36 (8), 628-634. doi: 10.1097/DBP.0000000000000190.

Ferber, A. (2007). The construction of black masculinity: White supremacy now and then. Journal of Sport \& Social Issues, 31 (1), 11-24. doi: 10.1177/0193723506296829

Fleming, P. J., Lee, J. G. L., Dworkin, S. (2014). "Real Men Don't": Constructions of masculinity and inadvertent harm in public health interventions. American Journal of Public Health, 104, 1029-1035. doi: 10.2105/AJPH.2013.301820

Ford, K. A. (2011). Doing fake masculinity, being real men: Present and future constructions of self among black college men. Symbolic Interaction, 34 (1), 38-62. doi: 10.1525/si.2011.34.1.38.

Garner, S. (2006). The uses of whiteness: What sociologist working on Europe can draw from US research on whiteness. Sociology, 42 (2), 257-275, doi: 10.1177/0038038506062032 Gilbert, K. L. \& Ray, R. (2015). Why police kill Black males with Impunity: Applying public 
health critical race praxis (PHCRP) to address the determinants of policing behaviors and justifiable homicides in the USA. Journal of Urban Health: Bulletin of the New York Academy of Medicine, 93 (1), s122-s140. doi:10.1007/s11524-015-0005-x

Gordon, A. (2017). Black students hindered by academic streaming, suspensions: Report. Toronto Star. https://www.thestar.com/yourtoronto/education/2017/04/24/black-studentshindered-by-academic-streaming-suspensions-report. html

Gould, W. T. (2005). Vulnerability and HIV/AIDS in Africa: From demography to development. Population, Space and Place, 11, 473-484. doi: 10.1002/psp.395

Government of Canada. (2014). A case study of diversity in corrections: The Black inmate experience in federal penitentiaries final report. Retrieved from http://www.ocibec.gc.ca/cnt/rpt/oth-aut/oth-aut20131126-eng.aspx

Graham, L., Brown-Jeffy, S., Aronson, R., \& Stephens, C. (2011). Critical race theory as theoretical framework and analysis tool for population health research. Critical Public Health, 21 (1), 81-93. doi: 10.1080/09581596.2010.493173

Gray, E., Bailey, R., Brady, J., \& Tecle, S. (2016). Perspectives of Black Male Students in Secondary School Understanding the Successes and Challenges - Student Focus Group Results. Mississauga, ON: Peel District School Board. Retrieved from http://www.peelschools.org/Documents/We\%20Rise\%20Together\%20Action\%20Plan\% 20FINAL.pdf

Grewal, S. (2015, September 24). Black three times more likely to be carded by police than Whites. Toronto Star. Retrieved from 
https://www.thestar.com/news/gta/2015/09/24/blacks-three-times-more-likely-to-becarded-by-peel-police-than-whites.html

Griffiths, D. M., Gunter, K., \& Watkins, D. C. (2012). Measuring masculinity in research on men of color: Findings and future directions. American Journal of Public Health, 102, s187s194. doi: 10.2105/AJPH.2012.300715

Halpern, C. T., Hallfors, D., Bauer, D., Iritani, B, Waller, M. W., \& Cho, H. (2004). Implications of racial and gender differences in patterns of adolescent risk behaviour for HIV and other sexually transmitted diseases. Perspectives on Sexual and Reproductive Health, 36, 239-247. doi: 10.1111/j.1931-2393.2004.tb00028.x

Hammond, W. (2012). Taking it like a man: Masculine role norms as moderators of the racial discrimination-depressive symptoms association among African American men. American Journal of Public Health, 102(S2), S323-S241. doi: 10.2105/AJPH.2011.300485

Haney-Lopez, I. F. (1994). The Social Construction of Race: Some Observations on Illusion, Fabrication, and Choice. Berkeley Law. Retrieved from http://scholarship.law.berkeley.edu/facpubs/1815

Harrington, A. (2005). Modern social theory: An introduction. Oxford; New York: Oxford University Press

Harris, F., Palmer, R. T., \& Struve, L. E. (2011). "Cool posing" on campus: A qualitative study of Masculinities and gender expression among Black men at a private research institute. The Journal of Negro Education, 80 (1), 47-62. Retrieved from: http://www.jstor.org/stable/41341105 
Haynes, F. E. (2000). Gender and family ideals: An exploratory study of black middle-class Americans. Journal of Family Health Issues, 21 (7), 811-837. Retrieved from: https://doiorg.ezproxy.lib.ryerson.ca/10.1177/019251300021007001

Hill, M. (2016, March 5). African leaders gather to discuss New Zealand police racism claims. Aukland Now. Retrieved from http://www.stuff.co.nz/auckland/77582387/african-leadersgather-to-discuss-new-zealand-police-racism-claims

hooks, b. (2004). We real cool: Black men and masculinity. New York: Routledge.

Hunting, G. (2014). Intersectionality-informed Qualitative Research: A Primer. Institute of Intersectionality Research and Policy. Retrieved from https://www.sfu.ca/iirp/documents/resources/QuantPrimer_Final_v4.pdf

Husbands, W., Oakes, W., Ongoiba, F., Pierre-Pierre, V., Soje, P., McGee, F., Mbulaheni, T. (2013). Talking Black: Understanding the HIV-related needs, challenges and priorities of heterosexual Africans, Caribbean and Black men in Ontario Canada. Retrieved from: http://www.accho.ca/Portals/3/documents/resources/Talking_Black_Oct2013.pdf Interagency Coalition on AIDS Development, African and Caribbean Council on HIV/AIDS in Ontario (ACCHO), Women's Health in Women's Hands Community Health Centre. (2011). Towards the Improvement of HIV Prevention on Services for African, Caribbean and Black Communities in Canada: A Gap Analysis. Retrieved from: http://icadcisd.com/pdf/CHABAC/BackgroundReports/Gap-Analysis-EN-FINAL.pdf

James, C. E. (2012). Students "at risk": Stereotypes and the schooling of Black boys. Urban Education, 47 (2), 464-494. doi: 10.1177/0042085911429084

James, C.E. \& Turner, T. (2017). Towards Race Equity In Education: The Schooling of Black 
Students in the Greater Toronto Area. Toronto, Ontario, Canada: York University. Retrieved from http://edu.yorku.ca/files/2017/04/Towards-Race-Equity-in-EducationApril-2017.pdf

Kerr, J. C., Valois, R. F., Diclemente, R. J., Fletcher, F., Carey, M. P., Romer, D., Vanable, P. A., Farber, N. (2014). HIV-related stigma among African-American youth in the northeast and southeast US. AIDS Behavior, 18, 1063-1067. doi: 10.1007/s10461-013$0687-6$

Khanlou, M. \& Wray, R. (2014). AWhole Community Approach toward Child and Youth Resilience Promotion: A Review of Resilience Literature. International Journal of Mental Health Addiction, 12, 64-79. doi: 10.1007/s11469-013-9470-1

Khenti, A. A. (2013). Homicide among young black men in Toronto: An unrecognized public health crisis? Canadian Journal of Public Health, 104(1), e12. Retrieved from: http://ezproxy.lib.ryerson.ca/login?url=https://search-proquestcom.ezproxy.lib.ryerson.ca/docview/1323981754?accountid=13631

Klein Hattori, M., Ritcher, K., \& Greene, J. (2010). Trust, caution, and condom use with regular partners: An evaluation of the trusted partner campaign targeting youth in four countries. Social Marketing Quarterly, 16 (2), 18-48. doi: http://dx.doi.org/10.1080/15245001003746774

King, N. \& Horrocks, C. (2010). Interviews in Qualitative Research. London; Sage Publications. Kinser, A. (2004). Negotiating space for/through third wave feminism. NWSA Journal, 16 (3), 124-153. Retrieved from https://muse-jhu-edu.ezproxy.lib.ryerson.ca/article/175042 
Kwate, N. \& Goodman, M. (2015). Cross-sectional and longitudinal effects of racism on mental health among residents of Black neighbourhoods in New York City. American Journal of Public Health, 105(4), 711-718. doi: 10.2105/AJPH.2014.302243

Kwate, N. \& Goodman, M. (2015). Racisms at the intersections: Gender and socioeconomic differences in the experience of racism among African Americans. American Journal of Orthopsychiatry, 85(5), 397-408. doi: 10.1037/ort0000086

Lawson, E., Gardezi, F., Calzavara, L., Husbands, W., Myers, T., \& Tharao, W. (2006). HIV/AIDS stigma, denial, fear and discrimination: Experiences and responses of people from African and Caribbean communities in Toronto. Retrieved from: http://www.accho.ca/pdf/hiv_stigma_report.pdf

Levant, R. F., Hirsch, L. S., Celentano, E., Cozza, T. M., Hill, S., MacEachern, M., Marty, N., \& Schnedeker, J. et al. (1992). The male role: An investigation of contemporary norms and stereotypes. Journal of Mental Health Counseling, 14, 325-337.

Levant, R. F., Richmond, K., Majors, R. G., Inclan, J. E., Rossello, J., M., Heesacker, M., Rowan, G. T., \& Sellers, A. (2003). A multicultural investigation of masculinity ideology and alexithymia. Psychology of Men and Masculinity, 4(2), 91-99. doi:10.1037/15249220.4.2.91

Li, A. \& Wong, J. (2016). CHAMP: Mobilizing people living with HIV and allies to champion HIV prevention and care in ethno-racial communities. Retrieved from: http://www.catie.ca/en/pif/fall-2016/champ-mobilizing-people-living-hiv-and-allieschampion-hiv-prevention-and-care-ethno-r\#team 
Liang, C., Salcedo, J., \& Miller, H. (2011). Perceived racism, masculine ideologies, and gender role conflict among Latino men. Psychology of Men \& Masculinity, 12(3), 201-215. doi: http://dx.doi.org.ezproxy.lib.ryerson.ca/10.1037/t02889-000

Lindsey, M. A., \& Marcell, A. V., (2012). "We're Going Through a Lot of Struggles That People Don't Even Know About": The need to understand African American males' helpseeking for mental health on multiple levels. American Journal of Men's Health, 6, 354364. doi: $10.1177 / 1557988312441520$

Lindsay, M, \& McQuaid, R. W. (2004). Avoiding the 'Mcjobs': Unemployed job seekers and attitudes to service work. Work Employment and Society, 18(2), 297-319. doi: $10.1177 / 09500172004042771$

Lu, A., \& Wong, Y. (2013). Stressful experiences of masculinity among U.S.-born and immigrant Asian American Men. Gender \& Society, 27(3), 345-371. doi: $10.1177 / 0891243213479446$

Luthar, S. S. (1996). Resilience: A construct of value. Paper presented at the 104th Annual Convention of the American Psychological Association, August 1996, Toronto, Ontario.

Lutz, H., Vivan, M. T. H., \& Supik, L. (2011). Framing intersectionality: Debates on a multifaceted concept in gender studies. England: Ashgate Publishing Limited.

Mankowski, E. S. \& Maton, K. I. (2010). A community psychology of men and masculinity: Historical and conceptual review. American Journal of Community Psychology, 45, 7386. doi: 10.1007/s10464-009-9288-y

Manyena, S. B. (2006). The concept of resilience revisited. Disasters, 30 (4), 433-450. doi: 10.1111/j.0361-3666.2006.00331.x 
Merriam-Webster (2017), Resilience, Retrieved form: https://www.merriamwebster.com/dictionary/resilience

McCall, L. (2005). The complexity of intersectionality. Journal of Women in Culture and Society, 30 (3), 1771-1800. Retrieved from: http://www.jstor.org/stable/10.1086/426800.

McIntyre, C. (2016, April 21). Canada Has a Black Incarceration Problem. Torontoist. Retrieved from https://torontoist.com/2016/04/african-canadian-prison-population/

Mikkonen, J., \& Raphael, D. (2010). Social determinants of health: The Canadian facts. Retrieved from: http://www.thecanadianfacts.org/

Milner, A. N., George, B. J., \& Allison, D. B. (2016). Black and hispanic men perceived to be large are at increased risk for police frisk, search, and force. PLoS One, 11 (1), 1-13. doi:10.1371/journal.pone. 0147158

Mykhalovskiy, E. (2011). The problem of "significant risk": Exploring the public health impact of criminalizing HIV non-disclosure. Social Science \& Medicine, 73(5), 668-675. doi: 11.1016/j.socscimed.2011.06.051

Mykhalovskiy, E., Hastings, C., Sanders, C., Hayman, M., \& Basaillon, L. (2016). Callous, cold and deliberately duplicitous: Racialization, immigration and the representation of HIV criminalization in Canadian mainstream newspapers. Retrieved from: http://www.publicimpactpr.com/images/clients/can/callous_cold_report_final.pdf

Nash, J. C. (2008). Re-thinking intersectionality. Feminist Review, 89, 1-15. Retrieved from https://www.sfu.ca/iirp/documents/Nash\%202008.pdf 
Nixon, D. (2009). 'I can’t put a smiley face on': Working class masculinity, emotional labor and service work in the 'new economy'. Gender, Work and Organization, 16 (3), 300-322. doi: $10.1111 / \mathrm{j} .1468-0432.2009 .00446 . x$

Nonn, T. (1995). Hitting bottom: homelessness, poverty and masculinities. Theology and Sexualities, 3(1), 11-26. doi: 10.1177/135583589500300102

Ontario Advisory Committee on HIV/AIDS. (2016). Focusing our efforts: Changing the course of the HIV prevention, engagement and care cascade in Ontario, HIV/AIDS strategy to 2026. Retrieved from:

http://www.health.gov.on.ca/en/pro/programs/hivaids/docs/oach_strategy_2026.pdf

Palinkas, L., Horwitz, S., Green, C., Wisdom, J., Duan, N., \& Hoagwood, K. (2015). Purposeful sampling for qualitative data collection and analysis in mixed method implementation research. Administration of Policy of Mental Health, 42 (5), 533-544, doi: 10.1007/s10488-013-0528-y

Patterson, A., \& Veenstra, G. (2016). Black-White health inequalities in Canada at the intersection of health and immigration. Canadian Journal of Public Health, 107(3), e278e284. doi: 10.17269/CJPH.107.5336

Patton, M.Q. (2002). Qualitative research and evaluation methods. 3rd ed. Thousand Oaks, CA: Sage.

Pierre, M. R., Mahalik, J. R., \& Wooldland, M. H. (2001). The effects of racism, African selfconsciousness and psychological functioning on Black masculinity: A historical and social adaptation framework. Journal of African American Men, 6(2) 1-21. doi: $10.1007 / \mathrm{s} 12111-001-1006-2$ 
Pieterse, A. L., \& Carter, R. T. (2007). An examination of the relationship between general life stress, racism-related stress, and psychological health among Black men. Journal of Counselling Psychology, 54 (1), 101-109. doi: 10.1037/0022-0167.54.1.101

Pleck, J., Sonenstein, F., \& Ku, C. (1993). Masculinity ideology: Its impact on adolescent males' heterosexual relationship. Journal of Social Issues, 49 (3), 11-29. doi: 10.1111/j.15404560.1993.tb01166.x

Public Health Agency of Canada. (2009). Population-Specific HIV-AIDS Status report: People from countries where HIV is endemic - Black people of African and Caribbean descent living in Canada. Retrieved from: http://www.phac-aspc.gc.ca/aids-sida/publication/pspd/africacaribbe/ch3-eng.php

Public Health Agency of Canada. (2011). HIV/AIDS epi updates - July 2010. Retrieved from: http://www.phac-aspc.gc.ca/aids-sida/publication/epi/2010/4-eng.php

Public Health Agency of Canada. (2012). HIV/AIDS Epi Updates - April 2012. Retrieved from: http://www.phac-aspc.gc.ca/aids-sida/publication/epi/2010/chap13-eng.php

Public Health Agency of Canada. (2014). HIV/AIDS epi updates - October 2014. Retrieved from: http://www.phac-aspc.gc.ca/aids-sida/publication/epi/2010/1-eng.php

Public Health Agency of Canada. (2015). HIV/AIDS epi updates - April 2012. Retrieved from: http://www.phac-aspc.gc.ca/aids-sida/publication/epi/2010/chap13-eng.php

Purdy, I. B. (2004). Vulnerable: A concept analysis. Nursing Forum, 39 (4), 25-33. doi: 10.1111/j.1744-6198.2004.tb00011.x

Raj, A., Dasgupta, A., Goldson, I., Lafontant, G., Freeman, E., \& Silverman, J. (2013). Pilot evaluation of the Making Employment Needs [MEN] Count intervention: Addressing 
behavioral and structural HIV risks in heterosexual Black men. AIDS Care, 26(2), 155159. doi: $10.1080 / 09540121.2013 .804901$

Reed, E., Santana, M. C., Bowleg, L., Welles, S. L., Horsburgh, C. R., Raj, A. (2012).

Experiences of racial discrimination and relation to sexual risk for HIV among a sample of urban Black and African American men. Journal of Urban Health, 90 (2), 314-322. doi: $10.1007 / \mathrm{s} 11524-012-9690-\mathrm{x}$

Remis, R. \& Liu, J. (2013). Report on HIV/AIDS in Ontario 2011. Ontario HIV Epidemiologic Monitoring Unit. Retrieved from: http://www.ohemu.utoronto.ca/doc/PHERO2011_report_preliminary.pdf

Remis, R., Swantee, C., Liu, J. (2012). Report on HIV/AIDS in Ontario 2009. Ontario HIV Epidemiologic Monitoring Unit. Retrieved from: http://www.ohemu.utoronto.ca/doc/2011/PHERO2009_report_preliminary.pdf

Richardson, L. (1997). Fields of play: Constructing an academic life. New Jersey: Rutgers University Press.

Richardson, J. \& St. Vil, C. (2015). Putting in work: Black male youth joblessness, violence, crime and the code of the street. Spectrum: A Journal on Black Men, 3 (2), 71-98. Retrieved from: http://www.jstor.org/stable/10.2979/spectrum.3.2.71

Riessman, C. K. (2002) Analysis of Personal Narratives. In Jabar F. Gubrium and James A. Holstein (Eds.), Handbook of Interview Research: Context and Method. (pp.695-710). Thousand Oaks, California: Sage Publications.

Roberts, S. (2012). Boys will be boys....won't they? Change and continuities in contemporary young working-class masculinities. Sociology, 47 (4), 671-686. doi: 


\section{$10.1177 / 0038038512453791$}

Rogers, A. C. (1997). Vulnerability, health and health care. Journal of Advanced Nursing, 26, 65-72. doi: 10.1046/j.1365-2648.1997.1997026065.x

Rose, M.H. \& Killen, M. (1983). Risk and vulnerability: A case for differentiation. Advances in Nursing Sciences, 5 (3), 60-73.

Rutter, M. (1985). Resilience in the face of adversity: Protective factors and resistance to psychiatric disorders. British Journal of Psychiatry, 147, 598-611. doi: $10.1192 / b j p .147 .6 .598$

Savin-Baden, M. \& Van Niekerk, L. (2007). Narrative inquiry: Theory and practice. Journal of Geography in Higher Education, 31, 459-472. doi: 10.1080/03098260601071324.

Shek, Y. L. (2006). Asian American masculinity: A review of the literature. Journal of Men's Studies, 14 (3), 379-391.

Shields, S. (2008). Gender: An intersectional perspective. Sex Roles, 59, 301-311. doi: $10: 1007 / \mathrm{s} 111199-008-9501-8$

Squire, C. (2008). Experience-centered and culturally-oriented approaches to narrative. In M. Andrews, C. Squire, \& M. Tamboukou (Eds.), Doing narrative research (pp.1-33), doi: http://dx.doi.org/10.4135/9780857024992

Statistics Canada (2012). Life expectancy, at birth and at age 65, by sex and by province and territory. Retrieved from: http://www.statcan.gc.ca/tables-tableaux/sumsom/101/cst01/health72a-eng.htm

Statistic Canada. (2015). Employment and unemployment rates of the second-and the third-andhigher-generation Canadians aged 25-54, May 2006 (Data file). 
Stewart, E. A., Schreck, C. J., \& Simons, R. L. (2006). "I ain't gonna let no one disrespect me" does the code of the street reduce or increase violent victimization among African American adolescents? Journal of Research in Crime and Delinquency, 43 (3), 427-458. doi: $10.1177 / 0022427806292338$

Stewart, E.A. \& Simons, R. L. (2010). Race, code of the street, and violent delinquency: A multilevel investigation of neighbourhood street culture and individual norms of violence. Criminology, 48 (2), 569-605. doi: 10.1111/j.1745-9125.2010.00196.x

Stewart, D. W., Shamdasani, P. N., \& Rook, D. W. (2007). Focus groups: Theory and practice. Sage Publications: California. doi: http://dx.doi.org.ezproxy.lib.ryerson.ca/10.4135/9781412991841

Streubert, H. J. \& Carpenter, D. R. (2011). Qualitative research in nursing: Advancing the humanistic imperative. Philadelphia: Lippincott, Williams \& Wilkins.

Swenson, R. R., Rizzo, C. J., Brown, L. K., Vanable, P. A., Carey, M. P., Valois, R. F., DiClemente, R. J., \& Romer, D. (2010). HIV knowledge and its contribution to sexual health behaviors of low-income African American adolescents. Journal of the National Medical Association, 102 (12), 1173-1182.

Thompson, E. H. \& Pleck, J. H. (1986). The structure of male role norms. American Behavioral Scientist, 29(5), 531-543. doi: 10.1177/000276486029005003

Toronto Public Health (2013). Health inequities and racialized groups: A review of the evidence. Retrieved from: http://www1.toronto.ca/City\%20Of\%20Toronto/Toronto\%20Public\%20Health/Healthy\% 
20Public\%20Policy/PDF\%20Reports\%20Repository/Health\%20Inequalities\%20and\%20 Racialized\%20Groups\%20A\%20Review\%20of\%20the\%20Ev_2.pdf

Torres, J. B., Soleberg, V. S. H., \& Carlstrom, A. H. (2002). The myth of sameness among Latino men and their machismo. American Journal of Orthopsychiatry, 72, 163-181. doi: $10.1037 / 0002-9432.72 .2 .163$

Tyler, K. M., Thompson, F. A., Gay, D. E., Burris, J., Lloyd, H., \& Fisher, S. (2016). Internalized stereotypes and academic self-handicapping among Black American male high school students. Negro Educational Review, 67(1-4), 5. Retrieved from: http://ezproxy.lib.ryerson.ca/login?url=https://search-proquestcom.ezproxy.lib.ryerson.ca/docview/1926455544?accountid=13631

Veenstra, G, \& Patterson, A. C. (2015). Health differences between native-born Black and White Canadians: Revisiting Lebrun and LaVeist (2011, 2013). Canadian Ethnic Studies, 47(3), 163-176. doi: 10.1353/ces.2015.0027.

Vijaya, R. M., Esheleman, A., Halley, J. (2015). The culture of class and its economic impact. Review of Black Political Economy, 42, 7-18, doi: 10.1007/s12114-014-9176-z

Wade, J. C. (1995). Gender role perceptions and gender role conflicts of middle-class African American men. Journal of African American Men, 1, 103-120. doi: 10.1007/BF02692078

Wade, J. C. (1996). African American men's gender role conflict: The significance of racial identity. Sex Roles, 34 (1/2), 17-33. doi: 10.1007/BF01544793

Wade, J. C., \& Rochlen, A. B. (2013). Introduction: Masculinity, identity, and the health and well-being of African American men. Psychology of Men \& Masculinity, 14(1) 1-6. doi: $10.1037 / \mathrm{a} 0029612$ 
Watkins, D. C., \& Neighbors, H. W. (2007). An initial exploration of what 'mental health' means to young Black men. Journal of Men's Health and Gender, 4, 271-282. Retrieved from http://journals1.scholarsportal.info/pdf/15718913/v04i0003/271_aieowhmtybm.xml

Western, B., Kleykamp, M, \& Rosenfeld, J. (2006). Did falling wages and employment increase U.S. imprisonment? Social Forces, 84 (4), 2291-2311, doi: 10.1353/sof.2006.0114

Whitehead, T. (1997). Urban low-income African American men, HIV/AIDS, and gender identity. Medical Anthropology Quarterly 11 (4), 411-447. doi: http://www.jstor.org/stable/649531

Wiebold, L., \& Spiller, M. (2017). Explaining mainstream success: Accounts from black men "in the middle.” Journal of Black Studies, 48 (1), 3-25. doi: 10.1177/0021934716658863

Williams, D. R. \& Mohammed, S. A. (2013). Racism and health I: Pathways and scientific evidence. American Behavioral Scientist, 57(8), 1152-1173. doi: $10.1177 / 0002764213487340$

Williams, D. R. \& Mohammed, S. A. (2013). Racism and health I: Pathways and scientific evidence. American Behavioral Scientist, 57(8), 1152-1173. doi:

$10.1177 / 0002764213487340$

Wilson, C. (2013). The impact of the criminalization of HIV non-disclosure on the health and human rights of "Black" communities. Health Tomorrow: Interdisciplinarity and Internationality, 1 . Retrieved from http://ht.journals.yorku.ca/index.php/ht/article/view/37275/33847

Wolfe, W. A. (2003). Overlooked role of African-American males' hypermasculinity in the epidemic of unintended pregnancies and HIV/AIDS cases with young African-American 
women. Journal of National Medical Association, 95, 846-852. doi:

http://ezproxy.lib.ryerson.ca/login?url=http://search.proquest.com.ezproxy.lib.ryerson.ca/ docview/214050116?accountid=13631

Wong, J. P., Macpherson, F., Vahabi, M., \& Li, A. (2017). Understanding sexuality and sexual health of Muslim young people in Canada and other Western countries: A scoping review of research literature. Canadian Journal of Human Sexuality, 26 (1), 48-59.

doi:10.3138/cjhs.261-C1

World Health Organization. (2015). Global summary of the AIDS epidemic 2014. Retrieved from: http://www.who.int/hiv/data/epi_core_july2015.png?ua=1

Wortley, S. \& Owusu-Bempah, A. (2011). The usual suspects: police stop and search practices in Canada. Policing \& Society, 21 (4), 395-407. Retrieved from http://dx.doi.org/10.1080/10439463.2011.610198 